JOY LIDDICOAT

\title{
DOMAIN NAME DISPUTES: \\ IS PRIVATE DISPUTE RESOLUTION \\ WORKING?
}

LLM DISSERTATION
LLM BY DISSERTATION (LAWS 592)

FACULTY OF LAW

VICTORIA UNIVERSITY OF

WELLINGTON 
TABLE OF CONTENTS

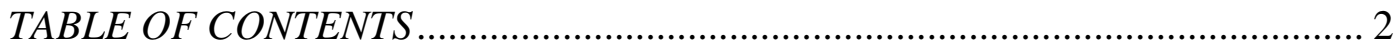

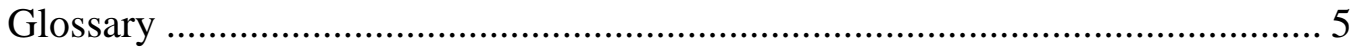

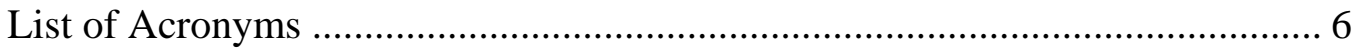

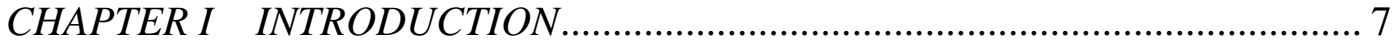

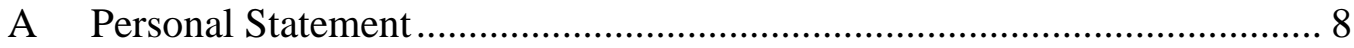

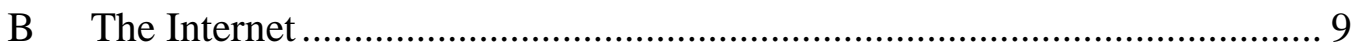

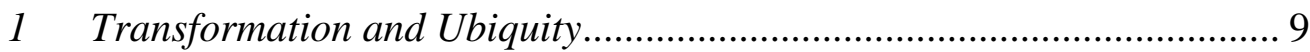

$2 \quad$ What is a Domain Name? ..................................................................... 10

3 The Critical Nature of the Domain Name System .................................. 11

$4 \quad$ Domain Name Disputes ....................................................................... 12

5 Overview of the Dispute Resolution Service .......................................... 13

$6 \quad$ Has the Internet Outstripped the Law?................................................... 14

C Original Contribution of Dissertation ................................................... 16

1 The Primary Research Questions ....................................................... 16

$2 \quad$ New Legal Processes .......................................................................... 17

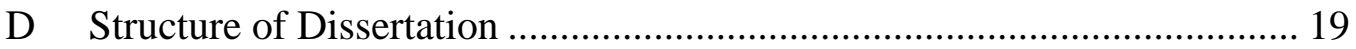

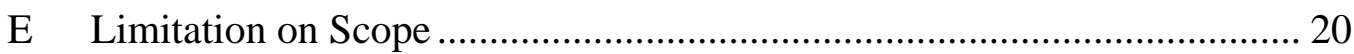

CHAPTER II THE DOMAIN NAME SYSTEM IN NEW ZEALAND ................. 21

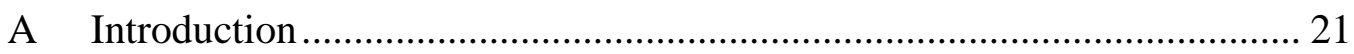

B The Domain Name System ..................................................................... 21

1 The Root Zone File and the Root Name Servers ................................... 21

2 Administration of the Domain Name System ........................................ 26

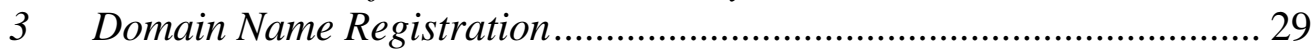

$4 \quad$ The Domain Name System in New Zealand ......................................... 30

$5 \quad$.nz Domain Name Service Policies ........................................................ 33

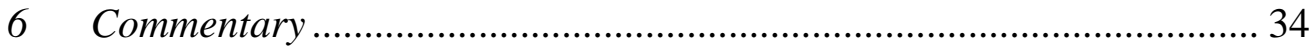

C Domain Name Disputes ......................................................................... 36

$1 \quad$ Categories of domain name disputes .................................................... 36

2 Scope of protected rights................................................................... 37

$3 \quad$ Categories of domain name dispute resolution systems ....................... 39

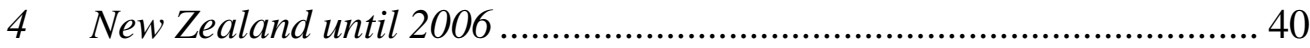

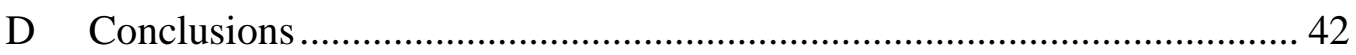

CHAPTER III DISPUTE RESOLUTION THEORY ....................................... 44

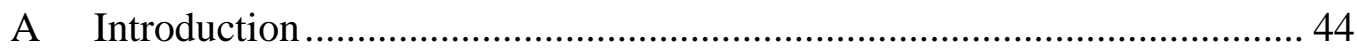

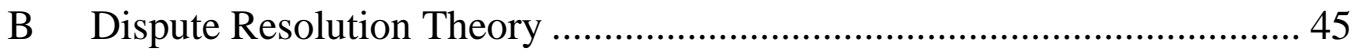

1 Dispute Resolution and the Rule of Law ............................................ 45

2 Alternative Dispute Resolution ............................................................... 45

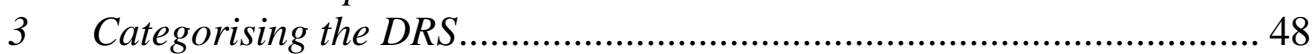

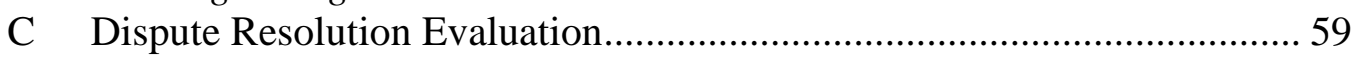

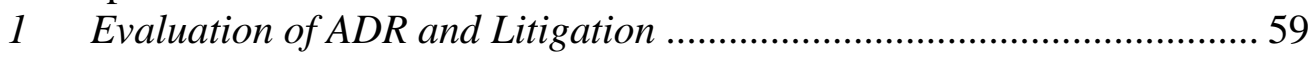

2 Evaluation of the Dispute Resolution Service ....................................... 62

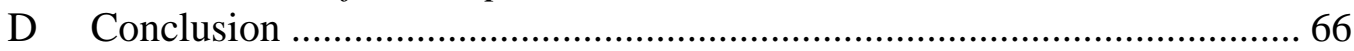

CHAPTER IV THE DISPUTE RESOLUTION SERVICE DEVELOPMENT .... 68

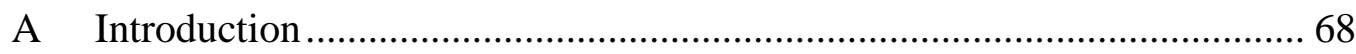


B The Dispute Resolution Service Policy …………………………………..... 68

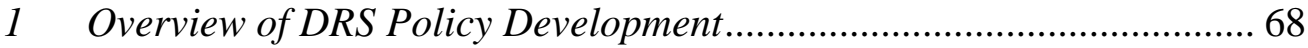

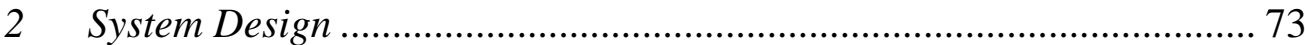

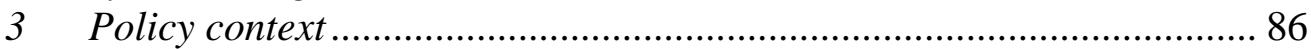

4 Process integrity …………………………………………………... 92

C Conclusion ........................................................................................... 95

CHAPTER V THE DISPUTE RESOLUTION SERVICE IN PRACTICE......... 98

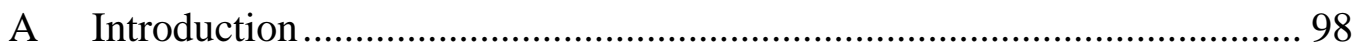

B Evaluation of DRS ........................................................................... 98

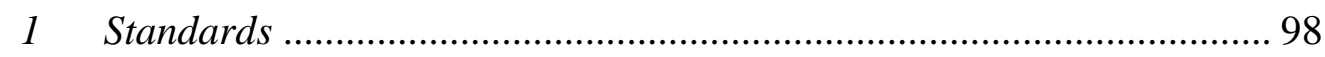

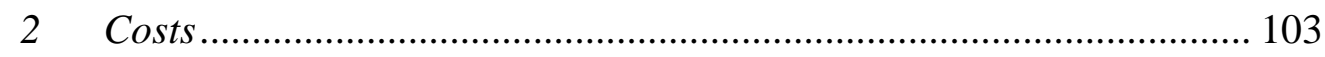

3 Analysis of Complaints..................................................................... 106

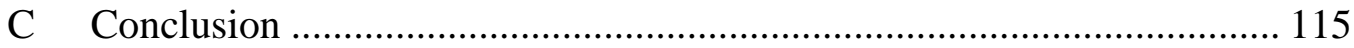

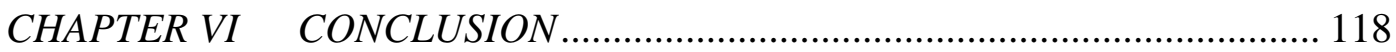

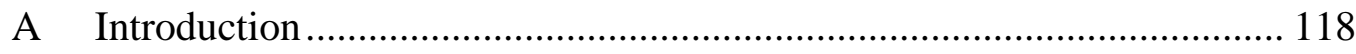

B The Primary Research Questions............................................................. 118

1 The DRS is Operating Effectively ………………………………...... 118

2 InternetNZ is Acting Responsibly ......................................................... 119

3 Contribution to the Review of the DRS ................................................ 119

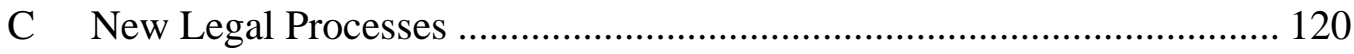

D Wider Implications................................................................................. 120

1 Human Rights............................................................................ 121

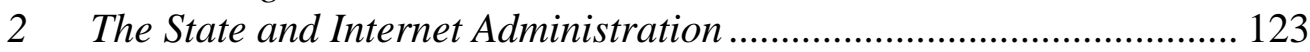

APPENDIX 1 DISPUTE RESOLUTION SERVICE POLICY ............................... 126

APPENDIX 2 SUBMISSIONS ON 2004 CONSULTATION PAPER ..................... 144 APPENDIX 3 RECOMMENDATIONS TO THE REVIEW OF THE DISPUTE RESOLUTION SERVICE POLICY …………………………........................ 145

APPENDIX 4 TABLE OF INTERNETNZ POLICIES, AGREEMENTS AND

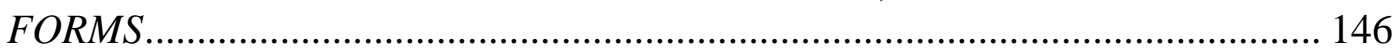

APPENDIX 5 TABLE OF EXPERT DECISIONS 2006 - JANUARY 2010 ......... 148

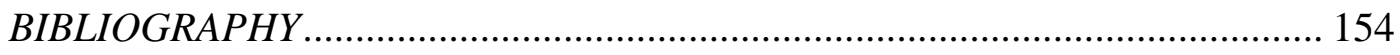




\begin{abstract}
InternetNZ has responsibility for management of the .nz domain name space. This dissertation examines InternetNZ's development and implementation of the Dispute Resolution Service Policy (the DRS). The DRS, which is being reviewed in 2010, provides a substantive legal test for unfair registration of a domain name and a dispute resolution process. This dissertation asks whether the DRS is working effectively and, if so, what this reveals about the operation of the Internet in New Zealand. The dissertation shows that the DRS is a low cost, high quality alternative to litigation and is being run in a pragmatic but principled way by InternetNZ. Implications are discussed and recommendations are made for minor improvements. The dissertation concludes with a call for more participation in, and critique of, Internet policy developments given the important human rights issues that can arise and the significance of the Internet in New Zealand today.
\end{abstract}

\title{
Word length
}

The text of this paper (excluding abstract, table of contents, footnotes, bibliography and appendices) comprises approximately 34,978 words.

\section{Subjects/Topics}

Internet-Domain Names-Dispute Resolution. 


\section{Glossary}

Domain name:A domain name is the alphabetical representation of a string of numbers assigned to each computer on the Internet. Domain names have several levels and is read from right to left with each level separated by a full stop (commonly referred to as a dot). The furthest right hand level is known as the top level and may be a country code (such as .nz) or a generic code (such as .org).

Domain name server: A computer that accepts requests from other programs or servers to convert domain names into numerical addresses (typically known as IP or TCP addresses).

The Domain Name System: The world wide system of domain name services that process and contain data about domain names and numbers. The Domain Name System is often known simply as "the DNS" and is sometimes referred to as the Domain Name Service or domain name space.

.nz: the suffix for domain names registered in the New Zealand part of the DNS.

Root servers: The computers that store lists of domain names and associated IP address and other data, about a subset of the name space (those subsets are called zones).

The Internet: The Internet is a global system of thousands of interconnected computer networks.

The world wide web: The software application that allows users to use programmes such as electronic mail and other file transfer protocols (which move files between computers) thereby enabling users to use browsers such as Internet Explorer, Safari and FireFox. The world wide web is not the same as the Internet, although the two terms are often used interchangeably.

The WHOIS service: The resource record which enables a facility to query the details of a specific domain name, in other words, to ask "who is" the registrant of a domain name. 


\section{List of Acronyms}

\begin{tabular}{ll} 
ADR & Alternative dispute resolution \\
AMINZ & The Arbitrators' and Mediators' Institute of New Zealand \\
ccTLD(s) & country code Top Level Domain(s) \\
DNC & Domain Name Commissioner \\
DNCL & Domain Name Commission Limited \\
DNS & Domain Name System \\
DRS & The Domain Name Dispute Resolution Service Policy \\
gTLD(s) & generic Top Level Domain(s) \\
IANA & Internet Assigned Numbers Authority \\
ICANN & Internet Corporation for Assigned Names and Numbers \\
InternetNZ & Internet New Zealand Incorporated \\
IP & Internet Protocol address \\
ISOCNZ & Internet Society of New Zealand \\
ISP & Internet Service Provider \\
ODR & On-line dispute resolution \\
NZOC & .nz Oversight Committee \\
NZRS & New Zealand Domain Registry Services \\
RFCs & Requests For Comments \\
TCP & Transfer Computer Protocol address \\
UDRP & Universal Dispute Resolution Policy \\
WIPO & World Intellectual Property Organisation \\
& \\
\hline
\end{tabular}




\section{CHAPTER I INTRODUCTION*}

What do Julia Roberts, Jeanette Winterson, and New Zealand Post have in common? They all have famous names that have been registered as domain names by someone else. ${ }^{1}$ As the Internet ${ }^{2}$ becomes more important in every day life, certainty about rights in domain names has also become more important. ${ }^{3}$ Legal $^{2}$ disputes about domain names and questions about the efficacy of dispute resolution systems are increasing. These developments place increased pressure on dispute resolution systems, public and private, to operate effectively.

Disputes about .nz domain names must be dealt with under New Zealand law, which includes the option of resolving disputes using the Dispute Resolution Service (the DRS). ${ }^{4}$ The DRS is operated by the Domain Name Commission Limited (DNCL), which is reviewing the DRS in 2010.

This dissertation takes a closer look at the organisation responsible for operating the DRS and related policies on which the Internet in New Zealand operates. As the Internet becomes more important in everyday life so does the need to be assured of the integrity of those responsible for its administration (including management of .nz domain names). This dissertation examines one aspect of this, the DRS, and considers the implications for other Internet developments. In a broad sense these developments may point to the need for a more coherent response to related legal issues or formal recognition of those responsible for Internet administration.

\footnotetext{
* I am very grateful for the assistance of Debbie Monahan, Domain Name Commissioner, Andy Linton and Dr Judy McGregor for comments on draft material. Errors or omissions are my own.

${ }^{1}$ Diane Rowland and Elizabeth McDonald Information Technology Law (3rd ed, Cavendish Publishing, London, 2005) at 533 - 534 and 539.

2 "Internet" (2010) Wikipedia <www.wikipedia.org>. This dissertation uses the upper case "I" when referring the Internet. This is considered more appropriate in this context because the term is being used to refer to the proper name of the network of thousands of computers on which the “world wide web” functions. Parliamentary law drafting practice in New Zealand varies: see Joy Liddicoat, "The Copyright (New Technologies) Amendment Act 2008 Internet Service Provider Liability” (LLM Research Paper, Victoria University of Wellington, 2009).

${ }^{3}$ Rowland and McDonald, above n 1, at 525.

${ }^{4}$ Domain Name Commission Limited "Dispute Resolution Service Policy” (2008) Domain Name Commission $<$ www.dnc.org.nz $>$.
} 


\section{A Personal Statement}

My interest in this research flows from three sources. Firstly, I am a lawyer specialising in public law who is interested in legal theory and public and international law. Secondly, I am a Human Rights Commissioner with the New Zealand Human Rights Commission and I have a strong interest in human rights and dispute resolution. Thirdly, I am a member of InternetNZ and a Director and Chair of the Board of Directors of DNCL. I became interested in the Internet in 2007 when I was challenged by another human rights advocate to understand how the Internet functioned globally and to get involved in advocating for democratic, fair and inclusive processes in its administration. ${ }^{5}$

Until that challenge I had never turned my mind to the infrastructure of the Internet, despite being an early adopter of the technology for my own law practice and despite having an interest in human rights and public law. I joined InternetNZ and applied to be a member of the .nz Oversight Committee. I was appointed and subsequently became a Director of DNCL when the company was formed in 2008. I was appointed Chair of the Board in 2010.

In 2010, Dr Judy McGregor, Equal Opportunities Commissioner with the New Zealand Human Rights Commission, asked me to prepare a section on the Internet in a draft Chapter on Freedom of Expression, which forms part of the Commission's status report on human rights in New Zealand. This further roused my interest in Internet administration and human rights and caused me to think about what, if any, priorities for action there might be to enhance and protect human rights, including the right to freedom of expression.

This research provides an opportunity for me to reflect on and examine in more detail the integrity of InternetNZ's oversight of the .nz domain name space. My experience in all three areas (law, human rights and the administration of the Internet infrastructure in New Zealand) provides a strong and unique basis from which I can examine and critique why the DRS was established and its

\footnotetext{
${ }^{5}$ Conversation between author and Jac sm Kee, Women's Rights and ICT Project Coordinator, Association for Progressive Communications, (Pune, India, 14 March 2007).
} 
subsequent operation. It also provides an opportunity to reflect on whether this dissertation has any wider implications for discussion about human rights and Internet administration.

\section{B The Internet}

\section{Transformation and Ubiquity}

The Internet has transformed life as we know it. A 2009 survey of New Zealanders showed that 83 per cent use the Internet. ${ }^{6}$ Many users conduct everyday business online. More than half of those who use the Internet use their bank's online services at least weekly. The Internet is ubiquitous. All users rely on the Internet to be available all day, every day, most without ever considering how the Internet actually works and who is responsible for it.

The technical developments that formed the basis for what we now call "the Internet" began in the 1960s and involved diverse actors including government, academic, technical and other non-government agencies and individuals in different parts of the world. ${ }^{7}$ Leiner helpfully summarises that: ${ }^{8}$

The Internet is as much a collection of communities as a collection of technologies, and its success is largely attributable to both satisfying basic community needs as well as utilizing the community in an effective way to push the infrastructure forward.

In New Zealand this “collection of communities” is anchored in Internet New Zealand Incorporated, trading as InternetNZ (InternetNZ). InternetNZ is a membership based organisation with three operational parts. Firstly, InternetNZ has a Council, which is elected by InternetNZ members, and an office with a public advocacy function. Secondly, InternetNZ has a wholly owned subsidiary

\footnotetext{
${ }^{6}$ Philippa Smith and others World Internet Project New Zealand: The Internet in New Zealand 2009 (World Internet Project New Zealand, Institute of Culture, Discourse and Communication, Auckland University of Technology, Auckland, 2010) at 2.

${ }^{7}$ Vint Cerf "Histories of the Internet: A brief history of the Internet and related works" (2010) Internet Society <www.isoc.org $>$.

${ }^{8}$ Barry M. Leiner and others "Histories of the Internet: A brief history of the Internet" (2010) Internet Society $<$ www.isoc.org $>$.
} 
company, the DNCL, which has charitable status. This company oversees the policies for .nz domain names, including the DRS. Thirdly, InternetNZ has another wholly owned subsidiary company the New Zealand Domain Name Registry Limited, trading as .nz Registry Services (NZRS), which also has charitable status. NZRS operates the register of .nz domain names and is responsible for ensuring that the .nz domain name system (including root servers) operates all day, every day. Without this system, the Internet as we know it in New Zealand would cease to function.

InternetNZ has responsibility for the .nz domain name space, a role recognised by the Internet Corporation for Assigned Names and Numbers (ICANN). ICANN has agreements with a variety of individuals and organisations around the world who are responsible for their respective country code top level domains (ccTLDs) such as .nz. ${ }^{9}$ InternetNZ's specific responsibility is to oversee the management of the .nz domain name space. ${ }^{10}$ InternetNZ, through its subsidiary companies, is able to charge a fee for the provision of this service. This fee is \$1.50 per domain name per month and will become \$1.25 per month from 1 July 2010. The fee generates annual revenue of approximately \$6 million for InternetNZ. ${ }^{11}$

\section{$2 \quad$ What is a Domain Name?}

A domain name is a means of identifying computers and networks by name, rather than number. Each computer connected to the Internet by a server has a unique string of numbers attached to it. In practice it is the user friendly allocation of unique literary equivalents of these numbers, known as domain names, which take an Internet user to a specific address, ${ }^{12}$ for example, www.victoria.ac.nz. For this system (known as the Domain Name System, the DNS) to work it is vital that no two domain names are identical and,

\footnotetext{
${ }^{9}$ David Harvey internet.law.nz (2 ed LexisNexis NZ Limited, New Zealand, 2005) at 114.

${ }^{10}$ Internet New Zealand Incorporated, “About InternetNZ” $2010<$ www.internetnz.net.nz>.

${ }^{11}$ Ibid.

${ }^{12}$ Chris Reed and John Angel Computer Law: The Law and Regulation of Information Technology (6 ${ }^{\text {th }}$ ed, Oxford University Press, London, 2007) at 437.
} 
to ensure this, most domain name registries operate name registration on a "first come first served” basis. ${ }^{13}$

Domain names are hierarchical, with the hierarchy divided into levels. Top level domains (TLDs) are in two categories: country specific (ccTLDS, for example, the New Zealand country specific code is “.nz”) and generic (gTLDS, which are non-country specific, ending, for example in “.com”). Subsequent levels in the hierarchy are further categorised, for example, second level domains such as ac.nz (for universities) and third level domains such as victoria.ac.nz (for specific universities). ${ }^{14}$

There are more than 390,000 registered.$n z$ domain names: ${ }^{15}$ website addresses that end in .nz. With the growth in Internet use, domain names are featuring in a wider variety of cases. Contests for rights in domain names have become routine in contracts for sale of businesses, relationship property disputes and employment disputes. Domain names are valuable and can be bought and sold, sometimes for significant sums of money. ${ }^{16}$

3 The Critical Nature of the Domain Name System

The technical operation of the DNS is fundamental to the Internet. In a broad, dispute resolution sense, domain name disputes are not unique. But the policies on which the operation of the DNS is founded (including registration based on the principle of "first come first served") do affect the nature of disputes and provide a unique context for dispute resolution. The DNS therefore affects how domain name disputes can arise and their various forms.

\footnotetext{
${ }^{13}$ Rowland and McDonald, above n 1, at 524-528.

${ }^{14}$ Domain Name Commission Limited "Common Terms" 2003 < www.dnc.org.nz>.

15 The Domain Name Commission Limited "Monthly .nz Statistics - Domain Names by 2LD” (2010) Domain Name Commission <www.dnc.org.nz >

${ }^{16}$ For example, in Kremen v Cohen 2001 F. 2d 1502 (9th Cir 1991) the Court upheld a jury verdict ordering USD\$65 million in damages where the respondent had fraudulently obtained the domain name sex.com by deceiving a registrar into transferring it to him from the registered owner.
} 
The Internet is increasingly seen as part of the critical infrastructure of New Zealand, along with water, electricity and roads. ${ }^{17}$ Yet little is widely known about the organisation which administers that infrastructure, how it operates the DNS or oversees the domain name registration system.

Domain names disputes fall into two categories: legitimate dispute and cybersquatting. ${ }^{18}$ The first are those in which both parties have some legitimate interest or claim in the name (such as where a company is wound up or sold). ${ }^{19}$ The motivation in these cases may be a genuine dispute (where one party has simply registered a name earlier in time, unbeknown to the other) or anticompetitive actions (such as where a business attempts to register the domain name of a competitor).

The second category, cybersquatting, are disputes in which a person (who does not have rights in a domain name) acquires a domain name in which another person has rights and then attempts to sell the name to the rights holder or to otherwise deal with it contrary to the rights of the rights holder. ${ }^{20}$ Cybersquatting can take different forms, such as typosquatting (where many common typographical errors of a domain name are registered) $)^{21}$ or domain name hijacking (where a person, in bad faith, attempts to deprive a registered domain name holder of a domain name by using a domain name dispute resolution policy). ${ }^{22}$ The motivation for cybersquatting is usually either monetary or punitive. The categories of disputes are not exclusive since the nature of a dispute may change, beginning as one kind and ending up another.

\footnotetext{
${ }^{17}$ See, for example, Cabinet Paper “Infrastructure Stocktake Report” 17 May 2004 Ministry of Economic Development, at para 70 and Appendix 6 at para 3.

${ }^{18}$ Rowland and McDonald, above n 1, at 526-528.

${ }^{19}$ Keith Newman Connecting the Clouds: The Internet in New Zealand (The Internet Society of New Zealand and Activity Press, New Zealand, 2008) at 291 and also available at $<$ www.nethistory.co.nz $>$.

${ }^{20}$ Rowland and McDonald, above n 1, at 526.

${ }^{21}$ Christopher G Clark "The Truth in Domain Names Act of 2003 and a Preventative Measure to Combat Typosquatting” (2004) 89 Cornell Law Review at 1476.

${ }^{22}$ Domain Name Commission Limited, above n 4, at cl 3.
} 
Disputes over.nz domain names were initially taken to public dispute resolution processes (the courts). Litigation, primarily seeking injunctive relief and court orders as to domain name use, was based on common law rights (such as passing off), statutory rights (such as trade marks or copyright) and statutory consumer law (such fair trading). ${ }^{23}$

While case law developed promptly, there were concerns about the need for accessible, speedy, low cost and remedy appropriate processes. Questions arose about the scope of legal tests to be applied to domain name use. ${ }^{24}$ Specific domain name dispute resolution processes developed in response. In New Zealand, this took the form of the DRS.

\section{Overview of the Dispute Resolution Service}

The DRS may be used where a person (the respondent) has registered a domain name in which another person (the complainant) has rights and where it is asserted by the complainant that registration in the hands of the respondent is unfair. The policy lists various factors which may be taken into account in assessing whether registration is unfair and provides for how a respondent might show that the registration is a fair one. The process can not be used merely to enforce an existing contractual right.

The DRS has three steps. The first is informal mediation, which is mandatory if a response to the complaint is filed. The second, if mediation fails or if there is no response to the complaint, is for the complaint to be referred to an independent Expert. The third step is an appeal to a panel of three Experts. Once a valid complaint is received proceedings are deemed to have commenced and the domain name is locked by the Domain Name Commissioner. The effect is to suspend any dealings (such as transfer) in the domain name by any person. Once the proceedings have been determined (whether by settlement or orders of the Expert or appeal panel) the name is unlocked and will either remain with the respondent, be transferred to the complainant or otherwise dealt with in

\footnotetext{
${ }^{23}$ Harvey, above $n$ 9, at 161.

${ }^{24}$ Susy Frankel and Geoff McLay, Intellectual Property in New Zealand (Wellington Lexis Nexis Butterworths 2002) at 712 .
} 
accordance with the outcome of the dispute. Each of these steps is time limited, including the time within which mediation must be completed and Expert decisions rendered.

The DRS is administered by the DNCL, with day to day operations overseen by the Domain Name Commissioner. Complaints (and responses) are be lodged electronically, but must also be lodged by mail. Mediators and Experts are appointed by the DNCL. Decisions of Experts are published and information about the operation of the DRS is published in the annual report of the DNCL. There is no fee to file a complaint or for mediation. The fee for an Expert decision is $\$ 1800$ plus GST and for an appeal is $\$ 6600$ plus GST. All fees are paid in full directly to the Experts. The jurisdiction of the courts is not excluded and the process will yield to proceedings before a court or arbitral tribunal.

A full copy of the DRS is attached as an Appendix.

$6 \quad$ Has the Internet Outstripped the Law?

While there is no single international legal or other instrument regulating the Internet, the operation of the Internet is subject to law in a variety of ways. ${ }^{25}$ Laws govern the contracts between Internet Service Providers and individual Internet users. An Internet Service Provider (ISP) is an organisation which provides access to the world wide web and related services such as storage of data and publication of content. "One could say that ISPs establish the connection between people and content" ${ }^{26}$ on the Internet.

Contract law also governs relationships between registrants of domain names and registrars, between software manufacturers and consumers. Laws govern issues of jurisdiction and conflict of laws which inevitably arise in electronic transactions. ${ }^{27}$ A significant area of disputes has been the laws governing who may register domain names, who has rights in names and how

\footnotetext{
${ }^{25}$ Harvey, above n 9, at 491.

${ }^{26}$ Judit Bayer "Liability of Internet Service Providers for Third Party Content" (2006) VUWLR Working Paper Series, Volume 1, at 1.

${ }^{27}$ Ibid, at 54 .
} 
those rights can be contested. National laws and international agreements govern intellectual property rights and disputes about those rights.

The DNS, however, is one area where the legal system has engaged directly with the technical operation of the Internet, as opposed to legal debates about substantive content (such debates about censorship and freedom of expression). This engagement has been by way of litigation seeking protection of rights in domain names and appropriate remedies. As in other countries, in New Zealand no single law regulates the Internet, but the operation of the Internet in New Zealand is subject to New Zealand law. The establishment of the DRS as an alternative to litigation moved domain name disputes away from the Courts, distancing this aspect of Internet administration from legal scrutiny.

Legal debates about the Internet in New Zealand have largely focused on what is on the Internet rather than who runs it. ${ }^{28}$ There are signs that this is changing and that concerns about what is on the Internet, how the Internet operates and who exercises policy control over its administration are converging. This convergence can be seen, for example, in proposals to filter Internet content in order to prevent access to child pornography which are to be implemented in $2010 .^{29}$ Proposals to terminate user accounts for copyright violation have also been developed and will be implemented in new legislation. ${ }^{30}$

These proposals have not been without controversy, but the breadth and depth of public participation in these processes has, perhaps surprisingly, been variable. So, too, have the public policy results as there appears to be an ad hoc or issue specific approach. In a broad sense these developments may point to the need for a more coherent public law response to Internet related legal issues or a more formal recognition of the roles of this "collection" of actors (government and non-government) in Internet infrastructure administration and security (including management of .nz domain names).

\footnotetext{
${ }^{28}$ Ibid, at 27-29.

${ }^{29}$ Department of Internal Affairs Digital Child Exploitation Filtering System Code of Practice (2010).

30 The Copyright (Infringing File Sharing) Bill was introduced to Parliament on 23 February 2010.
} 


\section{Original Contribution of Dissertation}

Little has been written by legal commentators about domain name disputes in New Zealand. Two major New Zealand legal texts are out of date, even though published within the last ten years. ${ }^{31}$ A recent article analysing the jurisprudence in published DRS decisions highlighted the paucity of legal commentary in New Zealand and concluded the DRS is operating well. ${ }^{32}$ However, there has been no detailed critique of the development of the DRS, nor any detailed analysis of all complaints since the DRS was established in 2006.

The result is that a private organisation operates an asset (the ability to manage .nz domain names) on which the operation of the Internet in New Zealand is founded, including the related dispute resolution system. A closer look is needed at this "collection" of actors which control the operation of the Internet in New Zealand. The original contribution of this dissertation is to examine the detailed operation of the DRS and draw conclusions about the efficacy of the administration of the Internet in New Zealand.

\section{The Primary Research Questions}

The two primary research questions are: (a) is the DRS operating effectively? and (b) is InternetNZ is acting responsibly in the exercise of its DRS functions?

This dissertation answers these in three steps: by determining the criteria for assessing effectiveness, applying these criteria to the development and operation of the DRS, and by analysing the findings and drawing appropriate conclusions.

The dissertation develops criteria for assessing effectiveness by answering two secondary research questions. First, do any special considerations apply to domain name system evaluation or to cCTLD domain name disputes? Second,

\footnotetext{
${ }^{31}$ Frankel and McLay, above n 24 and Harvey, above n 9.

32 Kevin Glover “Domain name dispute resolution” (2009) February NZLJ 35.
} 
what kind of dispute resolution system is the DRS? The dissertation applies the criteria to both the development and operation of the DRS. The dissertation examines the rationale for developing the DRS, the sorts of disputes it was designed for, and the integrity of its processes. Finally, the dissertation will examine whether the DRS is dispute specific and clear, whether it is working effectively and, if so, for whom, and how the system is administered.

Conclusions will be drawn about whether the DRS: (a) is appropriate for the nature of disputes falling within its scope; (b) has process quality and rigour; and (c) is low cost and timely. Conclusions will also be drawn about how InternetNZ has exercised its dispute resolution functions and any wider implications.

\section{$2 \quad$ New Legal Processes}

The Internet is subject to law. Many laws regulate Internet transactions, including banking and finance laws. But the Internet is a network of computers operated by a collection of individuals and organisations spread around the world. From a lay perspective, it is not governed by laws in the traditional sense. Yet battles for control of the technical operation of the Internet (including who makes or determines the policies by which it operates) form the backdrop to many legal disputes about Internet use. The underlying values of those participating in these battles also influences, and is in turn influenced by, a variety of geo-political and other factors. $^{33}$

While those matters are outside the scope of this dissertation, the technical operation of the Internet has resulted in the development of new rights and new legal processes in which rights are contested. Domain name disputes, for example, involve rights which are not adequately provided for under common law or statute in New Zealand. The result is that new legal processes have been developed to accommodate these rights, provide for remedies, and protect the DNS.

\footnotetext{
${ }^{33}$ For a useful introduction see Harvey, above n 9, Chapters 1 and 3.
} 
There is no single global system for resolution of domain name disputes for TLDs. Systems vary by type of domain name (generic or country specific), domain name space administration (by individual or organisation, moderated or unmoderated), and by jurisdiction (national, regional and international). ${ }^{34}$ Within each system the scope of protected rights also varies. In some cases rights are prescribed under general law (common law and statute), in others new rights are created under specific law (such as domain name rights legislation), in others under specific policies. ${ }^{35}$ Neither is there consensus about which dispute resolution system is best or most appropriate. In fact the need for new systems or new legal tests is highly contested, even as these new systems are developed or adopted in an increasing number of jurisdictions and new gTLDs are created. ${ }^{36}$ The result is that despite the global operation of the DNS it is not possible to compare all domain name dispute resolution services.

ICANN developed a new and separate process, the Universal Dispute Resolution Policy (UDRP), for domain name disputes involving gTLDs such as .com., .edu, or .org. ${ }^{37}$ The UDRP has been criticised because of delays in dealing with disputes. For example, the World Intellectual Property Organisation (WIPO) has dealt with 27,000 domain name disputes under the UDRP over 10 years: 75\% of these have been undefended. ${ }^{38}$ Complaints about the effectiveness of the UDRP, itself designed as a fast track dispute resolution process, have led to calls for a faster "fast track" dispute resolution process. ${ }^{39}$ But ccTLD dispute resolution systems, such as that operating for .nz, have attracted less attention. There appears to be little analysis of ccTLD domain name dispute resolution systems in general commentary on alternative dispute resolution. ${ }^{40}$

\footnotetext{
${ }^{34}$ Ibid, for an overview of international and domestic regulation of domain names, at 130 .

${ }^{35}$ For example the DRS in New Zealand.

${ }^{36}$ Milton L. Mueller Ruling the Root: internet governance and the taming of cyberspace

(Massachusetts Institute of Technology, United States of America, 2002) at 201-202.

${ }^{37}$ Internet Corporation for Assigned of Names and Numbers Universal Dispute Resolution Policy, (ICANN, United States of America, 1999).

${ }^{38}$ Eun Joo, “ICANN'S new gTLD procedure - Trademark-related concerns” World Intellectual Property Organisation, (paper presented to ICANN Conference Sydney, June 2009), at 20.

${ }^{39}$ Ibid, at 19.

${ }^{40}$ See, for example, Peter Spiller (ed) Dispute Resolution in New Zealand (2 ed, Oxford University Press, Melbourne, 2007) which contains no discussion of the DRS.
} 
In addition, the concept of the rights of registrants is widely used in advocacy and referred to by Internet commentators and in a way that echoes how public law commentators and advocates might refer to human rights. Given the public good involved in the operation of the Internet infrastructure and the Internet's increasing importance to diverse New Zealanders, there have been new questions about whether access to the Internet should be a human right. ${ }^{41}$ The dissertation will conclude with any wider implications from analysis of this new legal process, the DRS.

\section{Structure of Dissertation}

Chapter II outlines the technical aspects of how the DNS works and why that matters in relation to domain name disputes. The general policy of registration on a first come first served basis and the significance of no two domain names being the same are explained. The Chapter outlines the Internet infrastructure in New Zealand, the .nz domain name space, the shared register system for registrars, and policies governing registrants. There is a brief description of domain name dispute resolution process in relation to gTLDs and other ccTLD processes in order to better understand where New Zealand fits in the models available. The secondary question of whether special considerations apply to domain name system evaluation is answered.

Chapter III places domain name dispute resolution systems within the broader landscape of dispute resolution theory and sets out six criteria by which effectiveness may be assessed. The chapters answer the secondary research question about what kind of system the DRS is.

Chapter IV outlines the development of the DRS and assesses this in light of three criteria: system design, policy context, and process integrity. Chapter V is a detailed assessment of the operation of the DRS since it commenced in 2006 in light of three other criteria: standards, cost, and complaints. Together, these chapters provide the findings on which the primary research can be answered and

\footnotetext{
${ }^{41}$ For example, Michael L. Best “Can the Internet Be A Human Right?” in Steven Hick and others (eds) Human Rights and the Internet (Palgrave MacMillian, New York, 2000) 23, at 23.
} 
answer secondary questions about the rationale for the DRS, the disputes it was designed for and the integrity of its processes.

Chapter VI returns to the primary research questions. Conclusions are drawn on whether the DRS is operating effectively and whether any improvements and further research would be desirable. Finally, wider implications for new legal processes are briefly considered.

\section{E Limitation on Scope}

All research is necessarily selective and must have limited scope. The Internet is a very wide topic and this dissertation overcomes the possible risks of lack of focus by looking at the operation of the Internet through one particular window: dispute resolution for .nz domain names. Internet governance or the notion of "government of the internet", ${ }^{42}$ while interesting, is ultimately not relevant for this purpose. Nor is the current coordination of the DNS by international bodies such as ICANN. The wider geo-political issues and other politics of the collection of communities and individuals that are responsible for the operation of the Internet would also be a distraction. Instead, these developments and wider issues are taken as a given.

The relevant jurisprudence, including intellectual property law, is also developing and highly contested. Detailed consideration of these developments is beyond the scope of this dissertation. Instead, where relevant, this dissertation considers the nature of disputes and the application of domain name policy. For example, to whether the DRS is effective for all or only some domain name disputes. Conclusions will be drawn on whether the DRS protects a wider range of disputes than previous jurisprudence, including intellectual property law.

For ease of reference, a glossary and list of acronyms have been included in the front of the paper.

42 Mueller, above n 36, at 7. 


\section{CHAPTER II THE DOMAIN NAME SYSTEM IN NEW ZEALAND}

\section{A Introduction}

The chapter outlines the technical, day-to-day operation of the Internet in New Zealand. While this chapter has some technically complex material, the area is not, in principle, more complex than any other area of law and understanding it does not require special technical expertise. As noted in Chapter I, it is a collection of individuals and organisations operate technical and policy guidelines which, operating together, allow the Internet to function.

This sense of community and the notion of satisfying community needs by means of a collection, if not a collective, of technologies and people, are important aspects of both the history of the Internet and the manner of its operation. Understanding how the collection of technologies operates to form the infrastructure of the Internet assists with understanding how disputes about domain names arise, why dispute resolution systems were created, the values which underpin them, and the criteria by which such systems are best evaluated.

\section{B The Domain Name System}

$1 \quad$ The Root Zone File and the Root Name Servers

The rules by which the Internet operates are not statute or common law. Put simply, the Internet operates through a system of mutual recognition of and adherence to various technical guidelines and policies by a collection of organisations and individuals. For practical purposes, that system of collective mutual recognition takes place by means of a network of computers which share information having agreed on the rules for how this will happen. The unifying feature of this system is the fact that it operates to allow a single Internet to 
operate. Without this system of mutual recognition and adherence to guidelines, the Internet would not function. ${ }^{43}$

The technical day-to-day operation of the Internet is guided by a set of rules including those known as Requests For Comments (RFCs), technical and policy guidelines and protocols on data transfer. These rules have developed through a continual process of seeking comments on proposals for protocols, testing of ideas and decisions to implement a protocol where there was a "rough consensus" amongst technical experts about the best approach. ${ }^{44}$ RFCs, guidelines and policies might never be formalised in the sense that a final version is necessarily promulgated. Instead, the RFC or policy or guideline may simply adopted and put into practice. ${ }^{45}$

This system of requesting comments on draft proposals and developing "rough consensus" became, and remains, a very important way in which the collection of organisations which operate the Internet carry out policy development and other functions. The politics of this process remain highly contentious and are not directly relevant for the purposes of this research. The key points are, first, that consultative processes are part of the values of the technical operation of the Internet and, second, the rules which form the basis of operation are not dependent on formal processes of promulgation to be implemented.

One of the most fundamental set of RFCs and policy guidelines relates to the protocols on which the DNS is based and which were designed in the 1960s

\footnotetext{
${ }^{43}$ InternetNZ “Internet Overview” (2009) InternetNZ < www.old.internetnz.net.nz>. In this research a number of references are sourced to the Uniform Resource Locator $<$ www.old.internetnz.net.nz $>$. This refers to the Uniform Resource Locator on which the cited documents are currently hosted. In 2010 InternetNZ created a new website $<$ www.internetnz.net.nz $>$ which does not host all of the documents cited in this research. The InternetNZ website was previously $<$ www.internetnz.org.nz $>$. All materials cited in this research were publicly available at the previous Uniform Resource Locator and remain available at $<$ www.old.internetnz.net.nz $>$. To assist with verifying the research trail, reference is made to the Uniform Resource Locator at which all of the referenced material can be located.

${ }^{44}$ Mueller, above n 36, at 32.

${ }^{45}$ Ibid.
} 
and 1970s as a way for computers to communicate with each other. ${ }^{46}$ The RFCs developed an agreement on the use of Internet Protocol (IP) addresses, which have a set numbers represented in an hierarchical decimal form, for example, 123.45.06.7. ${ }^{47}$ It is these addresses and numbers which form the backbone of Internet operations to distribute data across the network via routers. ${ }^{48}$ Technically, domain names are not needed in order for the Internet to function ${ }^{49}$ because such names are not used by the routers through which packets of information travel to and from computers on the network. The routers use packets of information and exchange these packets of data, not names. But domain names developed to replace this numbering system when a system to resolve numbers to names was developed.

The original name resolution system was operated by the Network Information Center (NIC) which entered domain names in a file called host.txt, a list that served as a world wide root zone file for resolving domain names and IP addresses. This system was replaced with the Domain Name System which divided the single name space of host.txt into a multi-level hierarchy of names. ${ }^{50}$ The hierarchy divides domain names into levels: top level domain names, second level, third level and so on up to a possible 127 levels. In practice there are few domain names which contain more than four levels. ${ }^{51}$

If a domain name is to be used instead of a set of numbers, there must be a process for the name and its correlating number to be matched to each other. This matching is done by a system for "resolving" names and their corresponding numbers, which uses "resolvers" and "resource records". Resolvers are software programs that "ask the question” about the domain name generating queries about a domain name and extracting information from a name server. ${ }^{52}$ Resolvers are in

\footnotetext{
${ }^{46}$ Walt Howe "A Brief History of the Internet” (2009) <www.walthowe.com> and "The Domain Name System” (2010) Wikipedia <www.wikipedia.org $>$.

${ }^{47}$ Patricia Bellia (ed) Cyberlaw Problems of Policy and Jurisprudence in the Information Age ( $3^{\text {rd }}$ ed, ThomsonWest, St Paul, 2007) at 167.

${ }^{48}$ A router connects networks together, determining logical routing for data packets across networks until appropriate destinations are reached.

${ }^{49}$ Mueller, above n 36, at 39.

${ }^{50}$ Ibid, at 41.

${ }^{51}$ Bellia above n 47, at 167.

52 Ibid.
} 
the end-user's computer and operate when a domain name is typed into an Internet web browser.

For example, when a student types in the domain name victoria.ac.nz to their computer, their computer converts the name into a number and sends a query to the local domain name server, which then searches its stored numbers to see if there is a match for the numbers for victoria.ac.nz. If there is, the request is resolved and the website page is displayed. If not, the request is sent to other name servers until the query is resolved or a message returned that it is not resolved.

Resource records are data or content stored in the root name servers, which "answer the question" from the resolver when a person types this into their computer. For example, “who is the registrant of $\mathrm{x}$ or $\mathrm{y}$ domain name?" The most complete and authoritative resource records for a domain such as .nz are the otherwise unnamed "root zone files". Those records include information about the address as well as who is the authoritative source of information for a domain, who the domain name registrant is, how the current root zone file is being used, and administrative information. For this reason, these databases are sometimes called "who is" services. ${ }^{53}$

The operation of the Internet is therefore founded on a network of computers which, through root name servers, share information about root zone files. This entire system operates via a series of just thirteen root name servers situated in different parts of the world. ${ }^{54}$ These servers are in turn supported by a vast network of domain name servers, many operating in different parts of the world, including New Zealand, which contain stored (cached) information about domain names and addresses.

\footnotetext{
${ }^{53}$ Meuller, above $n$ 36, at 43-45.

${ }^{54}$ Ibid, at 47. The 13 servers are located in four countries: ten in the United States of America (four in California, four in Virginia, and two in Maryland) and one each in the United Kingdom (London), Sweden (Stockholm), and Japan (Keio).
} 
Domain names developed for several reasons. ${ }^{55}$ The first was "simply mnemonics": 56 the use of names recognisable to humans makes those names easier to remember and can provide a structure to a numbering system. For example, naming systems can be based on geographic regions (wellington.govt.nz) or other categorisations. ${ }^{57}$ These advantages are not available with numbers. Second, names provided a "single, more stable identifier". ${ }^{58}$ Changing IP numbered addresses is quite complicated whereas changing a name is much simpler requiring only that numbers be re-directed to a single name.

The development of the DNS greatly increased the available domain name space, meaning that more domain names were possible. There are more than 257 top-level domain names listed in the root directory of the DNS: over 240 are ccTLDs with the codes drawn from an international standard. ${ }^{59}$ Originally there were seven gTLD with the generic three-letter suffixes defined to serve as a rough taxonomy of the types of users (.com, .net, .org, .mil, .edu, .int, and .gov). There are now twenty gTLDs. Guidelines and policies have been developed about who can register names in which domain and these rules must be implemented by the person or organisation responsible for managing the domain, or the domain name system in which their top level domain name operates. The official list of all top level domains is maintained by the Internet Assigned Numbers Authority which is the global co-ordinator of the root zone files. ${ }^{60}$

Generic top level domain names are not, as is often thought, used exclusively by organisations or individuals in the United States of America. There is a country code for the United States ( .us), but this is less frequently used by United States registrants than the generic TLDs. In addition, many people and organisations outside the United States use gTLDs such as .mobi, .asia, and .museum which are not country specific.

\footnotetext{
${ }^{55}$ Chris Reed and John Angel Computer Law: The Law and Regulation of Information Technology $\left(6^{\text {th }}\right.$ ed, Oxford University Press, Oxford, 2007) at 437.

${ }^{56}$ Mueller, above n 36, at 39.

${ }^{57}$ Ibid, at 40.

${ }^{58}$ Ibid.

${ }^{59}$ International Organisation for Standardization "ISO 3166-1" (2010) <www.iso.org>.

${ }^{60}$ Internet Assigned Numbers Authority "Introducing IANA" (2010) <www.iana.org>.
} 
Each organisation that manages a domain name space (including ccTLDs such as .nz) must provide name server computers to support the domain. These are computers that store lists of domain names and associated IP address and other data (such as the names and address of people who register domain names) about a subset (or zone) of the name space. ${ }^{61}$

In New Zealand, both the policy and technical operation of the DNS are under the control of InternetNZ. On a day to day basis, all of the root zone files, the root zone servers and local name servers are under the management of InternetNZ's wholly owned subsidiary charitable companies, the DNCL and NZRS.

\section{Administration of the Domain Name System}

For the DNS to work all domain names must be registered and details entered into the root zone file so that all names can be resolved to their correct number. This registration system requires administration and an infrastructure to support that administration. Administrative arrangements are guided by the system of mutual recognition mentioned above, predominantly in the form of exchange of letters or by contract. A person or organisation which operates a subset of the DNS (such as a ccTLD or gTLD) will generally have some mutually recognised delegated responsibility for that space and will operate a single registry of public databases (the resource records for the root zone file for that domain). The administration requires a registry database containing information about persons that have registered domain names.

Administration of a domain name system is assigned to a manager who may or may not also operate the registry database. A ccTLD manager is responsible for ensuring appropriate policies are in place for that domain name

${ }^{61}$ Meuller, above n 36, at 43. 
space. ${ }^{62}$ In particular, such managers must operate a dispute resolution policy of some kind. This can be a public or private system or a mixture of both. ${ }^{63}$

There are important distinctions between the manager responsible for these policies, the "registry" that operates the computer system which operates the DNS and the various "registrars" who operate, usually commercially, to register, with the registry, domain names for individuals and organisations. The registry will typically be responsible for the technical operation of the network of computers that is resolving queries about domain names. Registration policy for assigning names may be set by the registry or it may be set by another entity with responsibility for managing the local root zone file. Registrars are often private companies, charging fees to register domain names and offer related services to the public such as hosting websites. An ISP typically provides access to the Internet via a subscription based service allowing clients to download content into their computers. An ISP may be, but does not have to be, a registrar offering domain name services. ${ }^{64}$

In the early years of the Internet the task of administering the DNS (and making sure all names were unique) could be performed by a single computer programmer. By 1990, as the potential value of a recognisable domain name became increasingly understood, pressure increased to create trademark rights in domain names and to develop more structure to the administration system. ${ }^{65}$ At the same time, Internet use grew and the number of domain names expanded, and increased demands were placed on the administration of the root zone file and responsibility for ensuring the system operated as a single network.

Delegation of the responsibility for this administration across the top level domains soon began and with it came controversy. This controversy centred on

\footnotetext{
${ }^{62}$ Governmental Advisory Committee "Principles and guidelines for the delegation and administration of country code top level domains” (2000) ICANN, www.icann.org>.

${ }^{63}$ Ibid, at 9.1.6.

${ }^{64}$ Bayer, above $n$ 26, at 1.

${ }^{65}$ Bellia, above n 47, at 166.
} 
the individuals and organisations that asserted or wanted the power to operate the unnamed root zone file. As Mueller notes: ${ }^{66}$

The DNS was designed on the basis that there is only one authoritative zone file. That method of ensuring technical consistency creates an institutional problem. If there can be only one zone file, who controls its contents? Who decides what top-level domain names are assigned, and to whom?

Put simply: ${ }^{67}$

A price must be paid for the advantages of names. Their use creates the need for another assignment process; someone (or some process) must co-ordinate the names used on the network to ensure that each one is unique.

The importance of assigning names and the power associated with doing so began to raise significant issues. Once it was clear that the limits on domain names were not technical and could be determined by policy, it become inevitable that there would be disputes not only about the policy but also who sets the policy and how they do so. The centre for this coordination of policy and the operation of the DNS is ICANN.

Oversight of the DNS is maintained by ICANN which has developed policies on the registrations related to gTLDs. ICANN provides a forum for ccTLD managers to consider policy developments, but individual countries are not bound by those developments if, for example, these conflict with their local domain name policies or contexts. There are many tensions over the role of ICANN. For example, Mueller notes that: ${ }^{68}$

ICANN is not primarily concerned with technical coordination, nor is it a standards setting organization. Rather, it is an institution that ties the need for technical coordination to regulation of the industry built around the resources it manages .... In ICANN's case, regulation of conduct and market structure is imposed on registries and registrars via contracts with the root administrator. ICANN's control of the root is used to make and enforce policy in three broad areas: defining and enforcing rights to names; regulation of the domain name supply industry; and the linkage of online identity to law enforcement.

\footnotetext{
${ }^{66}$ Mueller, above n 36, at 50.

${ }^{67}$ Ibid, at 40 .

${ }^{68}$ Mueller, above n 36, at 218.
} 
ICANN's relationship with ccTLD managers has been particularly fraught at times, as Froomkin notes: ${ }^{69}$

ICANN's difficulties in legitimating its decisions are exemplified by its relationship with the managers of country-code domains (ccTLDs) such as .uk and fr. ICANN sought to have the ccTLDs tie into contracts in which they would acknowledge ICANN's authority and would agree to pay ICANN annual fees based on how many second-level domains they registered. Many ccTLD managers balked, denying ICANN's authority and questioning the process by which ICANN purported to charge them fees or make policy affecting them.

ICANN and its operations have many critics and generate significant controversy. ${ }^{70}$ Analysis of these would be a major distraction from the primary research question. But these controversies about power and how it is exercised in relation to rights of domain name registrants may be relevant if these affect, for example, the administration of the .nz domain name space by InternetNZ. Assessing this requires some understanding of how domain names are registered.

\section{Domain Name Registration}

A person wishing to register a domain name typically goes to a registrar who will liaise with the registry for them, much the same as a would be company director might liaise with their lawyer for registration of a company. Registrars collect information about which addresses are assigned and to whom and which domain names might be available. ${ }^{71}$ Registrars are typically bound by contract with the organisation responsible for the registry and must, amongst other things, abide by domain name policies and dispute resolution processes (where these exist). ${ }^{72}$

An important registration concept is that a registrant does not own a domain name. Instead, a registrant is assigned a licence to use the domain name,

\footnotetext{
${ }^{69}$ A. Michael Froomkin “Habermas@discourse.net: towards a critical theory of cyberspace” (2003) 116 Harvard Law Review 749 at 849.

${ }^{70}$ See Harvey above n 9, at 113-115.

${ }^{71}$ Mueller, above n 36, at 35-36.

${ }^{72}$ Ibid.
} 
subject to terms and conditions which include abiding by the policies which govern the operation of the .nz domain name space. A registrant is authorised to use the domain name and, typically, pays a fee to do so. That fee (usually monthly or annual) is not the same as, and will not usually include, any purchase or resale value that might attach to the domain name itself. ${ }^{73}$

Top level domains operate on a first come first served basis: registration will be granted to the first person to register the domain name, who is then entitled to use it. ${ }^{74}$ In order to know whether the domain name has been already been assigned, a registrar will check with the registry. If the name is not registered, it will automatically be allocated to the person requesting it. There is generally no pre-registration vetting process. ${ }^{75}$

The first come first served policy developed as a practical, administratively simple and fast way to allow name registration without the need for a substantive vetting process. While a first come first served policy provides for administrative simplicity, it also immediately raises legal issues where there may be pre-existing rights in a name outside the context of the Internet rules on registration. Domain name disputes were inevitable.

$4 \quad$ The Domain Name System in New Zealand

The DNS is not subject to any specific New Zealand legislation, but it must operate within the framework of New Zealand law. Initial responsibility for the .nz DNS rested with the University of Waikato Information Services Department. The Department had responsibility for managing the domain and dealing with domain name registration. ${ }^{76}$ Initially there was no fee for domain name registration and the administrative costs associated with running the DNS were borne by the University. However, the administrative task eventually became too large and in 1995 the University gave this responsibility to the

\footnotetext{
${ }^{73}$ Domain Name Commission Limited, above n 14.

${ }^{74}$ Ibid.

${ }^{75}$ Newman, above n 19 at 294 notes that some countries do have pre-registration vetting.

${ }^{76}$ Ibid, at 287.
} 
Internet Society of New Zealand (ISOCNZ). ${ }^{77}$ The decision to give this responsibility to ISOCNZ was an interesting one, since this could have been given to another university, a private company or to government. The decision was presumably to keep government out of Internet administration.

ISOCNZ subsequently set up a subsidiary company, the New Zealand Internet Registry Limited (trading as Domainz) which had responsibility for operating the DNS. A fee paying service was introduced to cover the cost of operating and managing the domain name space, which eventually included operating its own root zone server system. ${ }^{78}$ A first-come first-served domain name registration policy was adopted allowing registration of any domain name provided no other person already had it and it was not objectionable. The "not objectionable" component was later removed. ${ }^{79}$ These policy developments were guided by working groups and commmittees. ${ }^{80}$

Criticisms of the ICANN model for DNS administration were echoed in critique of the New Zealand arrangements. InternetNZ was criticised for operating both the registry of domain names (Domainz), setting policy for the level of domain name fees, and, as sole registrar of domain names, collecting those fees through a profit-making business. ISOCNZ was soon criticised for having both the power to control root zone file policy and the root zone servers, when it was considered these powers should not reside in a single entity. ${ }^{81}$

ISOCNZ responded to these criticisms and, in 2001, rebranded itself as InternetNZ. The new organisation subsequently established a .nz Oversight Committee (NZOC) which was given responsibility for policies in relation to the .nz domain name space, separating regulatory policy from the technical operation of the registry. In 2002, a new registry company was established that did not operate as a Registrar. The NZRS provided the single register for all registered domain names and the registry was shared by all Registrars, establishing a

\footnotetext{
${ }^{77}$ Ibid, at 288.

${ }^{78}$ Ibid.

${ }^{79}$ Ibid, at 289.

80 Ibid.

${ }^{81}$ Ibid, at 290 and 294.
} 
competitive market. Domainz moved to become one of a number of Registrars in that market.

NZRS took over operation of the servers through which requests for domain name and address resolution are routed. The NZRS resource record is known as the WHOIS service which is the data available on the public database about registrants of .nz domain names. In 2002, completing the overall separation of the registry and policy functions, the Domain Name Commissioner was established, the first of its kind in the world. ${ }^{82}$

Subsequently. ICANN and InternetNZ had an exchange of letters in relation to the .nz delegation in which ICANN acknowledged that responsibility for management of the .nz domain resides with InternetNZ. ${ }^{83}$

In 2007 InternetNZ further separated its policy and technical functions by making the NZOC and the NZRS two wholly owned subsidiary companies. The NZOC became the Domain Name Commission Limited, a registered company with charitable status headed by the Domain Name Commissioner. ${ }^{84}$ The Commissioner is now the regulator of the .nz domain name space and is responsible for authorising registrars (and removing them in the case of misconduct) and for setting related policies, including dispute resolution. The NZRS, trading as .nz Registry services, is also a wholly owned subsidiary company of InternetNZ and has charitable status.

The DNCL has a service level agreement with NZRS on technical aspects of the zone file and zone server operations. DNCL has established policies for both the information stored on the WHOIS service, who may access it, and in what circumstances access can be denied or restricted. ${ }^{85}$

\footnotetext{
${ }^{82}$ See ibid, at Chapter 14 "Battle of the Names" for an overview of these developments 83 See ibid, at 292-295.

${ }^{84}$ InternetNZ “About InternetNZ” (2010) < www.internetnz.org.nz >.

85 The Domain Name Commission Limited "Second Level Domains Policy” (2009) $<$ www.dnc.org.nz $>$.
} 
There are sixteen policies relation to the .nz domain name space including a Policy Development Process Policy and an Outline Document Policy which provide the basic framework within which all policies are developed. The Second Level Domains Policy deals with what second level domains are offered in the .nz DNS and how these are established and moderated. ${ }^{86}$ There are fourteen second level domains including .ac.nz. .co.nz, .geek.nz, .maori.nz, .net.nz, .org.nz, and.school.nz. ${ }^{87}$ A full list of these policies, standard agreements and forms is attached as an appendix.

While policies may be developed and implemented by DNCL, InternetNZ has ultimate decision-making power in relation to strategic decisions. ${ }^{88}$ The Second Level Domains Policy, makes it clear that it is InternetNZ which will "make a final decision as to whether the application will be accepted.", 99

Two policies relate to disputes and complaints. The first, The Disputes and Complaints Policy deals with complaints that .nz policies have not been complied with. ${ }^{90}$ The Policy principles provide that "The DNC will become involved in disputes and complaints where a party believes that an agreement, or any of the .nz policies, has been breached."91 The investigation "will be restricted to issues addressed in defined and published agreements and .nz policies". 92 The second is the Dispute Resolution Service Policy ${ }^{93}$ which applies to disputes about .nz domain names.

There are more than 390,000 registered .nz domain names. ${ }^{94}$ Of these, more than 330,000 are .co.nz domain names, followed by .org.nz and .net.nz

\footnotetext{
86 Ibid.

${ }^{87}$ Ibid, at Schedule 1.

${ }^{88}$ Ibid.

${ }^{89}$ Ibid, at Clause B2.8 and see also clause B5.4 in relation to moderation of existing 2LDs.

90 The Domain Name Commission Limited "Disputes and Complaints Policy" (2008)

$<$ www.dnc.org.nz>.

${ }^{91}$ Ibid, at clause 3.2.

${ }^{92}$ Ibid, at clause 3.6.

93 The Domain Name Commission Limited, above n 4.

94 The Domain Name Commission Limited, above n 15.
} 
(approximately 21,000 each). This means that 95 per cent of domain names are registered in just three domains. There are 73 registrars, with the top four registrars having 45.6 per cent of the market share of registrants, the next four having 20.2 per cent and the remaining 60 registrars having 34.2 per cent. $^{95}$

\section{$6 \quad$ Commentary}

It is remarkable that the entire system of the Internet operations in New Zealand is, as it is in many other parts of the world, carried out on the basis of a largely informal system of mutual recognition and cooperation amongst predominantly private actors. This system is supported by a web of contractual relationships: between InternetNZ, the DNCL and the NZRS; between the DNCL and authorised registrars; between the shared registry and registrars; between registrars and registrants; and between registrants and their ISPs. The system also has tacit government approval as there appear to be no government policy statements on Internet administration.

The Courts have also supported these administrative arrangements by noting them with approval. The most important decision to recognise the role of InternetNZ is Oggi Advertising Limited v McKenzie ${ }^{96}$ (Oggi). In this case the Court found the contractual arrangements and the rules of Domainz conferred no rights to the applicant regarding the legitimacy the name of the applicant, nor conferred any ownership rights in the name. Baragwanath $\mathrm{J}$ broadly outlined the technical operation of the Internet and Domainz's role (now InternetNZ's) in New Zealand. His Honour stated: ${ }^{97}$

While the eventuality of a registration in breach of some legal duty is not dealt with explicitly [in the domainz contracts], it is to be inferred that domainz, which is serving a major public interest and acting in the public good, will facilitate any Court ordered rectification that is consistent with the first come first served policy. The letter from its solicitors to which I have referred, makes that position quite plain. Given the responsible attitude taken by domainz it is, in my view, the responsibility of the Court to devise procedures for any necessary

\footnotetext{
95 Ibid.

${ }^{96}$ Oggi Advertising Limited v McKenzie [1999] 1 NZLR 631.

${ }^{97}$ Ibid, at 636.
} 
rectification as may most efficiently permit correction without imposing cost or unnecessary burden on domainz.

The Court clearly defers to the first come first served registration policy, which has no formal status as law in the traditional sense. In doing so, the Judge considers it important that the registry made clear it would facilitate an order of the Court "that is consistent with the first come first served policy" and that Domainz has a "responsible attitude". It is important, too, that the Court considers the registry is "serving a major public interest and acting in the public good". For this reason, it appears the Court is willing to take the "responsibility" for imposing orders that would allow the registry to correct registration details efficiently.

The implication is that if the registry (Domainz, referred to in Oggi is now NZRS and related organisations) was not acting responsibly or otherwise "in the public good" the Court might respond differently. It is not clear what would happen if a Court made orders that the registry considered were not consistent with its policy. The case highlights that the Courts have become one of the institutions in the system of mutual recognition by a collection of organisations which allows the Internet to function. The case highlights the tensions which were to emerge in the development of the DRS: the operation of the DNS was of significant public interest yet was being done by a small, relatively unknown, private sector group.

Returning to the primary research question of whether the DRS is operating effectively, the matters outlined in this Chapter provide a much clearer landscape against which that question can be answered. The assertion that InternetNZ is acting responsibly in the exercise of its dispute resolution functions must be tested in the light of its much larger responsibility to develop and implement policies that affect the rights of domain name registrants.

That larger responsibility has been carried out for more than ten years and has not been without controversy and challenges, particularly in relation to policy and operational matters. Those controversies have in part reflected wider debates 
on the international stage, including at ICANN. InternetNZ was initially responsive rather than proactive in answering those challenges, for example, by separating the regulator (DNCL) from the registry (NZRS). This step will have also reduced some of InternetNZ's exposure to perceived risks, including of regulatory intervention by government or adverse litigation, in the carrying out of its functions.

Such risks appear to be low in light of the tacit approval of InternetNZ's activities by successive governments and the express judicial endorsement of InternetNZ's public good role. More importantly, the risks will remain low so long as the .nz domain name space remains functional and New Zealand Internet users are able to access the Internet all day, every day. There remain two areas of possible risk, however. The first is that a dispute about a .nz domain name or the way that dispute is managed gives rise to concerns. This will be examined in more detail in the next part of this Chapter and in Chapters IV and V. The second risk, as noted in the Introduction, is that responsibility for the DNS oversight will clash with government's responsibility for wider policy and regulatory oversight in relation to Internet content. This will be considered in Chapter VI.

\section{Domain Name Disputes}

$1 \quad$ Categories of domain name disputes

Domain names disputes fall into two categories. The first involves those in which both parties have some legitimate interest or claim in the name. These include as simple case of first come first served where a party attempts to register a name unaware that another person has already registered it), where the parties have a prior business relationship (such as where a company is wound up or sold) or are business competitors where one party attempts a blocking registration to prevent the other party from having the name. ${ }^{98}$ The motivation in these cases may be a genuine dispute or anti-competitive actions (such as where a business attempts to register the domain name of a competitor).

${ }^{98}$ Newman, above n 19, at 291. 
The second, known as cybersquatting, involves those in which a person (who does not have a legitimate interest or rights in a domain name) acquires the domain name in which another person has rights and then attempts to sell the name to the rights holder or to otherwise deal with it contrary to the rights of the rights holder. ${ }^{99}$ Cybersquatting can take different forms, such as typosquatting (where many common typographical errors of a domain name are registered), ${ }^{100}$ or domain name hijacking (where a person, in bad faith, attempts to deprive a registered domain name holder of a domain name by using a domain name dispute resolution policy). ${ }^{101}$ More famous examples relating to individuals include Julia Roberts and Jeanette Winterson, but New Zealand Post has also been the subject of cybersquatting. ${ }^{102}$ The motivation in the second category is usually either monetary or punitive.

\section{Scope of protected rights}

Domain name disputes not only challenge public dispute resolution systems, they challenge substantive legal tests. New questions were raised, for example, is the tort of passing off applicable? Can copyright exist in a name? How far into a cyberspace with no geographical boundaries does the legal protection of a trade mark under national law extend? Should it extend at all? What if none of these substantive legal tests is directly applicable? What if the registration is lawful under these tests, but is still abusive or otherwise unfair? These areas of expertise are the traditional domain of the Courts.

Answers to these questions have varied across jurisdictions with the result that substantive rights in domain names vary. In some jurisdictions, notably the United States of America, specific legislation relating to domain names has been enacted in an attempt to protect certain types of rights or prevent particular activities. For example, the AntiCybersquatting Consumer Protection Act and the

\footnotetext{
99 Rowland and McDonald, above n 1 at 533-534 and 539.

${ }^{100}$ Christopher G Clark "The Truth in Domain Names Act of 2003 and a Preventative Measure to Combat Typosquatting” (2004) Cornell Law Review, Vol. 89, No. 6, 1476.

101 The Domain Name Commission Limited, above n 4, at clause 3.

102 See Rowland and McDonald, above n 1, at 526-528.
} 
Truth in Domain Names Act. ${ }^{103}$ The first of these, which provides a remedy for cybersquatting, was intended to address cases such as Panavision International $v$ Toepenn, ${ }^{104}$ where non-trademark holders register trademarks as domain names and attempt to sell these to the trademark owners.

This creation or allocation of substantive rights in domain names has been controversial. Commentators disagree about whether the creation of substantive rights has been necessary because of legal issues such as the proper jurisdiction for hearing disputes. Goldsmith, for example, argues that the issues are "no more complex than the same issues in real space" and while resolution is challenging "sceptics overstate the challenge."105 In contrast, Post argues that "scale matters" so that doing the same thing (such as illegal copying) can have different consequences and "rules and principles that may be quite reasonable at one scale may be incoherent and unreasonable at another.”106

Controversy has also arisen in jurisdictions where disputes fall to be dealt with under general, rather than domain name specific, law. For example, concerns have been raised about why the law relating to trade marks has been applied to domain names at all. Some argued that trade mark law was never intended to create global rights and that the extension of trade mark law into the area of domain names was unreasonable. There have been allegations of unscrupulous actions both by rights holders in one country attempting to stop legitimate businesses operating in another country and of unscrupulous businesses attempting to exploit trade mark rights. The extension of intellectual property rights into the scope of private dispute resolution processes has also been criticised. ${ }^{107}$

Controversies and criticisms aside, there is no single body of law applicable to domain name disputes nor consensus about whether this is required.

\footnotetext{
${ }^{103}$ The AntiCybersquatting Consumer Protection Act 106 Pub. L. 113 USC § 1125 and Truth in Domain Names Act 18 USC § 2252B (Supp 2003).

${ }^{104}$ Panavision International $v$ Toepenn $141 \mathrm{~F} 3 \mathrm{~d} 1316$ ( $9^{\text {th }}$ Cir. 1998).

105 Jack L. Goldsmith “Against Cyberanarchy” in Patricia Bellia (ed) Cyberlaw Problems of Policy and Jurisprudence in the Information Age ( $3^{\text {rd }}$ ed, Thomson/West, St Paul, 2007) at 77.

${ }^{106}$ David G. Post “Against “Against Cyberanarchy” ” in Bellia, above n 50, at 80.

${ }^{107}$ Mueller, above n 36, at 232-233.
} 
While the substantive law is not the direct focus of this research, the nature of disputes may be relevant to the dispute resolution system which might be used to resolve it and the effectiveness of that system. It is necessary therefore to understand the broad range of domain name dispute resolution systems.

3 Categories of domain name dispute resolution systems

Domain name dispute resolution systems fall into two categories: public and private. Public dispute resolution system refers to a court or tribunal. Until 2006 this was the primary means of resolving domain name disputes in New Zealand. Private dispute resolution system refers to a system outside the Courts, such as arbitration, expert determination or some other alternative dispute resolution system. The DRS is a private dispute resolution system. The systems may overlap in particular cases, for example, the DRS yields to litigation or an arbitral tribunal in certain circumstances.

Perhaps the most well known private dispute resolution system is the Universal Dispute Resolution Policy (the UDRP) that was developed by ICANN. ${ }^{108}$ The UDRP is a policy under which disputes about domain names may be referred to arbitration. ICANN approves organisations to provide arbitration services under the UDRP, with the World Intellectual Property Organisation (WIPO) handling the most cases.

The UDRP is perhaps misleadingly named. The UDRP is not "universal" in that it deals with all domain name disputes. The UDRP is restricted to disputes about trade and service marks and is primarily an exception to the first-come firstserved registration policy. ${ }^{109}$ Nor is the UDRP "universal” in the sense that it all applies to all disputes, everywhere. The UDRP is "universal” in the sense that it applies to disputes wherever these arise or, perhaps more correctly, regardless of national boundaries. The UDRP is applicable to all generic domain names. Country code managers may also opt to use this policy for domain name disputes.

\footnotetext{
${ }^{108}$ ICANN, above n 37.

${ }^{109}$ Ibid, at article 3(b)(ix).
} 
New Zealand persons who are registrants of gTLD domain names or those who have complaints about gTLD domain name registrations, must use the UDRP process for their disputes.

\section{$4 \quad$ New Zealand until 2006}

New Zealand has no legislation regulating the technical operation of the Internet or related services such as ISPs. ${ }^{110}$ Domain name disputes are dealt with under general law. Statute and common law causes of action are available. The Trade Marks Act provides a system for registration of a unique mark for use in trade. Registration secures rights to exclusive use, violation of which is actionable in civil and criminal law. In relation to a domain name dispute, registration of a domain name which is the subject of a registered trade mark may be grounds for infringement action under the Act. Trade mark registration can also support a domain name complaint.

Until 2006, the main recourse for .nz domain name disputes was High Court litigation. ${ }^{111}$ The early cases sought injunctive relief in the High Court. Case law developed reasonably quickly through a series of cases between 1999 and 2001 and legal principles were established.

The first principle, established in Oggi, ${ }^{112}$ was that a registrant could be liable for trade mark infringement and that a Court could order transfer of a domain name. A New Zealand registrant had registered Oggi.co.nz and then attempted to sell the name back to Oggi Advertising Limited which has rights in the name. The case, the first trade mark case in the world involving a ccTLD, also established that the registry itself should not be sued for infringement in such cases.

The second principle was that cybersquatting was not permitted in relation to registered trade marks. In Qantas Airways Limited v Domain Name Company

\footnotetext{
${ }^{110}$ Bayer, above n 26, at 14 .

111 Newman, above n 19, at 113-114.

${ }^{112}$ Above n 96.
} 
Limited $^{113}$ the defendants had registered domain names using the words Cadbury, Sanyo, Xerox and Qantas and then attempted to sell these back to the relevant companies which had registered trade marks. The Court ordered name transfer and issued a strongly worded judgment requiring the defendants to take no action which would further dilute the value of the plaintiffs' trade names or trade marks in relation to any Internet site in New Zealand.

In New Zealand Post $v$ Leng ${ }^{114}$ an interim injunction was granted requiring the defendant to stop using nzpost in any domain name and to change it insofar as it related to New Zealand. The Court held that the defendant's use of nzpost.com was likely to confuse and mislead people searching the Internet for the plaintiff's goods and services. The use was also contrary to the Fair Trading Act 1986, which provides for consumer protection measures in trade.

Injunctive relief would also be granted. In Dominion Breweries $v$ The Domain Name Company Limited 115 the Court followed British Telecommunications plc $v$ One in a Million Ltd ${ }^{116}$ holding that, in a claim based on the tort of passing off and trade mark infringement, registration of a domain name by the defendant amounted to an instrument of fraud. The Court held that it may grant an injunction where there is evidence that a domain name matching another person's trade mark will infringe that mark if it is used in relation to goods and services for which the mark is registered.

Other decisions strengthened the position of a Registrar acting in good faith. For example, the Privacy Commissioner, in Case Note 18511, ${ }^{117}$ concluded that publication of personal information about a domain name registrant by a Registrar which has been collected from the registrant by consent and used only for the purpose for which it was gathered (publication on the Internet) is not a breach of the Privacy Principles. The decision ensures that a person challenging a

\footnotetext{
${ }^{113}$ Qantas Airways Limited v Domain Name Company Limited (2000) 1 NZECC 70-005 (HC).

${ }^{114}$ New Zealand Post Ltd $v$ Leng [1999] 3 NZLR 667 (CA).

${ }^{115}$ Dominion Breweries Ltd $v$ The Domain Name Company Limited (2000) 1 NZECC 70-009 (HC).

${ }^{116}$ British Telecommunications plc v One in a Million Ltd [1998] 4 All ER 476 (CA).

${ }^{117}$ Case Note 18511 [2001] NZPrivCmr 9.
} 
domain name registration can access identifying information about the person who has registered the name in question.

By 2001 clear lines of authority were established and there were no apparent difficulties with particular cases or particular types of disputes. However, some commentators were questioning the scope of rights protected under general law and whether this was suitable for the full range of domain name disputes. The focus was on the first category of case where both parties had rights. For example, when considering the case law in relation to marketing law and Internet domain names, Frankel and McLay noted that: ${ }^{118}$

In New Zealand, Courts have struggled to manipulate the boundaries of registered trade mark law, passing off and the Fair Trading Act 1986 to come to what the Court perceives as a "just" result in favour of the "legitimate" domain name user.

InternetNZ was also undergoing considerable structural change. During this process the question arose whether an alternative dispute resolution system might be needed for .nz domain name disputes.

\section{Conclusions}

Three special considerations to apply to assessment of whether the DRS is operating effectively.

First, account must be taken of how the DNS operates. The Internet is based on the DNS which operates through a system of mutual recognition, cooperation and adherence by a collection of organisations and individuals to technical guidelines and policies. These guidelines and policies are developed through consultation and are implemented once there is a rough consensus that implementation can proceed. For practical purposes, that system of mutual recognition takes place via a network of computers which share information. The unifying feature of this system is the fact that it operates to allow a single Internet to operate. Without this system of mutual co-operation, recognition and adherence to guidelines and policies the Internet would not function. The values

\footnotetext{
${ }^{118}$ Frankel and McLay, above n 24, at 712.
} 
underlying this system of co-operation give rise to tensions about policy making and the registration system for domain names and dispute resolution policy. These matters need to be taken into account in assessing the DRS.

Second, the operation of the nz domain name space is a public good. New Zealand courts recognise the role of InternetNZ and have found that InternetNZ is operating responsibly. While there was no apparent doctrinal crisis in the case law, there were questions about the scope of existing rights and whether these were adequate for the full range of cases. At the same time, there were questions about the way in which InternetNZ was exercising its role over the .nz domain name space as it went through a separation of its policy and registry functions. The result is that InternetNZ is not free to operate the .nz domain name space however it chooses. Assessment of the DRS needs to take into this public good function and the manner in which must be exercised by InternetNZ.

Third, there are tensions between the public good function and the private nature of the way it is carried out. This dissertation will assess how these tension affected, positively or negatively, the way which InternetNZ designed the DRS or the policy context in which decisions about the DRS were made, how InternetNZ managed these tensions, and how it managed the wider risks, for example, of government intervention or judicial scrutiny. In particular, the manner of decision-making, including underlying values, will be considered.

Before doing so, Chapter III answers the secondary research question: what kind of dispute resolution system is the DRS? 


\section{A Introduction}

The advent of the Internet has brought new elements to both public and private dispute resolution. In relation to public dispute resolution, the Internet has added new dimensions to existing law, for example, when, where and how contracts are formed, where and how crimes are committed, and the types of communications that are within the scope of legal professional privilege and are subject to discovery in litigation. The Internet has also created new public places where existing law may apply, for example, laws relating to defamation, privacy, intellectual property, contract and commerce. ${ }^{119}$

The Internet has had at least three implications for dispute resolution. First, disputes about what is on the Internet have developed (such as publication of material subject to court suppression orders). Second, the Internet may be used as a technological aid to resolve disputes that are being litigated in the courts (for example communication by use of email or Internet video conferencing). Third, disputes about the Internet may be resolved by a mix of both public dispute resolution (such as online arbitration where the parties never meet each other or the arbitrator in person) and private dispute resolution (such as private companies offering online dispute resolution services about consumer disputes). ${ }^{120}$

The DRS is a private contractual dispute resolution system offering both mediation and Expert determination. This Chapter outlines public and alternative dispute resolution (ADR), considers a new form of dispute resolution, online dispute resolution (ODR), and summarises what kind of dispute resolution system the DRS is. Conclusions are drawn about how the DRS can be evaluated and six criteria are proposed.

\footnotetext{
${ }^{119}$ See, for example, Harvey, above n 9, for an overview of Internet related aspects of criminal law, evidence and technology, and online business relationships in New Zealand.

${ }^{120}$ Tania Sourdin, Alternative Dispute Resolution (2nd ed, Thomson Law Book Co, Sydney, 2005) at 197-208.
} 


\section{B Dispute Resolution Theory}

1 Dispute Resolution and the Rule of Law

The New Zealand legal system operates on the foundations of a Westminster style unwritten constitution based on the rule of law. Within this constitution, the functions of government are distributed across the legislature, the executive and the judiciary. ${ }^{121}$ Parliament is the supreme law maker. Courts uphold the rule of law when applying legislation and the common law. The Courts provide public dispute resolution, which can be contrasted to private and to alternative dispute resolution. The DRS sits within this legal system as an alternative to public dispute resolution.

\section{$2 \quad$ Alternative Dispute Resolution}

The term "alternative dispute resolution" was originally used to refer to dispute resolution that was an alternative to the traditional adversarial litigation process. $^{122}$ The concept of resolving disputes without recourse to the courts was not, of course, a new one. Diverse private dispute resolution systems have existed for many centuries. In the 1970s, however, a new form of legal theory and practice was articulated using the processes of mediation, negotiation and conciliation which were developed and formalised as an alternative to litigation. $^{123}$

Over time, many of these processes came to be used by the very legal systems to which they were originally offered as alternatives. Indeed, while the term is still in widespread use, the extent to which various courts have themselves adopted and integrated "alternative" dispute resolution processes has lead to some commentators preferring the term "assisted" or "appropriate" dispute resolution, rather than "alternative". ${ }^{124}$

\footnotetext{
${ }^{121}$ See The Laws of New Zealand Constitutional Law (online ed) at [4] and [13].

${ }^{122}$ Sourdin, above $\mathrm{n} 125$ at 17.

${ }^{123}$ Carrie Menkel Meadow and others Dispute Resolution Beyond the Adversarial Model (Aspen Publishers, New York, 2005) at xxxv.

${ }^{124}$ K Saville-Smith and R. Fraser Alternative Dispute Resolution: General Civil Cases, (Ministry of Justice, Wellington 2004) at 39 and Australian Law Reform Commission Alternative or Assisted Dispute Resolution (Background Paper 2, Sydney, 1996) at 12.
} 
Ware helpfully cautions against generalisations about ADR since "few traits are common to all ADR processes. The only thing all ADR processes have in common is that they are not litigation.”125 Other ADR proponents favour the “multi-door courthouse" 126 Sanders and Goldberg favour dispute resolution systems that make sure the "forum fits the fuss" rather than assuming that ADR will be appropriate in all cases. ${ }^{127}$ This notion of ensuring the forum fits the fuss is helpful in assessing the decisions made by InternetNZ when it developed the DRS. In the meantime, this dissertation will use the term "alternative dispute resolution” to refer to forms of dispute resolution outside litigation. ${ }^{128}$

\section{(a) Categories of dispute resolution}

Categorisation can be done in a variety of ways. For example, Sourdin notes the Australian National Alternative Dispute Resolution Advisory Council has categorised dispute resolution systems into three groups based on the nature of the process by which a dispute is resolved: ${ }^{129}$

(i) Facilitative processes: a third party assists with managing the dispute resolution process frequently with "no advisory or determinative role". Facilitative processes include negotiation, facilitation, partnering, conferencing, and mediation.

(ii) Advisory processes: a third party "investigates the dispute and provides advice on the facts and possible outcomes”. Advisory processes can include conciliation, evaluative processes, case appraisal, and dispute counselling.

(iii) Determinative processes: a third party investigates the dispute and makes a determination which is "potentially enforceable". Determinative processes include adjudication and arbitration and may be binding or non-binding and may be conducted by subject matter or by dispute resolution experts.

Despite this broad categorisation wide variation in ADR exists both within and outside the Courts. Variation may depend upon the length of the process and

\footnotetext{
${ }^{125}$ Stephen J. Ware Alternative Dispute Resolution (2nd ed Thomsen West, St Paul, 2007) at 11.

${ }^{126}$ Frank E.A. Sander "Varieties of Dispute Processing” (1976) 70 FRD 111.

${ }^{127}$ Frank E.A. Sander and Stephen B. Goldberg "Fitting the forum to the fuss: a user friendly guide to selecting and ADR procedure” (1994) 10 Neg.J 49.

${ }^{128}$ Laws of New Zealand Arbitration (online ed) at [1].

${ }^{129}$ Australian National Alternative Dispute Resolution Advisory Council "What is ADR" (2007) $<$ www.nadrac.gov.au> and Sourdin, above n 120, at 21-37.
} 
the degree of its formality; the extent to which different elements are incorporated; the role of the parties; the subject of the dispute; the reporting and referral requirements (where linked to a court process); and the objectives of the process (whether it is case management, settlement, or improved relationships). ${ }^{130}$ These variations may make categorisation of dispute resolution systems more difficult. $^{131}$

Categorisation may also be based on who decides the dispute, namely: the parties themselves; a neutral third party who assists the parties to achieve their own outcomes; or a neutral third party who adjudicates or imposes a decision. ${ }^{132}$ This categorisation has been further reduced by those who consider there are just two kinds of dispute resolution: adjudicatory and non-adjudicatory.

Spiller helpfully states that the "essential distinction ... is between the consensual processes and those in which a third party has the ability to impose a decision on the other parties.”133 Ware simplifies dispute resolution as either adjudicatory (arbitration and litigation) or non-adjudicatory (negotiation and processes in aid of negotiation). ${ }^{134}$ Ware defines adjudication as: "the process by which somebody (the adjudicator) decides the result of a dispute.”135 Ware notes that "litigation is the default process of dispute resolution .... Litigation produces legally binding results even on parties who have never agreed to have their disputes resolved by litigation." 136 Ware argues that "the basic division within ADR” is “Arbitration vs. Everything Else.”137

This two fold categorisation is very useful, although not straightforward. For example, both Moffitt and Schneider ${ }^{138}$ go further on the differences between adjudicatory and non-adjudicatory dispute resolution processes. They consider

\footnotetext{
${ }^{130}$ Ibid at 19-20.

${ }^{131}$ Sourdin, above $\mathrm{n} 120$, at 18.

${ }^{132}$ The Laws of New Zealand, above n 131, at [1].

133 Spiller, above n 40, at 71.

${ }^{134}$ Ware, above n 125, at 9.

135 Ibid, at 10 .

136 Ibid, at 5 .

137 Ibid, at 7.

${ }^{138}$ Michael L. Moffit and Andrea Kupfer Schneider Dispute Resolution: examples and explanations (Aspen Publishers, New York, 2008) at 111.
} 
that "the important difference is that mediation is explicitly designed to promote settlement, whereas litigation and binding arbitration are designed to promote a judgment." This focus on the outcomes that processes are designed to achieve is relevant to the DRS. For example, it will be necessary to consider whether the DRS designed to promote settlement or to promote judgment against a particular legal standard in the event that settlement is not reached.

On balance the two-fold categorisation is preferred. The simple question is whether the DRS is an adjudicatory or non-adjudicatory process.

\section{$3 \quad$ Categorising the DRS}

In order to determine which category the DRS falls into, the plain words of the DRS policy and relevant contractual and other material need to be considered. The DRS is a mixed model of dispute resolution offering mediation, expert determination and an appeal process within a single system. The introduction to the DRS states: "This policy provides an alternative to the Courts in situations where two parties are in dispute over who the registrant of a .nz domain name should be." 139 The complainant must agree to submit to the exclusive jurisdiction of the New Zealand courts in respect to any legal proceedings arising out of the decision to suspend or otherwise transfer a name and agree that such proceedings will be governed by New Zealand law. ${ }^{140}$

The DRS includes a mediation step within a wider process of adjudication by expert determination and appeal. There is a clear legal test in the DRS which defines unfair registration and the rights in respect of which complaints may be made. Referral to mediation is not possible unless the complaint relates to disputed rights. It is the rights, therefore, which form the backdrop for mediation, rather than any relationship between the parties.

Ware's question, the domain name dispute default process, also needs answering. The DRS specifies the effect of court proceedings or proceedings in

\footnotetext{
${ }^{139}$ Domain Name Commission Limited, above $\mathrm{n}$ 4, at clause 1.1 .

${ }^{140}$ Ibid, cl B2.3.8.
} 
any other decision-making body or arbitral tribunal on complaints within the DRS. Where such other proceedings are underway, the DNC, once the proceedings are brought to its attention, "will suspend the Dispute Resolution Service proceedings, pending the outcome of the legal proceedings." ${ }^{141}$ The parties may also request before or during the DRS proceedings, “an interim measure of protection from a Court."

The DRS process yields to litigation proceedings or proceedings before an arbitral tribunal. But does this make the DRS a non-adjudicatory process? The answer must be no, since the processes of Expert determination and appeal within the DRS are adjudicatory. Looking, as Moffitt and Schnieder do, at the apparent objective of the system, the DRS appears designed to promote settlement at the mediation stage and to promote adjudication if settlement is not reached. The DRS is not a facilitative or advisory process. The DRS provides a substantive test for domain name rights and dispute resolution processes which appear to have the objective of determining those rights. The objective is not to restore relationships nor to provide an entirely consensual process in which the parties alone may resolve their dispute. The DRS is therefore an adjudicative model offering both mediation and adjudication.

This simple categorisation is not, however, the end of the matter. The broad category of adjudicative models includes arbitration and Expert determination. Determining if the DRS is arbitration is important because if it is arbitration, the Arbitration Act 1996 applies. If that Act applies, it would prescribe how InternetNZ can act in relation to domain name disputes and, in doing so, restricted InternetNZ's power to manage and administer the .nz domain name space.

\footnotetext{
${ }^{141}$ Ibid, cl B19.

142 Ibid, cl B19.3.
} 
(a) Is the DRS a form of arbitration?

The Arbitration Act implements the Model Law on International Commercial Arbitration (the Model Law) ${ }^{143}$ developed by the United Nations Commission on International Trade Law. ${ }^{144}$ The purposes of the Act include:

(i) to encourage the use of arbitration as an agreed method of resolving commercial and other disputes; ${ }^{145}$ and

(ii) to promote international consistency of arbitral awards; ${ }^{146}$ and

(iii) to facilitate the recognition and enforcement of arbitration agreements and awards. ${ }^{147}$

The Act sets out the rules which apply to arbitrations, the disputes which are subject to arbitration, and provisions which apply to "consumer arbitration agreements" as defined in the Act. ${ }^{148}$ The Act provides for the powers of arbitral tribunals, liability of arbitrators, rules of disclosure and procedure, and applications to the Courts in related proceedings.

In relation to consumer arbitration agreements, the Act provides that a person enters into a contract as a consumer where that person is an individual and enters into the contract otherwise than in trade and the other party to the contract enters it in trade. ${ }^{149}$ Where the contract contains an arbitration agreement, the contract must specifically state if certain provisions of the Arbitration Act do not apply. ${ }^{150}$ The consumer must also certify that, having read the arbitration agreement, he or she has agreed to be bound by it. ${ }^{151}$ Mandatory arbitration agreements have caused controversy, particularly in relation to consumer

\footnotetext{
143 Arbitration Act 1996, s 3.

144 The Laws of New Zealand, above n 128 at [3(12)].

145 Arbitration Act 1996, s 5(a).

${ }^{146}$ Ibid, s 5(b).

${ }^{147}$ Ibid, s 5(e).

148 Ibid, s 7, s 10 and s 11 respectively.

${ }^{149}$ Ibid, s 11(2)(aa), (a), and (b).

${ }^{150}$ Ibid, s 11(1)(d).

${ }^{151}$ Ibid, s 11(1)(c).
} 
contracts where the terms and conditions of service provision may be heavily weighted in favour of the service provider, rather than the consumer. ${ }^{152}$

Arbitration is a contractual substitute for litigation, its nature varies widely and it can be tailored depending on the type of dispute and, in theory at least, the wishes of the parties. ${ }^{153}$ This flexibility brings both advantages and disadvantages. As arbitration is contractually based, the pre-dispute arbitration agreement may effectively force parties into a private forum for what is, in some cases, a dispute with a strong public element. The flexibility to design an arbitration system, and its administration, may also carry the potential risk that it favours one party or is otherwise skewed in some way.

Lon L Fuller comments on the attractions and limits of arbitration including the ability to tailor arbitration processes but cautions that "no dispute resolution process is appropriate for all disputes all of the time". ${ }^{154}$ Where arbitration is compelled Fuller suggests that it is important to ask whether "the designer of the arbitration designed it to be on terms more favourable to one party". Fuller also suggests that the nature of the dispute may be relevant to whether arbitration is appropriate: ${ }^{155}$

Arbitration is frequently criticized because it typically allows decisions to be made privately and thus does not allow public precedents that are important to support the development of law and inculcation of societal values.

Turning to the DRS then, is it a form of arbitration? The DRS itself is not explicit on this point and does not state whether or not the Arbitration Act 1996 applies. However, the DRS does refer to proceedings before an arbitral tribunal in several places. For example, the fact of mediation may be disclosed to an “arbitral tribunal of competent jurisdiction”. ${ }^{156}$ Where legal proceedings relating to a domain name which is subject of a complaint to the DRS are issued before an

\footnotetext{
152 Menkel Meadow, above n 123, at 545.

153 The Laws of New Zealand, above n 131, at [3(12)].

${ }^{154}$ Lon L. Fuller “Collective Bargaining and the Arbiter” in Carrie Menkel-Meadow and others Dispute Resolution Beyond the Adversarial Model (Aspen Publishers, New York, 2005) 450 at 451 155 Ibid.

${ }^{156}$ Domain Name Commission Limited, above n 4, at clause B6.4.
} 
“arbitral tribunal”, the DRS complaint proceedings will be suspended. ${ }^{157}$ In addition, neither party is permitted to use information gained in mediation for any other purpose or include it in any submission that may be seen by an arbitral tribunal. ${ }^{158}$

There is a strong argument that the DRS is not arbitration within the meaning of the Arbitration Act 1996 simply because the reference to deferral to an arbitral tribunal in the DRS would make no sense if the DRS was arbitration. It might be argued, however, that the DRS is a mandatory consumer arbitration agreement because any person who registers a .nz domain name must agree to abide by all .nz policies which include, in relation to domain name disputes, the DRS. But this argument is not consistent with the plain wording of the relevant registration contracts and the DRS, nor is it clear whom the arbitration contract would be between. The DRS is not a binding contract between the Registrars and the DNC as neither of them would use the DRS (only domain name registrants or those with rights in names do so), although Registrars do agree to be bound by .nz policies and to follow the directions of the DNC made pursuant to the DRS (for example to transfer a domain name). ${ }^{159}$

Turning to whether the contract is between the Registrar and the registrant, all Registrars are required to include certain core terms and conditions in their contracts with registrants. The "Registrant Core Terms and Conditions" is a standard form contract with minimum terms and conditions which all Registrars must agree to use in order to be authorised. That contract does not refer to the DRS at all, although it does refer to .nz policies generally. In relation to registration of domain names, the agreement notes that "the domain name is registered in your name [the registrant's name] only because no other person has it according to the records of the register." 160 A registrant agrees to "protect us [the Registrar] and everybody we have a business relationship with to provide

\footnotetext{
${ }^{157}$ Ibid, cl B19.1.

158 Ibid, cl B6.3.

${ }^{159}$ Domain Name Commission Limited “Registrar Authorisation Agreement” and "Registrar Connection Agreement” Domain Name Commission <www.dnc.org.nz>.

${ }^{160}$ Domain Name Commission Limited, "Registrant Core Terms and Conditions", Domain Name Commission <www.dnc.org.nz>, at cl 3.2.
} 
services to you, from any claim arising out of the domain name being registered in your name or as you direct.”161

The agreement does not contain a provision which states that any disputes about domain names with other registrants must be referred to the DRS. The agreement is simply to comply with .nz policies and, in the case of a domain name dispute, those policies include the optional use of a dispute resolution process. The DRS process is not mandatory. If a complainant wishes to choose litigation in relation to a domain name dispute then he or she remains free to do so. Similarly, the complainant is free to attempt arbitration, although whether the respondent would agree is another matter. Where parties use the DRS they simply agree that the substantive terms of the policy are available and applicable to the dispute.

The question remains whether the consumer arbitration agreement provisions of the Arbitration Act apply because the contract with the registrar is a mandatory one upon registering a domain name. This question cannot be answered definitively because the contractual agreement between a registrant and a Registrar does not specifically contain an arbitration agreement and because the DRS does not state whether it is arbitration or not. It is clear, however, that many persons would register domain names in the course of trade (contrary to the consumer test in section 11). Over 80 per cent of registered .nz domain names are registered as co.nz (company names). It can be assumed that all or most of these would be registered by persons "in the course of trade". A similar conclusion would apply to govt.nz and ac.nz names insofar as the registrations took place within the context of offering services to the public. At the same time, some names would be registered by individuals in the course of community or charitable or family and private pursuits. These could not universally be categorised as "consumers" and it is highly improbable that a court could find that the Arbitration Act applied to some domain name disputes and not others.

${ }^{161}$ Ibid, cl 3.3. 
This dissertation concludes that in the absence of specific reference to the Arbitration Act and in light of the express wording of the DRS and the nature of domain name registrations, the DRS is not arbitration and does not fall within the Arbitration Act 1996. The result is that InternetNZ has retained overall control of the DRS process and the DRS is not subject to a statutory dispute resolution regime.

(b) The DRS as expert determination

Expert determination is another category of adjudicative dispute resolution. ${ }^{162}$ Unlike arbitration, no specific statute governs this category. The distinction between expert determination and arbitration has traditionally been that the expert decides based on his or her particular subject matter expertise in a matter or area of business. An arbitrator, on the other hand, decides on the basis of the requirement to act judicially. ${ }^{163}$ Expert determinations are generally found in contract-based dispute resolution clauses, which are common in a wide variety of commercial and other contracts. ${ }^{164}$

In some areas, for example residential leases, the boundary between expert determination and arbitration is not so clear. The effect of the repeal of certain provisions of the Arbitration Act 1908 (in the Arbitration Act 1996) means that a matter may be referred to an expert valuer for determination without being deemed to be arbitration. ${ }^{165}$ This point is relevant to the DRS in the event of any doubt as to the application of the Arbitration Act for two reasons. First, it may be possible for a matter to be referred to expert determination without being deemed to be an arbitration. Second, it supports an argument that the less specific deeming provisions of the Arbitration Act may be limited in the face of specific wording of contractual provisions and the intention of the parties.

\footnotetext{
162 The Laws of New Zealand, above n 131, at [1].

163 Ibid.

${ }^{164}$ Carus-Wilson v Greene (1886) 18 QB 7 per Lord Esher MR at 9 cited with approval in Forestry Corporation of New Zealand v Attorney-General [2003] 3 NZLR 328 (HC) by Harrison J at 332.

165 The Laws of New Zealand, above n 52, Landlord and Tenant, at [31(183)].
} 
This point was addressed in Forestry Corporation of New Zealand $v$ Attorney-General. ${ }^{166}$ The Court was asked to consider the issue of the parties' appointment of an umpire to assess land value pursuant to a dispute resolution clause in a licence agreement. The key question was whether a clause specifying that "in undertaking this assessment the umpire shall be deemed to be acting as an expert and not as an arbitrator" could nonetheless be construed as an agreement to submit the dispute to arbitration under the Arbitration Act. ${ }^{167}$ Harrison J cited clause 4.4 of the agreement and stated that "the question of whether clause 4.4 constitutes an arbitration agreement or alternatively provides for resolution of disputes by an expert determination is one of contractual construction.”168

Harrison $\mathrm{J}$ concluded that the plain words of the contract should be considered and that there was no agreement to arbitrate. His Honour also concluded: ${ }^{169}$

Like arbitration, expert determination provides for the final resolution of disputes by a private tribunal to whom issues are referred for a binding decision (Russell on Arbitration, 22nd Ed, para 2-030)....With the increasingly informal nature of arbitration and the use of experts in the arbitration context this distinction is being increasingly blurred.

The facts of the case can be distinguished because in Forestry Corporation the parties themselves appointed the expert, whereas under the DRS the parties themselves do not appoint an expert. However, the general principle that arbitration and expert determination are distinct categories of dispute resolution is helpful. The case also supports the proposition that the DRS can be categorised as expert determination as a simple matter of contractual construction. In this case, the contract in question is the contract with the registrant to use the DRS for domain name disputes.

The final consideration is whether special considerations apply because the DRS relates to disputes about the Internet.

\footnotetext{
${ }^{166}$ Forestry Corporation of New Zealand v Attorney-General [2003] 3 NZLR 328.

${ }^{167}$ Ibid at [1].

${ }^{168}$ Ibid, para 11.

${ }^{169}$ Ibid, para 11(b).
} 
(c) The DRS as on-line dispute resolution?

Online dispute resolution techniques may be used for adjudicatory or nonadjudicatory dispute resolution processes. Such techniques allow dispute resolution to take different forms. As Menkel Meadow comments: ${ }^{170}$

Some of the most innovative forms of dispute resolution are those developed for use on the Internet. Variously called EDR (electronic dispute resolution) or ODR (online dispute resolution), these online processes vary tremendously. Some ODR directly involved the Internet (such as claims relating to sales made on the Internet or relating to rights over Web site addresses). Other ODR resolves disputes having nothing to do with the Internet, such as automobile accidents. Sometimes the ODR consists simply of taking conventional forms of mediation or arbitration and conducting the process through words and e-mails rather than face-to-face.

Many forms of ADR are currently carried out entirely online using a variety of technological processes, with these ODR techniques evolving largely in response to the rapid evolution of the Internet and a corresponding increase in online transactions and conflict. ${ }^{171}$ Many ODR services are offered through websites acting as referral and information points, while others provide online services. ${ }^{172}$ Arbitration can take place with neither the parties nor the arbitrator meeting in person but with evidence and submissions are exchanged online. As Menkel-Meadow observes: ${ }^{173}$

This form of arbitration is particularly common for disputes arising with respect to online activities. For example, the Internet Corporation for Assigned Names and Numbers (ICANN) has issued a Uniform Dispute Resolution Policy requiring that disputes over [page 470] ownership of a particular domain name be heard initially through arbitration, preferably online arbitration. Some companies that sell products over the Internet are now offering online arbitration in the event of disputes.

\footnotetext{
${ }^{170}$ Menkel Meadow, above n 123, at 628.

${ }^{171}$ Sourdin, above n 120, at 197-198.

${ }^{172}$ Ibid, at 207.

${ }^{173}$ Menkel Meadow, above n 123, at $469-470$.
} 
Domain name dispute processes which use arbitration also use some ODR techniques: ${ }^{174}$

The Internet Corporation for Assigned Names and Numbers (ICANN) uses a Uniform Dispute Resolution Policy (UDRP) that involves arbitration via selected providers to settle disputes about internet domain name registration. Disputants choose a dispute service provider, submit a claim, and the service provider then contacts the other party about a potential arbitration. Arbitrators then consider the claim and any filed documentation provided and make decisions based on the UDRP "bad faith” rules. According to Gaitenby: "arbitrators and disputants utilize an array of communication but never have a physical meeting or session, arbitrators make decisions and submit options via their respective service provider to ICANN to make them publicly available"”.

There are obvious benefits with these techniques such as rapid information transfer, a reduction in delays, easy access to disputed documents, lower travel costs, shifts in power imbalance and perspectives on the dispute, a reduction in emotional content in the dispute, and keeping parties separate. ${ }^{175}$ Disadvantages or risks are that information shared will not remain confidential because it can be easily transmitted to third parties and that barriers in accessing the technology may limit meaningful participation. ${ }^{176}$ Menkel Meadow suggests ODR mechanisms raise "unique issues” of both over and under use of the technology. Key questions include: "How or why should ODR be regulated when the rest of the Web is largely unregulated?” 177 “Are there particular issues in ODR that are sui generis to technology, or are the issues essentially the same as in other forms of dispute resolution?"178

There are widely divergent views among commentators about the answers to these questions. Some suggest that ODR raises unique issues and that technology can be used to facilitate or avoid disputes. For others, critique of ODR may be influenced by the nature of the dispute. For example, Sourdin's focus is the impact of ODR on the standard of non-adjudicative dispute resolution

\footnotetext{
${ }^{174}$ Sourdin, above n 120, at 208.

${ }^{175}$ Sourdin, above n 120, at 206 and see also Sturzaker "Dispute Resolution in the New Millennium - International Arbitration” (1999) 2(6) ADR Bulletin 60.

${ }^{176} \mathrm{Ibid}$, at 206 and 238-239.

${ }^{177}$ Menkel Meadow, above n 123, at 629.

${ }^{178}$ Ibid.
} 
processes and the place and appropriateness of ODR in contrast to "in person dispute resolution". Sourdin considers video conferencing, telephone conferencing and email communication and whether these can supplement and support face to face ADR approaches, particularly for family law disputes. Others question whether ODR, including technology assisted conferencing processes can ever replace "face to face" alternative dispute resolution processes. ${ }^{179}$

Despite reservations about the effectiveness of ODR for these cases, Sourdin goes on to state that ${ }^{180}$ :

... technology also has the capacity to provide globalised dispute resolution services. This is particularly important as business is increasingly being conducted across borders and with little reference to domestic dispute resolution systems. The lack of existing internet and global dispute resolution systems means that e-business disputes and other disputes (political and social) are more likely to be resolved outside traditional court and litigation systems.

Ultimately these new ODR techniques are not, in my view, relevant to what kind of dispute resolution system the DRS is. Instead, these techniques are simply tools that may be offered to assist dispute resolution processes. Such processes may, however, give rise to concerns about procedural and other safeguards which should be assessed in the practical operation of the DRS.

(d) Commentary

The DRS is a private contractual dispute resolution process that includes mediation, expert determination and appeal. The DRS is an adjudicatory model that does not fall under the Arbitration Act 1996. The DRS prioritises rights and the opportunity to test rights in an adjudicatory manner through determination by an expert. An appeal can be made to a three person expert panel from the expert decision. A further appeal on matters of law can be made to the Courts. The DRS provides for external scrutiny of domain name disputes and independent application of substantive rights. In terms of dispute resolution theory the DRS is

\footnotetext{
${ }^{179}$ Sourdin, above n 120 , at $197-198$ and at $238-239$.

${ }^{180}$ Ibid, at 239.
} 
adjudicative and more like the traditional adversarial litigation process than ADR. The implications of this are considered at the conclusion of this Chapter.

\section{Dispute Resolution Evaluation}

If categorisation of dispute resolution is difficult because of its rapid development and constant growth, evaluation appears more difficult, perhaps even problematic. Evaluation has bedevilled modern ADR. ${ }^{181}$ This research evaluates a private dispute resolution system. In order to answer the primary research question, to further questions must be answered: what kinds of evaluation methods are valid for these systems?; and, where do these methods lie within the broader field of dispute resolution evaluation?

\section{Evaluation of $A D R$ and Litigation}

Comparisons of litigation and ADR have been difficult, with some questioning whether it is possible to compare litigation and ADR at all. For example, Menkel Meadow considers the empirical evaluation of ADR and the claims made by both proponents and opponents. The author cites, with approval, Professor Lon Fuller, "the jurisprude of ADR" who developed the notion of “ 'process integrity'- the evaluation of each dispute resolution process for its own logic, function, purpose and morality”. ${ }^{182}$ In relation to this notion of process integrity the authors state: "We maintain that participation, empowerment, creativity, and self-determination are important values in the successful and satisfying resolution of disputes and conflicts." 183 Despite the apparent importance of process integrity, supporters of evaluation can find this difficult, as Menkel Meadow comments: ${ }^{184}$

Controversies abound about how to collect data, how to categorize inputs and outputs, how to evaluate inside processes, how to define program and process objectives (cost savings to systems versus party satisfaction or self-determination

\footnotetext{
${ }^{181}$ See Sourdin, above n 120, at 239 and for a commentary against settlement processes generally see also Owen Fiss “Against Settlement” (1984), 93 Yale L.J. 107.

${ }^{182}$ Menkel Meadow, above n 123, at xxxiii.

${ }^{183}$ Ibid, at Xxxiv.

${ }^{184}$ Ibid, at 890.
} 
for individuals), and how to find appropriate baseline comparisons of alternative treatments.

There have been demands for evidence that ADR processes are better than those they replace. Unfortunately, as Sourdin notes, "such "proof” has been difficult to obtain, partly because there is little empirical evidence about how the traditional system works and the costs and benefits of more traditional adjudicatory processes.”"185

Others consider it is really only possible to compare like with like. Ware, for example, suggests it is possible to compare litigation and arbitration "as if they were competing products on a store's shelf” and to compare mediation and negotiation, but cautions that it is not possible to compare litigation and arbitration with negotiation and mediation: ${ }^{186}$

Those who compare mediation to arbitration, for example, must be especially careful. Such comparisons often go awry due to failure to appreciate the basic difference between a process that casts the shadow of the law and a process that occurs in that shadow.

The generalisation of ADR features for the purposes of comparison may also be problematic since "few traits are common to all ADR processes. The only thing all ADR processes have in common is that they are not litigation.”187 Ware usefully separates the views of various commentators noting that commentators “cool” on ADR focus “on the cost of dispute resolution” while those "warm” on ADR focus "the quality of dispute resolution" and seeing "little quality in litigation”. 188 These opposing themes highlight the different views of litigation and ADR and, to some extent, the need for caution in using general comparators. $^{189}$

\footnotetext{
${ }^{185}$ Sourdin, above n 120, at 239.

${ }^{186}$ Ware, above n 125, at 11.

187 Ibid.

188 Ibid, at 12.

189 Ibid, at 12-13.
} 
There may also be specific "methodological and conceptual difficulties in comparing ADR with traditional litigation" 190 as well as evaluating and defining processes. Sourdin, for example, notes that one obvious problem in comparing costs and benefits of ADR with civil litigation is that many civil cases are settled out of court. In addition, many evaluations are "unreported” and are unavailable for public analysis with the result that many evaluations are useful specifically but not generally. ${ }^{191}$

Evaluation is difficult even between those models which can be compared. Arbitration, for example, has been especially difficult to evaluate and compare to litigation. Menkel-Meadow cites several reasons for this including the lack of published data on arbitration, problems with assuming an arbitration case would be the same as a litigation case, that the choice of arbitration or litigation can also affect whether a person can afford a lawyer, whether they might choose to bring the claim at all, whether the claim will settle and, if so, for how much. ${ }^{192}$

Evaluation is further hampered by the broader issue of whether private dispute resolution systems raise questions about fundamental principles regarding access to justice. Capelletti, for example, considers evaluation of access to justice has three elements: the people reflecting the problem, need, or demand that prompts intervention; the legal response or solution; and the results or impact of intervention or response to the need for intervention. Capelletti considers that "in modern societies there are new reasons to prefer the elements of conciliation, mediation and arbitration" and that "these new reasons include the very fact of the access [to justice] movement”. ${ }^{193}$ In relation to evaluation, Capelletti considers it important to ask who will staff the system and what standards will apply so as to ensure there is no: ${ }^{194}$

“... second class justice because, almost inevitably, the adjudicators in these alternative courts and procedures would lack, in part at least, those safeguards of

\footnotetext{
190 Sourdin above n 120 , at 240 .

191 Ibid, at 242.

192 Menkel Meadow, above n 123, at 556-557.

${ }^{193}$ Mauro Capelletti Alternative Dispute Resolution Processes (1993) Vol 56 Modern Law Review 282 at 287.

${ }^{194}$ Ibid, at 288.
} 
independence and training that are present in respect of ordinary judges. And those procedures themselves might often lack, in part at least, those formal guarantees of procedural fairness which are typical of ordinary litigation.

Evaluation is a contested area and there are significant unanswered questions about whether evaluation of litigation and ADR is possible and, if so, how that should take place. Evaluation requires caution and clarity about what is being evaluated and compared. That said, the DRS is an adjudicatory process and can therefore be compared to litigation and other forms of adjudicatory processes.

\section{Evaluation of the Dispute Resolution Service}

Despite their various reservations about evaluation, commentators have developed evaluation indicators or criteria. This dissertation draws on these for quantitative or objective evaluation criteria for the DRS. The parameters of this dissertation do not permit a focus on qualitative or subjective evaluation criteria. The primary research question is whether the DRS is operating effectively. "Effectively" in this context means the DRS: (a) is appropriate for the nature of disputes falling within its scope; (b) has process quality and rigour; (c) is low cost and timely. Based on the material examined in this chapter, the following six criteria will be used to evaluate this:
(a) System design
(b) Policy context
(c) Process integrity
(d) Standards
(e) Cost
(f) Statistical analyses

(a) System design

There are choices to be made about system design and these choices may reveal tensions in decision-making that affect the quality of a system. For example, there may be a tension between the need to regulate for consistency of standards (suggesting an adjudicative model) and the desire to design flexible 
dispute resolution systems (suggesting a non-adjudicatory model). ${ }^{195}$ Other tensions may relate to speed and ensuring business certainty or to promote efficiency. ${ }^{196}$ These tensions, and decisions in the light of them, should be evaluated. Consideration of system administration and administrative efficiency is also needed. Finally, consideration should be given to the influence of tradition, political context, and the role of institutions, power and ideology. ${ }^{197}$

System design involves choices about the use of ODR techniques. Such technology can create new issues which need to be considered. Gaitenby notes that ODR poses risks and dangers, for example, if service providers are difficult to identify, "their facilitators hidden behind the digital veil". ${ }^{198}$ If ODR techniques are chosen when a system is designed, assurances of privacy and confidentiality may be more important to participants at the same time as transparency and openness of process is more important to administrators. The result in practice has been a tendency to draw online practitioners from existing dispute resolution areas. ${ }^{199}$ These matters should be considered in relation to the DRS. For example, why this particular form of dispute resolution process was developed and whether the DRS was designed for a particular purpose (and, if so, whether it is fit for that purpose).

A feature of good system design is participation of those affected. ${ }^{200}$ It is important to evaluate the policy development process and the extent of participation of those affected by, or with an interest in, the development of the DRS. Some assessment should be made of the influences of political context, the role of institutions, and ideology in aspects of the DRS system design process. The objectives of InternetNZ can be examined to ascertain, for example, whether the objective in establishing the DRS was to remedy difficulties with litigation (such as cost or the tests that courts were applying) or to protect the DNS and the .nz domain name space (such as by avoiding suit against the registry or the DNC or some other party). Participation of those affected may also indicate whether

\footnotetext{
195 Sourdin, above n 120, at 195.

196 Ibid, at 170 .

197 Ibid, at 176.

${ }^{198}$ Ibid, at 213.

199 Ibid.

${ }^{200}$ Ibid, at 172-173.
} 
the DRS been designed to favour one party or even the system administrator itself.

(b) Policy context

The DRS should be evaluated in light of the broader domain name service policy context and the nature of domain name disputes. Dispute resolution policy may also be affected by whether the dispute is jurisdiction specific or must be seen in a wider policy or dispute resolution context. For example, many ADR processes are "mainstream" and the use of the Internet is ubiquitous. This may affect the policy context and how dispute resolution processes are perceived, as Sourdin notes: ${ }^{201}$

Already most [Australians] are 'net-aware' and a preferred method of communicating in the business setting is through the computer. These and other communication trends will have implications for our dispute resolution processes and may mean that ADR processes are adapted so that remote ADR communication (by net-based activity) becomes more common.

Three aspects of the policy context of the DRS will be considered. The first is whether the nature of domain name disputes was influencing the framework for the dispute resolution policy. If the nature of the disputes was influencing the framework, it will be important to consider whether the nature of those disputes, and those which were predicted, have in fact been the same as the nature of the disputes submitted to the DRS. The second is whether any other InternetNZ policies were influencing the DRS policy. The third is whether the DRS policy was influenced by the growing use of the Internet and whether this, in turn, influenced aspects of the proposed policy and procedures and its effectiveness in practice (such as a focus on online dispute resolution procedures, rather than face to face or in person procedures).

${ }^{201}$ Ibid, at 232. 
(c) Process Integrity

The underlying values of those developing the DRS will be assessed, together with how these affect its operation. These values can be distilled from a variety of source documents including policies, policy reviews, submissions, annual reports and other published material.

(d) Standards

Two standards related matters will be evaluated. First, the standard relating to quality of mediators and experts, for example, whether these are chosen for subject matter or dispute resolution expertise. Standards for dealing with complaints about mediators and experts should be assessed together with any information on how standards reviewed or maintained. Where mediation takes place, some assessment should be made of whether there clear terms of agreement with the mediator which set out the standards by which they will mediate. ${ }^{202}$ Provisions for confidentiality will be assessed together with processes for dealing with conflicts of interest. ${ }^{203}$ The different standards required of mediators compared to, for example, experts will be assessed and, if there are differences, whether those differences directly relate to the different nature of their respective roles and processes. ${ }^{204}$

Second, the quality of the operation of the DRS itself should be assessed by looking at matters such as procedural safeguards.

\section{(e) Cost}

The cost of the DRS will be compared to the cost of litigation where possible. The DRS timeframes can be compared to litigation. Process costs to the parties will be compared, for example the cost of mediators' and experts' services, legal fees, filing fees, and how these compare to litigation.

\footnotetext{
202 Ibid at 179.

203 Ibid.

${ }^{204}$ Ibid, at 184.
} 
Any emphasis on cost and "cost versus benefit analysis” by InternetNZ will be examined along with an assessment of where, and on whom, the costs and benefits were to fall. An attempt will be made to assess the cost of the DRS to domain name registrants, in this case registrants being the wider "taxpayer" or "public funder" of InternetNZ and the operation of the DNS and .nz domain name space.

(f) Complaints analysis

Complaints data will be analysed to determine the categories of domain name disputes; categories of complainants and respondents (including whether legally represented); settlement rates (including cases dropped, disposed of, closed or settled); aspects of system administration (such as processing times); number of expert decisions; and number of appeals (whether within the DRS to the panel, or to the courts). Empirical evidence supporting the need for a DRS will be assessed and estimates of the likely number or nature of disputes will be compared to actual number of complaints made.

\section{Conclusion}

The Internet has brought new elements to both public and private dispute resolution. The DRS, a new legal process, sits within broader dispute resolution theory as a private contractual dispute resolution process offering mediation, expert determination and an appeals process within an adjudicative model. The DRS can be evaluated objectively.

Together with the findings in Chapter II it is apparent a delicate balancing act is taking place in relation to the DRS and its administration by InternetNZ. On the one hand, complaints about the rights of domain name registrants logically lend themselves to adjudicative models of dispute resolution and the DRS is one such model, expert determination. On the other hand, the determination of those rights in an adjudicative model run by those responsible for .nz domain name 
system management and administration poses the risk of being seen as biased or self interested.

Moving to create such a private system might have upset the existing arrangements where the .nz DNS was administeredby InternetNZ with the tacit approval of government and explicit judicial support provided the administration was carried out responsibly. The next two Chapters look more closely at why InternetNZ moved to develop the DRS and how it managed the risks inherent in doing so. 


\section{CHAPTER IVTHE DISPUTE RESOLUTION SERVICE DEVELOPMENT}

\section{A Introduction}

This Chapter analyses the development of the DRS against three criteria: system design; policy context; and process integrity. Several themes emerge that are relevant to the primary research questions. These themes include the lack of empirical evidence justifying a service, the values underlying decision-making, the nature of disputes shaping discussion of the options, and management of tensions between the various criteria for choosing between the options and the wider political environment.

\section{B The Dispute Resolution Service Policy}

1 Overview of DRS Policy Development

InternetNZ developed the DRS between 2001 and 2006. ${ }^{205}$ A working group was established under its Legal and Regulatory Affairs Committee in early 2001 with the following terms of reference: ${ }^{206}$

(a) to investigate whether there is a need for an organised service outside the court system, to resolve, or in some way assist in resolution of, disputes relating to ownership and/or any other rights associated with domain names in the .nz country code top level domain; and

(b) if such a service is considered necessary or advantageous, to recommend the nature, scope, and methods of operation of such a service together with a basic plan for implementation of those recommendations.

The Working Group was to report back to InternetNZ Council with recommendations. There were seven members with a mix of legal and technical expertise: a District Court Judge, four lawyers, an InternetNZ Councillor and the Secretary of InternetNZ. The Working Group was initially called a Task Force

\footnotetext{
205 InternetNZ “Council Motion” (01/19) <www.old.internetnz.net.nz>. The first published document from InternetNZ in relation to the DRS development was this Council resolution. The policy became operational on 1 June 2006.

${ }^{206}$ Ibid.
} 
and subsequently renamed "the InternetNZ Domain Name Dispute Resolution Working Group”. 207

A set of "trigger questions" was developed and released for public discussion. ${ }^{208}$ The Working Group met with various individuals including representatives of the WIPO Arbitration and Mediation Centre. In October 2001 the Working Group released a preliminary report: Domain Name Dispute Resolution in the .nz Space: A Discussion Paper (the 2001 discussion paper). ${ }^{209}$

These initial steps followed soon after the decisions to create a shared registry system and separate policy and technical functions within InternetNZ. The Report of the Shared Registry Service Working Group considered "that some form of service for the resolution of disputes relating to domain names in the .nz space would be a valuable protection for registrants in a competitive shared registry system”. ${ }^{210}$ The 2001 Discussion Paper observed that this suggestion "coincided with an increased focus worldwide on alternative dispute resolution mechanisms in TLD spaces, which was recognised by InternetNZ council.” 211

The 2001 discussion paper canvassed nine options, set out criteria for decision making and applied the criteria to the options. The nine options were: ${ }^{212}$

(i) Status quo - private negotiation, arbitration and/or litigation

(ii) Facilitated mediation

(iii) Internet Commissioner

(iv) Internet Ombudsman

(v) Voluntary local dispute resolution procedure

(vi) Mandatory local dispute resolution procedure

\footnotetext{
${ }^{207}$ The reasons for this are unclear as the discussion paper was released in the name of the Task Force but stated in para 1 that it was "the first report of the InternetNZ Domain Name Dispute Resolution Working Group”.

${ }^{208}$ InternetNZ Domain Name Dispute Resolution Working Group Domain Name Disputes Resolution - Trigger Questions (2001) <www.old.internetnz.net.nz>.

${ }^{209}$ Domain Name Dispute Resolution Task Force Domain Name Dispute Resolution in the .nz Space: A Discussion Paper (Draft V1.2, 23 October 2001), <www.old.internetnz.net.nz >, at paras 4-6.

${ }^{210}$ Ibid.

${ }^{211}$ Ibid.

${ }^{212}$ Ibid, at paras 16, 17, 26, 31 and 43. There are some typographical and grammatical errors in some of the original InternetNZ documents. These have been reproduced without correction.
} 
(vii) Local dispute resolution procedure (mandatory or voluntary) with internal right of appeal

(viii) Non-local dispute resolution procedure

(ix) Some combinations of the above (including, for example a mixed model of mediation and arbitration).

There were three broad categories of options: the status quo (option (i)), some form of local service (options (ii)-(vii)), or a non-local dispute service (option (viii)).

In relation to the status quo, ${ }^{213}$ the paper outlined the existing Court structure. The paper noted that “All domain name dispute cases heard by New Zealand Courts to date have involved interim relief applications to the High Court,"214 as under statute and common law "neither the Disputes Tribunal nor the District Court have jurisdiction in trade mark and passing off cases.",215

The Working Group noted mediation was already an option for parties to disputes. The Working Group defined "facilitated mediation" to mean a process that was "run according to a procedure specified by the cCTLD manager and agreed to by a registrant as a condition of obtaining a domain name” and resulting in a binding and enforceable resolution. ${ }^{216}$

The Internet Commissioner proposal was for a review of the rights and obligations of registrants by a "semi-inquisitorial body" based on the Privacy Commissioner model with an investigation and mediation role. ${ }^{217}$ The option of an Internet Ombudsman role was explored. It was noted that use of term “Ombudsman” required special permission under the Ombudsman Act 1975. This option was for an Internet Ombudsman whose "principal powers and duties would be to consider, at no cost to the complainant, complaints over domain names; and to facilitate the satisfaction, settlement, or withdrawal of complaints” whether by agreement, recommendations or making awards. ${ }^{218}$

\footnotetext{
${ }^{213}$ Ibid, at paras 19-25.

${ }^{214}$ Ibid, at para 23.

${ }^{215}$ Ibid, at paras 19-22.

${ }^{216}$ Ibid, at para 26.

${ }^{217}$ Ibid, at para 27.

${ }^{218}$ Ibid, at para 28.
} 
The Working Group signalled that "if some form of ADR is introduced, a decision will also need to be taken as to the role of the Courts.” Options included limitation of rights until the alternative process was completed; concurrent jurisdiction offering an element of choice of procedure; and appeals to Courts on questions of law if "the ADR is more in the nature of an arbitration.",219

In relation to a non-local dispute resolution procedure, the Working Group noted the UDRP and that twenty ccTLD managers already had arrangements with WIPO to provide dispute resolution procedures for domain name disputes. ${ }^{220}$ Some countries had adopted the UDRP and WIPO procedures "without alteration” (such as Tuvalu and Venezuela) while others had adopted these with some modifications (such as Mexico). ${ }^{221}$

The Working Group did not make any firm recommendations or indicate a preferred option. It is not clear if there were any submissions on the discussion paper. No further papers were released by the Working Group between 2002 and 2004 and the process appeared to stall.

In March 2003 the NZOC, independently of the Working Group process, agreed to develop a questionnaire "to get feedback on the extent of the problem, and whether a DNDR [a domain name dispute resolution policy] would be useful in New Zealand” and proposed to post it on the DNC website. ${ }^{222}$ In August 2003 NZOC re-considered the issue and noted: ${ }^{223}$

\section{Domain Name Dispute Resolution}

It was acknowledged by the NZOC Chair and the DNC that the matter was not yet at the stage of going public. The DNC briefly summarized the relevant issues and stated that the working group (WG) did not yet have an agreed final position but that all agreed it was time to advance this matter.

\footnotetext{
${ }^{219}$ Ibid, at para 45.

${ }^{220}$ Ibid, at para 30 .

${ }^{221}$ Ibid, at para 30.

${ }^{222}$ NZOC “Minutes of Meeting” (InternetNZ, Wellington 14 March 2003) < www.dnc.org.nz> at para 9(b).

${ }^{223}$ NZOC “Minutes of Meeting” (InternetNZ, Wellington 29 August 2003) < www.dnc.org.nz> at para 7.
} 
A discussion about whether or not .nz needed a DNDR process took place. It was agreed that NZOC would suggest to the WG that a way forward, given the apparent lack of consensus in the WG (which was reflected in the NZOC) would be to attempt to better define the issues that a DNDR would address. The DNC Office would offer to assist this process by describing some of the operational issues that have come up and reporting these to the WG. The NZOC Chair would offer this approach to the Chair of the WG.

Eight months later, in May 2004, the NZOC agreed in principle to proceed with the development of a dispute resolution process. It noted that there were "a number of new complaints received" and that "this increase in complaints led to a jump in the cost of legal services for the month." ${ }^{224}$ The NZOC noted:

\section{Local Dispute Resolution Process}

NZOC discussed an example of a recent domain name dispute that is now before the courts. It is the type of dispute that may benefit from a local dispute resolution process being available for .nz domain names.

There were a variety of views expressed about the benefits and drawbacks of a local dispute resolution process (LDRP) but NZOC approved in principle the scoping of a LDRP for the .nz domain name space and agreed to assist the existing Dispute Resolution Working Group as required.

In October 2004 the NZOC noted: ${ }^{225}$

\section{Dispute Resolution Working Group Meeting}

The DNC attended a meeting in Auckland on 13 October 2004 regarding a Dispute Resolution Process for .nz. As a result of that meeting the DNC will be drafting a paper with options for implementing a dispute resolution process for .nz. This is expected to focus on systems based on the Nominet UK model and the WIPO system. It will be subject to public consultation and the results of that consultation period will be presented to the Working Group and to NZOC.

Eight weeks later the DNC released Consultation on establishing a dispute resolution process for the .nz domain name space ${ }^{226}$ (the 2004 Consultation Paper). Three options were proposed: the status quo, a local service or an

\footnotetext{
${ }^{224}$ NZOC "Minutes of Meeting” (InternetNZ, Wellington 3 May 2003) < www.dnc.org.nz> at para 2.

${ }^{225}$ NZOC "Minutes of Meeting” (InternetNZ, Wellington 18 October 2003), <www.dnc.org.nz> at para 2.

${ }^{226}$ NZOC Consultation on establishing a dispute resolution process for the .nz domain name space (InternetNZ, Wellington, 2004).
} 
international one modelled on the UDRP. The local service was based on "the Nominet UK model, which essentially has New Zealand looking after and controlling its own system”. The third option was based on the WIPO process “with some modifications to reflect the .nz policy environment.” Advantages and disadvantages of each option were listed. ${ }^{227}$

Eighteen submissions were received. ${ }^{228}$ A list of submitters and submission number is attached as an Appendix. In May 2005, the Working Group presented its findings to the NZOC and recommended that a new dispute resolution service be established. ${ }^{229}$ InternetNZ Council subsequently endorsed the proposal without change and the service began operating on 1 June 2006. The policy was reviewed in 2007. Three submissions were received and no substantive changes were made.

\section{$2 \quad$ System Design}

(a) Application of system design standards

InternetNZ did not design the DRS from any stated theoretical basis. No objective dispute resolution system design standards are cited in policy documents. There was no reference to such standards in any of the submissions in 2005 or the review in 2007. No specialist dispute resolution organisation made submissions, although a number of submitters were qualified dispute resolution practitioners and affiliated to professional bodies such as LEADR and AMINZ. ${ }^{230}$ In 2004 the criteria for assessing options did not refer to objective standards for dispute resolution systems. ${ }^{231}$

Instead, the approach was a pragmatic one. First, InternetNZ had a majority of lawyers as members of the Working Group. These were practitioners with expertise in dispute resolution, intellectual property rights and domain name

\footnotetext{
${ }^{227}$ Ibid, at 1.

${ }^{228}$ See NZOC "Submissions” (Wellington, 2005) < www.dnc.org.nz>. The Working Group, in its final report notes that 17 submissions were received, but 18 are posted on the DNCL website.

${ }^{229}$ Domain Name Dispute Resolution Working Group Implementation of a dispute resolution process for .nz domain names (Wellington, 2005) <www.dnc.org.nz>

${ }^{230}$ NZOC above n 228, Submitters 3 and 16.

${ }^{231}$ NZOC, above n 226, at para 33.
} 
disputes. Second, the Working Group used the UDRP as the starting point, considering adaptation for New Zealand conditions. The UDRP, as with other ICANN policies, was developed through a broad consultation process and with WIPO, a standards based organisation. The approach was therefore a sensible, if not theoretically pure, way to proceed as it avoided having to reinvent the wheel or start completely afresh.

At the time, new systems and related standards were also developing in other jurisdictions. When the 2001 Discussion Paper was released 20 ccTLD managers had adopted the UDRP (or a modified version of it). ${ }^{232}$ By early 2005, more than 40 had done so. ${ }^{233}$ Other ccTLD managers were developing their own dispute resolution systems such as Nominet in the United Kingdom.

InternetNZ's approach was also a principled one as there were common elements in these developing models. Such elements included the scope of justiciable disputes, a hands off approach by the registry manager in relation to the substance of the dispute, the exclusion of liability of registry managers, finality of decision-making, independent dispute resolution professionals, and, to one extent or another, a focus on speed of dispute resolution. These elements were sensibly cited as the basis for decisions by the Working Group in both the 2001 Discussion Paper and the 2004 Consultation Paper. ${ }^{234}$

InternetNZ's approach to system design also revealed a strong desire for flexibility. But there was disagreement about whether this need for flexibility meant that a local or an international service was needed. Submitters did not agree on how flexible the UDRP process really was. One submission noted that the process could be adapted entirely to local contexts and that this had worked well in Australia in relation to .au domain names. ${ }^{235}$ Another commented that the Consultation Paper "at times appears to assume that the form of the rules adopted [by the UDRP] dictates the organization that will run the dispute resolution

\footnotetext{
${ }^{232}$ Domain Name Dispute Resolution Task Force, above n 209, at para 30.

${ }^{233}$ NZOC, above n 228, Submission 1, at 2.

${ }^{234}$ Domain Name Dispute Resolution Task Force, above n 209, at para 14.

${ }^{235}$ NZOC, above n 228, Submission 1, at 2.
} 
process. We believe that greater flexibility exists." ${ }^{236}$ Others argued that the WIPO model was "designed to handle cybersquatting only", 237 and another that "the need to involve an international body to resolve .nz domain name disputes is probably not great." 238 A third view was that either model gave adequate flexibility to be adapted to New Zealand conditions. ${ }^{239}$

The desire for flexibility reflected the tensions in the role of InternetNZ as both manager and administrator of the .nz domain name space. Despite taking a pragmatic and principled approach to designing the DRS, InternetNZ no doubt wanted to retain ultimate control given that it had ultimate responsibility for the operation of the .nz DNS. Retaining flexibility for both process and possible remedies would be one way to ensure this. The desire for flexibility may also have reflected the tension in balancing the different views of those who participated. That can assessed by looking at who participated in the policy process.

(b) Participation of those affected

InternetNZ established a Working Group and the Council published information about the Group on its website together with the trigger questions. It seems no submissions were made on the trigger questions. Two consultation papers were released, but no submissions were received on the 2001 Discussion Paper. When the policy was reviewed in 2007, there were three submissions, one by a person who had made a submission on the 2004 Consultation Paper in another capacity (and who was also former Chair of the Working Group), the others from persons who had not previously made submissions. All were on minor matters.

In 2001 the Working Group stated: ${ }^{240}$

\footnotetext{
${ }^{236}$ NZOC, above n 228, Submission 14, at 1.

${ }^{237}$ Ibid, Submission 6, at 3.

${ }^{238}$ Ibid, Submission 4, at 3.

239 Ibid, Submission 7.

${ }^{240}$ Domain Name Dispute Resolution Task Force, above n 209, at para 10.
} 
... it is fair to say that there has been a low level of response to date. That is not surprising but it means that the Working Group does not consider it appropriate to make any firm recommendations at this stage.

It is unclear why the low level of response was unsurprising but it may be because the issue was being canvassed within InternetNZ membership or there was a generally low level of interest in legal issues such as dispute resolution. It may be because there was no particular case that was causing difficulty and therefore the issue was not a high priority, particularly in light of other restructuring activities that were happening at the time (including the development of the shared registry). Domain name numbers were comparatively low. Whatever the reasons, the lack of response tempered the Working Group's approach since it had no submissions on which to base recommendations.

Each of the submissions on the 2004 Consultation Paper was published on the DNCL website at the time it was submitted. Five were opposed to establishing a new policy, twelve were in support, and one submission was from Nominet supplementing information it had earlier supplied. ${ }^{241}$

Several factors may have lead to the increase in submissions. First, by 2004 a small number of New Zealanders had been appointed by WIPO as arbitrators for the UDRP. They were making decisions in relation to both gTLD and ccTLD domain name disputes that used the UDRP. ${ }^{242}$ Second, by 2005 some submitters had experience of both UDRP and litigation in relation to .nz domain name disputes (either as arbitrators or complainants). The result was more detailed consideration of the issues. In its report on the submissions in 2005, the Working Group commented that: ${ }^{243}$

A wide range of submissions were received with input from registrars, registrants, Intellectual Property attorneys, the general legal profession and other organisations such as Nominet UK and Emirates Team New Zealand. Of the 17 submissions, five did not consider a DRP was necessary for .nz domains. The rest supported a process being developed with a clear majority preferring something based on the Nominet model.

\footnotetext{
${ }^{241}$ NZOC, above n 228.

${ }^{242}$ Ibid, for example, Submissions 3 and 18.

243 Domain Name Dispute Resolution Working Group, above n 229, at 1.
} 
In fact most submissions were brief (some only a few lines or two or three paragraphs) and two at least had obviously been prepared in collaboration. For example, the Emirates Team New Zealand submission raised the same points almost word for word, as the points raised by another submitter, who was the Team's legal counsel. ${ }^{244}$ Of the submissions opposed, three were from registrars who supported each other and whose submissions were filed in early January 2005. Subsequent submissions, including one from the Chair of the Working Group in his business capacity, took issue with submissions opposed to the policy and specifically refuted them. ${ }^{245}$

In 2001 the Working Group emphasised "empirical evidence of the need for an ADR system."246 This was because "there have been and continue to be situations where domain names have allegedly been obtained for illegitimate ulterior motives seemingly in contravention of valid intellectual property rights” and a desire "for people to be aware of the possible issues". 247 By 2005 there were two views on the issue of empirical evidence. ${ }^{248}$

The first was that there was no need for a service and litigation remained the best option. Five submissions questioned the need for a new service. One commented that the proposal was "a solution in search of a problem.”"249 Others argued that there was no clear case for the service, questioned whether there was a sufficient need to change the existing situation, and called for this to be quantified. ${ }^{250}$ A further submission was that "the decision on the basic "rightness" of a domain name should be in the public arena." ${ }^{251}$ Another expressed concerns about cyberflight ${ }^{252}$ suggesting that a new process might be abused because a person could simply lodge a complaint and then leave the jurisdiction.

\footnotetext{
${ }^{244}$ NZOC, above n 228, Submissions 2 and 3.

245 Ibid, Submissions 9 and 10 compared to Submission 13.

${ }^{246}$ Domain Name Dispute Resolution Task Force, above n 209, at para 11.

${ }^{247}$ Ibid, at para 13.

${ }^{248}$ InternetNZ, Summary of Submissions (round one) - Establishing a Dispute Resolution Process for the .nz domain name space (2005) DNCL <www.dnc.org.nz>.

${ }^{249}$ NZOC, above n 228, Submission 17.

${ }^{250}$ Ibid, Submissions 9 and 10.

${ }^{251}$ Ibid, Submission 10.

${ }^{252}$ Ibid, Submission 18.
} 
The second, opposite, view was that a service was needed, regardless of the empirical evidence. These submissions were predominantly from lawyers with experience of domain name disputes. One commented that while the number of disputes was not large, it was significant. ${ }^{253}$ Another noted that while the need for a dispute resolution policy should be assessed carefully, based on existing United Kingdom and New Zealand estimates there would be about 15 new disputes annually which could use such a service. The submission went further and commented that information from lawyers and others suggested a higher percentage of domain names in New Zealand were in fact the subject of disputes. $^{254}$ Some law firms expressed concerns about the difficulties that small and medium-sized businesses were having in protecting their rights under both existing Court processes and the UDRP processes. ${ }^{255}$

In addition, there were several sets of competing interests. The first was the registrars, some of whom argued there was no need for a service and others who argued there was. The second was between two different private legal views on the need for a service: one that favoured a New Zealand based option and another which favoured either the status quo or the simple adoption (with necessary modification) of the UDRP model operated by WIPO. These different views seemed to reflect the different interests of registrars over those acting for registrants and reflected different experiences of the UDRP and litigation options.

This analysis is revealing. InternetNZ relied on the number and quality of submissions as an important measure of the integrity and robustness of its policy process. In 2001 it was not willing to proceed given no recommendation view from the Working Group. It was not until 2004, when it was apparent that the lack of an alternative to litigation was having a financial impact on the office of the DNC, that the NZOC revitalised the policy process. ${ }^{256}$ In 2005, with a much stronger, though not overwhelming, case for a new service InternetNZ decided to

\footnotetext{
${ }^{253}$ Ibid, Submissions 4 and 7.

${ }^{254}$ Ibid, Submission 6.

${ }^{255}$ Ibid, Submissions 4 and 5.

${ }^{256}$ NZOC, above notes 222-225.
} 
proceed. The Working Group ultimately found a much clearer mandate for the establishment of the service: ${ }^{257}$

Based on the content of the majority of submissions, the level of disputes being referred to the DNC's office, the experiences of some of the WG members and the other information gathered over that period, the WG considers that there is an issue regarding registrant disputes in respect of .nz domains and that there are, and will likely always be, a sufficient volume of such disputes to justify the implementation of a DRP, to enable complainants an alternative to Court. The WG considers that the model best suited for the .nz domain name space would be one based on the Nominet UK model, adapted for NZ conditions. (emphasis added)

While not referenced in the report of the Working Group, the Chair of the Working Group, at the NZOC meeting where the report was presented: ${ }^{258}$

... pointed out that with the growth of the .nz domain name space, the number of disputes relating to domain names, for example cybersquatting, were also on the rise. He discussed how it might work for .nz domain names.

Despite a desire for empirical evidence, on balance the case was weak. There were issues with the reach of existing law into domain name disputes and problems with access to the Courts for the increasing number of small and medium sized businesses that had domain names. But no significant doctrinal problems were detailed in submissions.

As to the breadth and depth of participation, participants were a small but diverse group. However, domain name registrants, those most affected by the proposals, seem to have had very little direct input. The process took place against an organisational background that favoured openness and transparency and with a membership that accorded a constitutional style status to the place of “rough consensus" in policy development. In large measure, this provided a safety net for registrants since InternetNZ began consideration with an open mind and did not move quickly.

${ }^{257}$ Domain Name Dispute Resolution Working Group, above n 229, at 1.

${ }^{258}$ NZOC “Minutes of Meeting” (InternetNZ, Wellington 16 May 2005) < www.dnc.org.nZ> at para 6. 
The process was open and consultative, but participation was limited to those who were already aware of either InternetNZ or the domain name system. Distribution of information was limited with consultation resulting in a small number of submissions from persons directly affected by domain name disputes, persons acting for them or from those administering domain name registration systems (Registrars). Submissions did influence the final form of the policy. Those who participated appeared to have "their concerns accommodated within the design and implementation stage of the dispute system”. 259 However, the lack of participation by domain name registrants and civil society more generally is a concern.

(c) Political context and role of institutions

If the objective of establishing the DRS was to not correct a problem, then what was the objective? Factors such as "political context, and the role of institutions, power and ideology" 260 provide answers this question.

InternetNZ's desire to maintain system control appears to be a significant factor, especially control and the power to act to protect the DNS and manage of the .nz domain name space. System control is apparent in the various and repeated reference in the policy process to the role of InternetNZ as the institution with responsibility for, and system control over, the .nz domain name space. This aspect remains present today and is reflected in the fact that the DRS process remains in the control of DNCL.

Ideology is evident in the fact that without a clear consensus (however "rough") and without any empirical evidence of the need for a new service, InternetNZ maintained its "hands off" approach to development of the DRS. When discussions were reinvigorated in 2004, there were still quite different views about whether a dispute resolution was necessary. At its meeting in March

${ }^{259}$ Sourdin, above n 120 , at 148.
260 Ibid, at 176. 
2005 the NZOC noted that the submissions period on the Consultation Paper had ended, that the Working Group was to consider the submissions, and that: ${ }^{261}$

NZOC members agreed that in considering this matter a priority was to ensure that the rights of the registrants were protected and that there should be no unnecessary costs imposed on registrants as part of the dispute resolution process.

The political and ideological differences in various international arenas, including ICANN, were also reflected within the range of views of InternetNZ members. InternetNZ sought to anticipate these, for example, the 2001 Discussion Paper states: ${ }^{262}$

Although it may not survive into the final agreement, it is also interesting to note that those who prepared the first draft Free Trade Area of the Americas agreement (see the draft "still under negotiation" Article XX in the Trademark section) raise the possibility of the UDRP as a compulsory mechanism for signatories to that report. New Zealand should not blindly follow those leads but neither can it ignore them (emphasis added).

The various criteria referred to in the decision making processes of the Working Group are also evidence of political context, role of institutions, power and ideology. The criteria in the 2001 Discussion Paper were listed as: ${ }^{263}$

- $\quad$ Likelihood that outcomes/decisions will adhere to NZ legal principles ("adherence")

- Consistency with international/other jurisdictional models ("harmonisation")

- Transparency/ability to monitor quality of decisions/outcomes and of those involved in assisting or making decisions ("quality control")

- $\quad$ Consistency of outcomes/decisions ("consistency")

- $\quad$ Usefulness of outcomes/decisions as precedent ("precedent value")

- $\quad$ Speed

- $\quad$ Cost to parties ("parties' costs")

${ }^{261}$ NZOC above n 258.

${ }^{262}$ Domain Name Dispute Resolution Task Force, above n 209, at para 14.

${ }^{263} \mathrm{Ibid}$, at para 33. 
- $\quad$ Cost to system (indirectly to DNS participants other than the parties) ("DNS cost")

- $\quad$ Flexibility of remedy (ability to award more than domain name transfer or non-transfer to successful party) ("flexibility")

- $\quad$ Finality of outcomes/decisions (ability to overturn outcomes/decisions other than through dispute resolution process) ("finality")

The Working Group attempted to apply these criteria to each of the proposed options and allocate a ranking of 1-5 (1 being a positive ranking and $5 \mathrm{a}$ negative ranking). The Working Group went to some lengths to emphasise that the assessments were "entirely subjective and at this stage lack any empirical evidence". ${ }^{264}$ The purpose was to attempt some categorisation of the advantages and disadvantages of the various options, but also to manage the various factors that lay behind these criteria. ${ }^{265}$

In describing the options and criteria in such detail and across such a wide range, the Working Group was doing several things. First, it was attempting to provide information about the broader political and ideological context for domain name dispute resolution. Second, it was attempting to position discussion about a New Zealand process within that broader context. Thirdly, it was going to some lengths to model itself on a public style policy development process. Finally it was taking care not to be seen to be favouring any one option in a way that might indicate predetermination of some kind. This approach in all likelihood also reflected the different views of those on the Working Group and that they did not agree on the best approach. The ranking was therefore also a way to avoid being explicit about the different views in the Working Group and manage the various political and ideological tensions.

These tensions were also caused by the role of InternetNZ as both responsible manager and day to day controller of the domain name space. On the one hand, there was a desire for disputes to be resolved quickly ensuring a business owner or potential registrant(s) had certainty and that the DRS was seen to promote business efficiency. On the other hand, InternetNZ was a private non-

\footnotetext{
${ }^{264}$ Ibid, at para 36.
}

265 Ibid, para 41. 
profit organisation with control over the infrastructure of the Domain Name Service. There was a risk it would be, or be seen to be, judge in its own dispute forum. There was a risk that the service would be perceived as self-serving or in some way biased and that this would be criticised both internally and externally. This was a real risk given the history that lead to InternetNZ separating policy and registry services. ${ }^{266}$

Such criticism might, in turn, have drawn the attention of government or courts to the actions of InternetNZ, with the risk of government regulation or other actions which would be perceived by InternetNZ as interference. One way to mitigate these risks was for InternetNZ to ensure it was working effectively, to consider developing a good quality dispute resolution process, at low cost and in a fair, even-handed manner. Such an approach was also consistent with a responsible that was commented upon favourably in Oggi. ${ }^{267}$

The influence of the institutional role is evident in the way in which InternetNZ went about the process: devolving the policy task to a working group and attempting to ensure a public policy style process. In carrying out the task in this way, InternetNZ was purporting to act transparently as the institution responsible for maintaining overall responsibility for the .nz domain name space.

(d) The rights of registrants

There are repeated references in the policy process to an undefined, yet persuasive, concept: "the rights of registrants". For example, it was persuasive in relation to whether there should be a power to award costs in disputes. On this issue, the Working Group concluded there should be no power to award costs. In setting out its reasons why, it said: ${ }^{268}$

It was agreed that one of the reasons for establishing a DRP was to protect the rights of legitimate registrants. Requiring a fee to be paid 'up front' by the

\footnotetext{
${ }^{266}$ See above Chapter II The Domain Name System in New Zealand.

${ }^{267}$ Above n 96.

${ }^{268}$ Domain Name Dispute Resolution Working Group, above n 229, at 3.
} 
registrant when a complaint is laid would not be fair or equitable and tends to undermine the "first come first served" principle. (emphasis added)

The exact parameters of the concept of the rights of registrants are not clear, yet it is persuasive, suggesting a strong ideological influence. This should be considered further and will be briefly discussed in Chapter VI.

In summary, political context, the role of InternetNZ, power and ideology all affected development of the DRS. InternetNZ attempted to steer a middle course by taking a principled approach to considering options, using explicit criteria, avoiding pre-determination and staying aware of international developments.

(e) Litigation, arbitration or ADR?

The issue of whether the new service was to be arbitration or some other form of dispute resolution was not directly addressed in the 2004 Consultation Paper, but a number of submissions on the Consultation Paper raised this issue. One stated: ${ }^{269}$

It is important to consider whether this procedure is an arbitration under the Arbitration Act 1996. The definition of 'Expert' in the Rules refers to an 'arbitrator'. This is clearly an indication of an arbitration rather than of an expert determination.... The distinguishing factor between arbitration and expert determination is whether the natural justice safeguards are important to the parties.

The submission went on to indicate that "it needs to be thought out very clearly whether InternetNZ intends to provide an expert determination or an arbitration.” 270 The International Trade Mark Association asserted that in its view "the UDRP is not radically different from the Nominet UK model" stating that "both are expedited, relatively inexpensive systems in which expert arbitrators apply multi-factor tests to assess the presence or absence of bad faith.”271

\footnotetext{
${ }^{269}$ NZOC, above n 228, Submission 17 at 2.

${ }^{270}$ Ibid.

${ }^{271}$ Ibid, Submission 14 at 2.
} 
The Nominet submission disagreed with the ITMA submission: ${ }^{272}$

... we would also take issue with their use of the word 'arbitrator' to describe the DRS Experts. The DRS is not an arbitration: for example, it does not oust the jurisdiction of the courts, and does not allow appeal to the courts on a point of law. To do this would be to lose much of the speed, simplicity, and efficiency that benefits the DRS. Incidentally, our understanding is that WIPO does not see the UDRP as being an Arbitration either.

The issue was not referred to in the Working Group's final report to NZOC. No clear statement was made in the final form of the DRS on whether or not it was arbitration for the purpose of the Arbitration Act 1996. However, several changes were made to the draft DRS after submissions in 2005 which demonstrate this issue was taken into account. First, the definition of "expert" was amended to state that: "Expert means a person appointed to resolve a Domain Name Dispute under paragraphs B7 or B17 of the procedure.” 273 References were added to proceedings before "arbitral tribunals". A provision was added for appeal to a panel of experts on a point of law while a complaint was proceeding. An inference can be made that the DNC was trying to more clearly establish the DRS as an expert determination which would defer to an arbitration process under the Arbitration Act, just as it would defer to any court proceedings that might be commenced.

The attempt to make it clear that the DRS is a process of expert determination is consistent with the analysis set out in Chapter III and the conclusion that the DRS is not arbitration. The failure to address the theoretical basis for system design (referred to in Chapter III) was therefore picked up by submitters with dispute resolution expertise. It does seem peculiar, however, that the opportunity was not taken to remove all doubt by being explicit. The DRS preamble states that "this policy provides an alternative to the Courts in situations where two parties are in dispute over who the registrant of a .nz domain name should be.” It is recommended, for the avoidance of doubt, that a provision be added to the DRS making it clear that the Arbitration Act does not apply.

\footnotetext{
272 Ibid, Submission 12 at 3.

${ }^{273}$ Domain Name Commission Limited, above n 4, at para 3.
} 
(f) Mandatory or voluntary?

The question of whether the DRS should be mandatory was an issue from the outset. The 2001 Discussion Paper noted that: ${ }^{274}$

The Working Group proposes to look at both a MANDATORY LDRP analogous to the UDRP (subject to the above considerations) and a VOLUNTARY mechanism. The only difference between the voluntary and mandatory alternatives is that under the voluntary one unless both parties agree at the time to use the procedure and thereby be bound by the results, it cannot be invoked. (emphasis in original)

Clause 2.5 of the DRS provides that: "This policy is one of the .nz policies that, as amended from time to time, all .nz registrants agree to be bound by when registering or renewing a .nz domain name.” The result is that the DRS is not "mandatory" in that it must be used in all disputes. Rather, where the DRS is used, parties agree that its provisions govern how the dispute is to be dealt with and the legal tests to be applied. To this extent, the DRS is a "mandatory" policy.

The question of a mandatory process was partly influenced by the factor of system control. A mandatory process could be implemented through the use of contracts which are entered into by domain name registrants with registrars. Registrars would in turn be required to include the clauses in their agreements with the NZRS, with failure to do so resulting in the risk of de-authorisation. In addition, if there was disagreement over the contractual provision for referral to the DRS, the point could be referred to the Court which could uphold the contractual agreement and refer the matter back to the DRS.

\section{$3 \quad$ Policy context}

(a) Nature of disputes

The policy context has two aspects: policies related to the DNS (set out in Chapter II) and policy debates about intellectual property rights. The DRS provides that, in the absence of substantive proof that a complainant has rights in

${ }^{274}$ Domain Name Dispute Resolution Task Force, above n 209, at para 29. 
a name and that the registration is unfair, the first come first served principle prevails and the original registrant will have a strong case for retention of the domain name. ${ }^{275}$

The 2001 Discussion Paper cites domain name disputes relating to trade marks and other intellectual property rights. The more significant case law at that time involved intellectual property rights of large corporations which were being unscrupulously targeted for exploitation. ${ }^{276}$ This perhaps reflected the then relatively low numbers of registered domain names, particularly by small and medium sized enterprises. ${ }^{277}$ The nature of these disputes was clearly influencing possible dispute resolution options. For example, the 2001 Discussion Paper notes the Disputes Tribunal as an alternative to litigation and states: ${ }^{278}$

For our purposes however, it is important to note that the Disputes Tribunal does not have jurisdiction to hear trade mark claims and therefore is unlikely to be an appropriate forum for the hearing of domain name disputes.

Together with the fact that other types of domain name disputes had not yet developed, it may have been difficult to justify moving from litigation as an option or to understand why a variation of the UDRP might be necessary. Large corporations also, presumably, had the resources for litigation or the UDRP process. On the other hand, the proposal for an Internet Commissioner or Internet Ombudsman indicates a wider range of disputes may have been anticipated and that these might have been better dealt outside litigation or the UDRP. This also suggests there were different opinions about the nature of disputes that it was appropriate for InternetNZ to be involved in.

Frankel and McLay, writing in 2002, noted when considering the case law in relation to marketing law and internet domain names, that: ${ }^{279}$

\footnotetext{
275 Domain Name Commission Limited, above n 4, at cl 5.

${ }^{276}$ See Chapter II, New Zealand until 2006.

277 Domain Name Commission Limited "Statistics" <www.dnc.org.nz>. At 31 July 2001 there were 98,168 registered .nz domain names. By 31 May 2006 (just prior to the DRS coming into force) there were 230,531.

${ }^{278}$ Domain Name Dispute Resolution Task Force, above n 209, at para 20.

${ }^{279}$ Frankel and McLay above n 24, at 712.
} 
In New Zealand, Courts have struggled to manipulate the boundaries of registered trade mark law, passing off and the Fair Trading Act 1986 to come to what the Court perceives as a "just" result in favour of the "legitimate" domain name user.

There is evidence then that during the five years that the DRS was being developed difficulties with some aspects of the jurisprudence were emerging and that the nature of domain name disputes was changing. Submissions on the 2005 Consultation Paper support this finding since only five submissions argued for the litigation option to be retained, although none outlined in detail any doctrinal problems. The majority simply favoured a new system and a considerable number of those submitters had direct experience of litigation for domain name disputes. The changing nature of disputes also gave rise to questions about the scope of registrants protected rights. This, in turn, affected InternetNZ's consideration of what dispute resolution system might be developed to better protect those rights.

The concern to provide for the range of disputes (and the still undefined rights of registrants) ultimately influenced selection of the preferred option. In 2005 the Working Group considered that the scope of protected rights (which could be the subject of a dispute) needed to go "wider than just registered trade mark rights." 280 It was agreed that the scope should include other rights enforceable under New Zealand law. However, disputes were to relate only to competing rights in domain names. The UDRP was much narrower in scope and considered inadequate. Complaints by registrants about registrars were also excluded. ${ }^{281}$ The Nominet experience of $64 \%$ of disputes being resolved at mediation was also influential, ${ }^{282}$ suggesting to the Working Group that the nature of disputes were amenable to mediation and an accessible service would be used by registrants if one was available.

The Working Group developed a substantive test of “unfair registration”. The Nominet policy referred to abusive registration, rather than unfair

\footnotetext{
${ }^{280}$ Domain Name Dispute Resolution Working Group, above n 229, at 2.

${ }^{281}$ Ibid.

${ }^{282}$ Ibid.
} 
registration. ${ }^{283}$ The fairness element in the DRS went beyond the existing legal tests. The "fairness" element in the DRS echoed the "abusive registration" language of the Nominet policy, but did not copy it. ${ }^{284}$ Unfair registration was defined to mean either: ${ }^{285}$

(i) registered or otherwise dealt with in a manner at the time of registration that took unfair advantage of or was detrimental to the complainants rights; or

(ii) has been or is likely to be used in a manner which took unfair advantage of or was unfairly detrimental to the complaint's rights.

The question of unfairness is a matter of evidence. The DRS prescribes a non-exhaustive list of the matters that will be considered evidence of unfair registration including circumstances indicating the respondent has registered the domain name primarily: ${ }^{286}$

(i) for the purpose of selling or otherwise dealing with the name for valuable consideration in excess of the respondent's reasonable out of pocket expenses in acquiring the name;

(ii) as a blocking registration against a name or mark in which the complainant has rights; or

(iii) for the purpose of unfairly disrupting the business of the complainant.

Other matters which may be evidence of unfair registration are: using the name in a way likely to confuse, mislead or deceive, a pattern of unfair registrations by the respondent, the provision of false details to a Registrar, or where it is clear from a previous relationship between the parties that the complainant is the proper holder of the domain name. ${ }^{287}$ Rights are defined to

\footnotetext{
${ }^{283}$ Nominet “Dispute Resolution Service Procedure” (2008) Nominet, Oxford, $<$ www.nominet.org.uk>.

${ }^{284}$ Jacob Grainer "Not abusive, just unfair? Dispute resolution in “.nz” domain namespace and the New Zealand Dispute Resolution Service Policy” (2006) NZIPJ 4(8) 186.

${ }^{285}$ Domain Name Commission Limited, above n 4, at clause 3.

${ }^{286}$ Ibid, at clause 5.1.1.

${ }^{287}$ Ibid, at clause 5.1.2 - 5.1.5.
} 
include "rights enforceable under New Zealand law" but a complainant "will be unable to rely on rights in a name or term which is wholly descriptive of the complainant's business”. ${ }^{288}$

In summary, the nature of disputes did influence the design of the DRS and the scope of protected rights. This is evidence that the DRS was designed to be fit for purpose. But the DRS was not tightly prescribed or tailored to only one kind of dispute. By going wider than existing law on trade marks, passing off, and consumer protection ${ }^{289}$ InternetNZ was providing improved protection for domain name registrants. This is further evidence that InternetNZ was acting in a responsible manner and in the public good. The DRS was not designed to be self serving or to deal only with a narrow range of cases.

(b) Influence of other InternetNZ policies

The DRS had to fit with the other 16 policies of InternetNZ as well as the restructuring of the Shared Registry Service and related policy developments. ${ }^{290}$ The influence of these policies was apparent throughout the DRS development. For example, the desire for coherence is reflected in the final form of the DRS. Clause 2.5 provides: "This policy is one of the .nz policies that, as amended from time to time, all .nz registrants agree to be bound by when registering or renewing a .nz domain name.”

The "hands off" administration policy of InternetNZ influenced the Working Group in its decision not to impose filing fees. The charging of administrative costs was considered to be revenue generating for the DNC and, it was concluded, likely to affect the perception of its independence, even if those costs were reasonable. It was noted that under the domain name fee funding model "all registrants were contributing to the cost of having a service available if it was required" and that this was: ${ }^{291}$

\footnotetext{
${ }^{288}$ Ibid, at clause 3.

${ }^{289}$ See Chapter II, New Zealand until 2006.

290 See Chapter II, Domain Name Service Policies.

${ }^{291}$ Domain Name Dispute Resolution Working Group, above n 229 at 3.
} 
... also consistent with InternetNZ's "trusteeship" of the .nz space that it (and consequently all registrants ultimately) should bear the expense of any system which improves the overall operation of that space. Such a system potentially benefits all registrants, and potential registrants, any of whom who may be faced with a dispute. It also balances any potential exploitation of the "first come first served" principle, without undermining it in any way.

There was support for the fee model adopted by Nominet because this enabled InternetNZ to "be seen to be completely unbiased as to the lodging of disputes and their progress.”292

This influence is reflected in the final wording of the DRS policy. For example, clause 2.4 of the DRS provides that: "Neither registrars nor the DNC get involved in disputes regarding who the true registrant of a domain name should be, but will undertake actions as directed either by the Courts or by the Experts under this policy.” Clause B21 deals with exclusions of liability and purports to protect the DNC, its officers and staff, as well as mediators and Experts, acting under the DRS from negligent acts or omissions, unless bad faith can be shown and clause B2.3.9 which is a further exclusion of liability. ${ }^{293}$

The policy of first-come first-served registration influenced the Working Group in deciding not to recommend there be a power for Experts to impose orders for costs. $^{294}$

Evidence of the inter-relationship of the policies is also apparent in the fact that the DRS Policy has been taken into account in other InternetNZ policy reviews. For example, in the 2007 policy review of the Registering, Managing And Cancelling A Domain Name Policy, the State Services Commission proposed a policy change that would allow the cancelling of domain names based on their use, for example, for spam and phishing. NZOC opposed such a policy on the basis that "the current position of not getting involved in the use of a

\footnotetext{
292 Ibid.

293 Domain Name Commission Limited, above n 4, at Clause 2.4.

${ }^{294}$ See above, Analysis of System Design.
} 
domain name” prevailed and should simply be reiterated in a new clause for that policy. $^{295}$

Policy coherence was a feature of the DRS system design. Policy developments in intellectual property law and the law related to domain name disputes were considered. The DRS drew heavily from, but did not exactly copy, the Nominet policy.

(c) The influence of ODR techniques

The growing use of ODR techniques was influential. The 2004 Consultation Paper set out the technical aspects of the Nominet process in some detail, with an emphasis placed on the case management system "which models the DRS Procedure precisely and provides a highly automated support to their staff." The Paper emphasised that the service was conducted by way of a "refined process of telephone based, facilitative mediation" 296 (rather than face to face mediation), email as a key form of communication, particularly helpful across time zones, and that "the parties do not talk to one another directly.,"297

These advantages translated to reduced costs and administrative ease. The system was estimated to require the equivalent of 1 FTE to operate, ${ }^{298}$ the use of a database system, and low administrative overhead. This meant easy monitoring and an ability to control process time frames. ${ }^{299}$ ODR techniques were listed as useful for administrative simplicity and lower cost, rather than other reasons.

\section{$4 \quad$ Process integrity}

Three values appear to underlie the development of the DRS: protection (of InternetNZ's .nz management role), process quality and administrative efficiency.

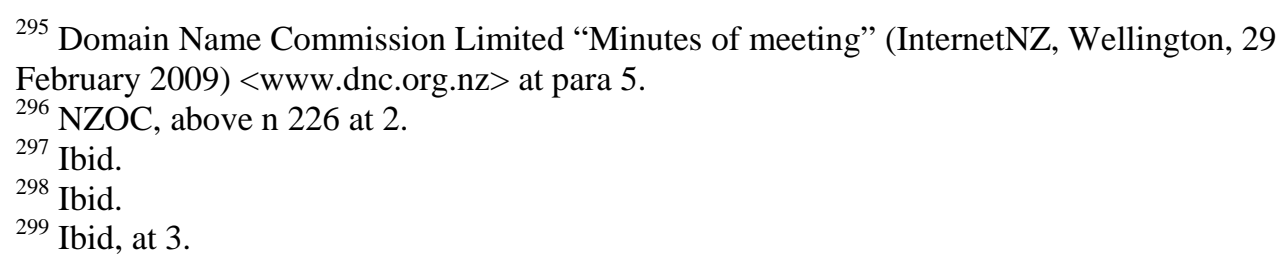


InternetNZ's technical role was a key factor in the 2001 Discussion Paper: ${ }^{300}$

MANDATE: InternetNZ has responsibility for maintaining the domain name space or system ("DNS") in the .nz country code top level domain ("ccTLD"). In doing so, under the various applicable RFCs (in particular RFC 1591) and its own rules, InternetNZ is charged with enhancing the use of the internet. To do so, from time to time, InternetNZ sets policy governing use of the internet in New Zealand following public consultation with affected participants or potential participants. Examples of such policies can be found on this site (eg that governing the creation of new second level domains ).

This paragraph was adopted almost without amendment in the final form of the DRS. ${ }^{301}$ It might be argued that InternetNZ placed greater weight on protection of this role over the concerns about domain name disputes. InternetNZ's primary focus was that the Internet functioned without interruption: how people used it was irrelevant. Such an approach was consistent with the hands off approach which InternetNZ was espousing and may also explain the carefully constructed neutrality of the 2001 Discussion Paper.

The 2001 Working Group’s criteria for assessing the options also reveal values relating to quality process (adherence, speed, finality, flexibility, decisionmaking quality) and administrative efficiency (cost to system, cost to parties, and precedent value). The 2001 Discussion Paper stated: ${ }^{302}$

It is considered by the Working Group that the primary driver as to whether a multi-tiered system is required will be one of cost vs benefit. Empirical evidence of the size of the domain name dispute problem in New Zealand and whether it appears to be growing or not will be important in considering this. We also need to make educated guesses (for that is all they can be at this early stage), based on relevant factors (including overseas experience), as to how the introduction of an shared registry system into the .nz space will impact on the level of domain name disputes, if at all.

\footnotetext{
${ }^{300}$ Domain Name Dispute Resolution Task Force, above n 209, at para 2.

${ }^{301}$ Domain Name Commission Limited, above n 4, at the Introduction and in parts A and B.

${ }^{302}$ Domain Name Dispute Resolution Task Force, above n 209, at para 44.
} 
The 2004 Consultation Paper did not list these criteria. However, the factors cited in relation to the advantages and disadvantages of each option echo some of the criteria of 2001. For example, the need for possible administrative changes is referred to (raising concerns about criteria of cost to system and flexibility) and whether there will be clarity about how to handle the disputes and complaints (concerns about consistency and precedent). Cost risks (both to parties and the administration of the service) were outlined for each option. Three criteria were no longer listed but can be implied, namely: adherence, harmonisation, and finality.

The Working Group was attempting to develop meaningful proposals with transparent criteria. It was clear that if a DRS was to be developed, InternetNZ wanted to be sure it was of good quality and administratively efficient. While the policy development process was not without tensions, the way in which these tensions were dealt with also provides insights into process integrity. In 2001 these tensions resulted in a lack of consensus and, in the absence of a consensus there were no firm recommendations. InternetNZ was clearly concerned to ensure that there was a rough consensus before taking final decisions.

A policy development that had the "look and feel” of a public policy development process is also evidence of process integrity. There were executive decisions by InternetNZ Council whether to proceed. A working group was established. There were public announcements of consultation. Trigger questions and a discussion paper were issued. A further consultation paper was issued and submissions received and published. InternetNZ was attempting to consult those likely to be affected and imbuing its processes with public policy elements. This was also happening in relation to other policies. For example, it developed policies for complaints and was explicit about consultation on any policy changes. While participation in those processes was weak, the steps were transparent.

In summary, InternetNZ took a principled approach to development of the DRS policy. There were strong values underpinning that approach. The more significant values related to protection of InternetNZ's technical role and oversight of the .nz domain name space coupled with an emphasis on consensus 
in decision-making. But there was also a desire to use, and be seen to use, a transparent policy processes.

\section{Conclusion}

The development of the DRS has been analysed in light of its system design, policy context, and process integrity. Several themes emerge: the lack of empirical evidence justifying a service, the mixed values underlying decisionmaking, the public process InternetNZ used to develop the policy and the careful management of tensions between the various criteria for choosing between the options.

InternetNZ took a pragmatic but principled approach, anticipating international developments and the nature of domain name disputes and considered the DRS before there was evidence it was needed. Questions were being asked about whether existing law adequately protected the rights of registrants, although these rights were not defined. By 2005, concern about this aspect of the nature of disputes was influencing the design of the DRS. The result was a test of unfair registration that was broader than existing law. Several conclusions can be drawn

First, the policy development process did reflect the principles of a system of mutual recognition and co-operation. The special nature of the DNS outlined in Chapter II infused the policy development process with transparency and a consultative approach. When there were no submissions (as in 2001) or there was no consensus, the proposal did not proceed. These principles did give rise to tensions in the development of the DRS policy but were also a safety net for domain name registrants, given how few people participated in the policy process over five years. The principles of mutual recognition and cooperation were a counterweight to rapid changes and the risk of capture of the process by a single voice or a narrow range of participants. They were also relied on by decisionmakers when there were no submissions or when submissions needed to be assessed. 
Second, InternetNZ exercised its policy function rationally, drawing on the best of overseas knowledge, on local legal and technical expertise, and developing its position over time in light of the nature of disputes. However, the Working Group ceased to function some time in 2002 (or perhaps had reached a stalemate). The push for change came from the Domain Name Commissioner and NZOC, driven by the changing nature of disputes at the shop front, and the cost implications for InternetNZ of being involved in litigation to protect the DNS.

Third, there were tensions between the public function and the private nature of the way it was carried out. InternetNZ managed these tensions in a principled way, skilfully navigating a middle course through both the differing views and the wider risks, for example, of government intervention or adverse judicial scrutiny. InternetNZ was interested in retaining system control, power and its own role in relation to the DNS. The DRS development process would have benefitted from being tested by having more participation by more diverse people. But InternetNZ acted fairly and was not self-serving.

Fourth, InternetNZ is operating a dispute resolution system in which rights are contested, rather than one in which the focus is settlement. InternetNZ is not free to operate the .nz domain name space however it chooses. Yet the DRS was not designed to be a closed system. The risks of intervention by government or the Courts appear to have been managed by having an adjudicative dispute resolution process. This would counter, for example, any possible perception of bias or self interest in the outcome of particular disputes and appear to reflect a "hands off” approach to management of the .nz domain name space. It can also be said that the DRS was designed to promote justice, rather than settlement.

The Working Group recommended "that InternetNZ should proceed to implement a Nominet style DRP for the .nz domain name space”. ${ }^{303}$ This recommendation was accepted and subsequently approved by the InternetNZ Council without change. The Chair of the Working Group commented: ${ }^{304}$

\footnotetext{
303 Ibid, page 4.

${ }^{304}$ InternetNZ “Domain name dispute process to be implemented” (18 May 2005) Press Release.
} 
The growth in the .nz name space has meant that disputes caused by such issues as cybersquatting and reverse domain name hijacking have continued unabated. However resolving such issues in Court is a massive investment in time, cost and people's patience - the committee established that there was definitely a need for a better route to conflict resolution. We looked at a number of well established systems from around the world and eventually decided that we should model ourselves on the UK Nominet process.

The NZOC representative also commented: ${ }^{305}$

InternetNZ already has a good name for its stewardship of the .nz domain. This new dispute resolution model will further improve the way the .nz name space is administered, for the benefit of all .nz registrants and the New Zealand local Internet community.

Implementation began in earnest and the DRS became operational on 1 June 2006, five years after the original Working Group had been established.

${ }^{305}$ InternetNZ “Domain name dispute process to be implemented” (18 May 2005) Press Release. 


\section{CHAPTER V THE DISPUTE RESOLUTION SERVICE IN PRACTICE}

\section{A Introduction}

This Chapter turns to the final aspect of the primary research questions and examines what has happened in practice with the administration of the DRS and the domain name disputes that it has been used for. Drawing on the criteria in Chapter II this Chapter evaluates the DRS in light of system standards (of dispute resolution personnel and procedures), the cost of the service to parties (including the time that proceedings take) and provides a statistical analysis of complaints.

\section{B Evaluation of DRS \\ $1 \quad$ Standards}

Mediation is mandatory if a response is made to a complaint. ${ }^{306}$ There is no fee for the mediation process. ${ }^{307}$ The DNC appoints a mediator within three days of receiving a reply with appointment made "on a rotational basis from its list of Mediators." 308 The list of mediators, and their qualifications, is published. ${ }^{309}$ Negotiations in mediation are "confidential as between the parties, the mediator and the DNC" 310 with mediation being conducted in "a manner which the DNC, in its sole discretion, considers appropriate.”311

It appears, by inference from this clause, that the DNC is somehow engaged in the process beyond simply administration. The definition of "party" in clause 3 of the DRS states that "party" "means a Complainant or Respondent and Parties has a corresponding meaning.” Clause B6.3 states that the mediation shall be confidential "as between the Parties, the mediator and the DNC." It is not clear that the DNC is a party, as defined, but there does appear to be some engagement beyond administration.

\footnotetext{
${ }^{306}$ Ibid, cl B6.1.

${ }^{307}$ Ibid, cl B20.2.

${ }^{308}$ Ibid, cl B6.1.

${ }^{309}$ Ibid, cl B6.2.

${ }^{310}$ Ibid, cl B6.3.

${ }^{311}$ Ibid, cl B6.1.
} 
The engagement of the DNC in the mediation is unusual. In practice it appears that the DNC does not actually take part in the mediation, but is able to view notes of the mediator and the mediation outcome, including any settlement. $^{312}$ The only apparent reason for this would be to ensure that any settlement was in accordance with InternetNZ and DNCL policies. It is unclear what would happen, for example, if the parties reached a settlement which the DNC did not approve of (or refused to enforce) and this was subsequently challenged by one or both of the parties.

\section{(a) Practitioners}

The standard of dispute resolution service providers was an issue throughout the development of the DRS. The trigger questions asked: ${ }^{313}$

9. What sort of qualifications/experience should arbitrators/mediators have? How should they be appointed to the pool of available people? Who appoints them? Are they employed by ISOCNZ or whatever agency runs the service or are they contracted as and when needed from the pool?

12. Should arbitrations/mediations be confidential? Should any decision/settlement be confidential? If not, should decisions be reported and therefore be available as some form of precedent?

13. What form of quality control should be maintained in respect of decisions and/or decision makers, if any?

The 2001 Discussion Paper noted “facilitated mediation” means mediation in which "the ccTLD manager would provide skilled mediators (either from its own personnel or through externally approved suppliers) and appropriate assistance in terms of resolving logistics for the mediation.” ${ }^{314}$ The 2004 Consultation Paper suggested that mediators or arbitrators be approved and noted that: "The Nominet mediators are trained and accredited and undergo a programme of continuing professional development.”315 The WIPO system of “approved panellists” was also noted.

\footnotetext{
${ }^{312}$ Domain Name Commissioner "Notes" to author regarding draft dissertation (23 March 2010).

${ }^{313}$ InternetNZ Domain Name Dispute Resolution Working Group, above n 208.

${ }^{314}$ Domain Name Dispute Resolution Task Force, above n 209, at para 26.

${ }^{315}$ NZOC, above n 226, at 2.
} 
InternetNZ's changed its views about the relevant standards during the development of the DRS according to the scope of the DRS and the disputes that would come before it. There was express reference in the 2004 Consultation Paper to the possibility of non-lawyers and non-trademark law experts being Experts or mediators. Expertise in both dispute resolution and subject matter (intellectual property law) subsequently became criteria for appointment. ${ }^{316}$

(i) Mediators

Mediator appointments are published. ${ }^{317}$ The DNCL states that: ${ }^{318}$

Mediators working with us are members of either or both of the following professional bodies: Arbitrators' and Mediators' Institute of New Zealand (AMINZ) - either Associate (AAMINZ) or Fellow (FAMINZ); Leading Edge Alternative Dispute Resolvers New Zealand (LEADR NZ).

These professional bodies establish certain criteria for membership including affiliate and associate, with the latter requiring specific dispute resolution qualifications. Members agree to abide by professional rules and standards, including codes of conduct and on-going professional development. There are 10 mediators. Eight have "advanced panel” membership of LEADR (NZ), one is a Board member and Treasurer of AMINZ, and one is a member of LEADR (NZ). All appear to be of a very high quality.

\section{(ii) Experts}

There are eight Experts. ${ }^{319}$ Three are former Judges of the High Court of New Zealand and four are Queen's Counsel. There is one non-lawyer. Six are Fellows of the Arbitrators' and Mediators' Institute of New Zealand (AMINZ) and five are or have been authorised WIPO panellists or otherwise involved in international domain name dispute resolution processes. Two made submissions

\footnotetext{
${ }^{316}$ Ibid, at 2.

${ }^{317}$ Domain Name Commission Limited, above n 4.

318 Ibid.

${ }^{319}$ Domain Name Commission Limited "Dispute Resolution Service” < www.dnc.org.nz>.
} 
on the 2005 Consultation Paper. ${ }^{320}$ There is a combination of both dispute resolution and domain name dispute resolution skills among the group.

(b) Procedural and other safeguards

Procedural standards include rules protecting privilege, confidentiality and other safeguards. There was little comment on these matters in the DRS policy development process. Reference is made by Nominet in its submission about the details of its process. The DNCL provides induction and training and has signed agreements with each mediator and Expert. ${ }^{321}$

The DRS contains provisions on mediator appointment, liability and confidentiality. Settlements and mediation proceedings are confidential and privileged. Mediators acting in good faith are protected from liability, except in the case of bad faith. ${ }^{322}$ Mediation is not face to face. Complaints and submissions to Experts must be in writing, filed with the DNC, and comply with prescribed word limits. Submissions are forwarded by the DNC to the respective parties within prescribed time limits. Failure to meet time limits will result in the complaint lapsing or moving to the next stage of the process by default. No hearings in person have been held by Experts (although there is provision for this in a particular case). ${ }^{323}$

In relation to impartiality, Experts make a declaration of conflict of interests in their decisions, although this is not expressly required in the DRS policy. The DRS has adequate confidentiality, privilege and immunity provisions in Part A and Part B. The mediator role is clear and includes the requirement to act independently and disclose possible conflicts of interest. The process for dealing with complaints against mediators or Experts is not clear and it is not known if any such complaints have been received. There are no published

\footnotetext{
${ }^{320}$ NZOC, above n 228, Submitters 3 and 18.

${ }^{321}$ Domain Name Commissioner, above n 312.

${ }^{322}$ Domain Name Commission Limited, above n 4, at paras B6.2 (publication of Mediator qualifications and limitation on challenge to appointment), B6.3, B6.5 (confidentiality) and B21.1 (exclusion of liability).

${ }^{323}$ This conclusion is based on an assessment of the published Expert decisions, none of which notes that a hearing in person was held.
} 
guidelines for parties to the mediation, although some information is available on the DNC website. ${ }^{324}$

The principles of natural justice are a further procedural safeguard. The DRS provides that in addition to the right of appeal, parties can request a rehearing. The non-exhaustive list of examples which might justify a re-hearing are: ${ }^{325}$

(i) serious misconduct by an Expert;

(ii) false evidence having been offered to the Expert;

(iii) the discovery of new evidence; and

(iv) a breach of natural justice.

The right to be heard is provided for, with the DRS setting out procedures for written evidence and a right of reply to a complaint. There is an emphasis on written rather than oral presentation of evidence to Experts while mediation takes place via telephone. There are word limits on complaints and responses which may limit the right to be heard in some circumstances although no information about that is available. Time limits are tight and may cause difficulties in some cases (see further below). The DNC manages complaints through the process, however, and retains the discretion to take into account individual circumstances in particular cases.

One area of concern is the requirement for a complaint to be referred to an Expert for determination even if a response to the complaint has not been filed. Referral to an Expert incurs a fee of $\$ 1800$ plus GST. There is potential for abuse of this system, for example, by a person who wishes to annoy a complainant by registering names in which the complainant has rights and then simply ignoring a complaint. The complainant is still required to obtain an Expert decision and that may be unfair in some cases, especially where the registration is plainly unfair. Improvements should be considered for example automatic transfer of the name

\footnotetext{
${ }^{324}$ Domain Name Commission Limited, "Make a Complaint” < www.dnc.org.nz>

${ }^{325}$ Domain Name Commission Limited, above n 4, at clause 12.7.
} 
after the period for a response or introducing a discretion for the DNC to transfer the name after proof of "final notice" to the respondent by the complainant.

On balance, the procedures are clear, fair and further safeguarded in both the criteria for appointment and the quality of those appointed as mediators and Experts. The process is rigorous with the parties required to contest rights in domain names through an adjudicative process based on clear legal tests. Improvements could be made to the process for handling complaints where no response is filed.

\section{Costs}

(a) Time

“Time” includes the overall dispute resolution process and each step. There is no purposive provision requiring the DNC to deal with complaints "in good faith", "promptly” or any similar duty based clause. The time for each step is (with the running total in square brackets):

Initial (valid) complaint received and proceedings commenced - sent to respondent within three days [3]

Response - within 15 days [18]

Right of reply - within 5 days [23]

Informal mediation - arranged within 3 days of reply [26]

No resolution within 10 days - notification of referral to expert [36]

Complainant pays Expert fee - within 10 days of notice of referral [46]

Expert appointed - within 5 days from payment of fee [51]

Expert has ten days to render a decision [61]

Communication of decision to parties - within 3 days of receipt [64]

Implementation within 10 days of communication unless appeal filed [74]

Appeal statement - must filed within 15 days of notice of appeal [89]

Notice of appeal forwarded to other party within 3 days [92]

Appeal response within a further 10 days [102]

Appeal decisions within 30 days of appointment of last panellist with option for further 10 days by agreement with DNC [142] 
The maximum possible time is 142 days. ${ }^{326}$ Complaints are managed and may proceed more quickly. For example, if there is no response to the complaint and it proceeds to an Expert for determination, the maximum time is 56 days. The DNCL does not publish information on the average time taken for a complaint to be resolved. The DNCL has noted that "On average, disputes take around 90 days to process from submission to the receipt of the Expert determination.”327 On average there are eight cases in the DRS system at any given time. $^{328}$

To compare this with litigation is somewhat difficult. The High Court Rules provide an allocation of time 5.9 days for counsel to prepare an interlocutory application for an interim injunction. ${ }^{329}$ That is not to say that an injunction would be granted within approximately six days, but does give an indication of the time that might be recoverable when costs are awarded.

An effective dispute resolution system will be timely and efficient, so that parties are not left waiting for administrators to respond and so that the disputes is resolved as quickly as practicable. The DRS clearly provides timely dispute resolution compared to litigation. A purposive provision could usefully be added to the DRS to make clear the duty of the DNCL to manage cases in a timely manner.

(b) Fees

There is no fee for filing a DRS complaint or for re-submitting a complaint. Mediation is free to the parties. Mediators are paid directly by the DNCL on a set fee basis. The first fee payable by either party is the filing fee for an Expert decision, which is $\$ 1800$ plus GST for disputes involving 1-5 domain names. Fees are determined "on a cost-recovery basis and are passed on in their entirety to the Expert(s). The DNC does not charge for its mediation or administration services in respect of the Dispute Resolution Service.”330 Fees are

\footnotetext{
${ }^{326}$ The DRS defines “days” in clause 3 to mean calendar days excluding Saturday, Sunday and public holidays.

${ }^{327}$ Domain Name Commission Annual Report 2006-2007 (InternetNZ, Wellington, 2007).

${ }^{328}$ Domain Name Commission Annual Report 2008-2009 (InternetNZ, Wellington, 2009) at 9.

${ }^{329}$ See also the next section in the Chapter, (b) Fees, where this is explained in more detail.

${ }^{330}$ Dispute Resolution Service Policy, cl B20.1.
} 
only payable if mediation is unsuccessful and an Expert is to be appointed. ${ }^{331}$ The DNC reserves the right to charge higher fees for more complicated cases and in the event that an in-person hearing is held. ${ }^{332}$ It is not clear whether these higher fees have ever been charged. Fees for appeals are $\$ 6600$ plus GST. There is no power to award costs.

In comparison, the fee for a complaint to a single WIPO panellist for a ccTLD dispute under the UDRP is \$USD1500 of which the Panellist receives $\$ 1000$ and WIPO \$500. For some ccTLDs the fee is greater (for example, for .au disputes the fee is \$USD 2000). ${ }^{333}$ This equates to a filing fee of $\$ 1950$ which is close to the New Zealand fee for the equivalent part of the process (\$1800). However, under the DRS the Expert receives the full amount of the fee.

Comparison with High Court filing fees requires some assumptions as the High Court Rules allocate costs across both experience of counsel and case complexity. ${ }^{334}$ Assuming a mid-level of complexity and counsel seniority, a fair comparison would be 5.9 days at $\$ 1600$ per day resulting in a costs award (if successful) of $\$ 9440 .{ }^{335}$ Other disbursements are also recoverable, ${ }^{336}$ including interim injunction filing fees of $\$ 15,080 .^{337}$ The DRS fees are much lower compared to litigation.

Parties can represent themselves or have legal representation. The DNC encourages parties to take legal advice. ${ }^{338}$ Assuming, for the purposes of comparison, that a complainant has taken legal advice and the cost of that advice

\footnotetext{
${ }^{331}$ Ibid, cl B20.2.

${ }^{332}$ Ibid, cl B20.1 and B20.3

${ }^{333}$ World Intellectual Property Organisation "Schedule of Fees" < www.wipo.int>.

${ }^{334}$ See High Court Rules.

${ }^{335}$ Ibid. the assumption is that a domain name dispute would be a straightforward civil proceedings application dealt with under the Rules as an interim injunction, with Category B time allocated (a comparatively large amount of time for an interim injunction step) and experienced (category 2 $\$ 1600$ per day), rather than highly skilled counsel (category $3 \$ 2370$ per day). On this basis, the minimum costs (and time) to the complainant would be: commencement of proceedings (3 days), preparation of interlocutory application for injunction (0.7 days), preparation for and attendance at a defended application (2.2 days): 5.9 days in total.

${ }^{336}$ Ibid, High Court Rules, r 14.2.

${ }^{337}$ Ibid. Fees cover filing proceedings, interlocutory application, a half day hearing and sealing of the judgment).

${ }^{338}$ Domain Name Commission Limited, above n 324.
} 
would be the same for litigation, the DRS process is clearly cheaper than litigation.

(c) Costs of running the DRS

InternetNZ emphasised a “cost versus benefit analysis” throughout the development of the DRS and was concerned to minimise the costs to name registrants who, in paying domain name registration fees, are the wider “taxpayer” or "public funder" of InternetNZ. ${ }^{339}$ But it is difficult to determine the cost of the DRS from published data. The DRS is not a separate line item in the annual reports of either InternetNZ or the DNCL between 2006 and 2009. The only published figure is the overall cost of the DNCL, which in the 20082009 financial year is listed as $\$ 659,618 .^{340}$ That will not represent the actual costs of running the DRS.

The domain name registration fee is $\$ 15$ per annum per domain name. The DRS is a very small part of InternetNZ's overall system for managing the .nz domain name system. My conclusion is that the DRS is paid for and provided to domain name registrants and that they are receiving a value for money, low cost and timely service. This supports Glover's assessment that the DRS “is generally functioning well and is attractive for complainants compared with litigation in the High Court”. 341

\section{Analysis of Complaints}

The DNCL categorises complaints as "valid" or "deemed invalid". A complaint will as deemed invalid if: the complaint does not concern a .nz domain name, the complaint does not fall within the scope of the DRS, or the complainant did not comply with formalities (for example, did not send a signed copy of the complaint). ${ }^{342}$ Valid complaints are categorised as: proceeded to mediation; proceeded to Expert determination; withdrawn; or continuing through the process.

\footnotetext{
${ }^{339}$ Domain Name Dispute Resolution Task Force, above n 209.

${ }^{340}$ InternetNZ InternetNZ Annual Report 2008-2009 Advocating for the Next Generation (InternetNZ, Wellington, 2009).

${ }^{341}$ Glover, above n 32, at 40.

${ }^{342}$ Domain Name Commission Limited, above n 15.
} 
Complaints are also categorised according to outcomes: settlement ("premediated" or "mediated"), name ordered transferred or cancelled, dispute dismissed, or dispute withdrawn.

Using this data has been difficult for two reasons. First, because it is not possible analyse across categories: for example to determine how many mediations resulted in transfer or cancellation of a domain name. Second, the published data is not presented consistently. ${ }^{343}$ For this reason this analysis uses only the data published in annual reports. This research also draws on published Expert decisions and a comment is needed as these are not published in accordance with any particular publication style guide. ${ }^{344}$ As these are adjudicative decisions, publication should be consistent with the New Zealand Law Style Guide. ${ }^{345}$

(a) The empirical evidence

Estimates varied on the likely number of disputes. Nominet estimated 1 dispute per 5,000 registrations per year or about one per 2,000 over the life of its registrations. ${ }^{346}$ The New Zealand Law Society estimated “about 15 new disputes would arise annually” and noted that the DNC was receiving about 12 enquiries each month. ${ }^{347}$ Two submissions anticipated the number of disputes would not be large. ${ }^{348}$ One registrar noted receiving only one dispute in the previous two years, which was resolved without going to court. ${ }^{349}$

\footnotetext{
${ }^{343}$ For example, the annual report data is supplemented by summary data for calendar years 20062008, which is published on the DNCL website. However, the summary data does not use a consistent calendar, with the "calendar" for 2009 being October 2008 to September 2009. This overlaps with the summary data for 2008 (1 January to 31 December). By calendar year there are 154 valid complaints to 31 December, but there are 170 such complaints based on the annual reports.

${ }^{344}$ For example, some Experts have paragraph numbers in their decisions, some do not. Some use key words to assist with searching across all decisions, some do not. The case numbers are not consecutive and decisions are not expressly listed by consecutive, last in time, date order. No hard copy publication appears to have been produced. An examination of the cases shows that the most recent decisions are in fact posted at the top of the website list. While decisions currently on appeal are highlighted, appeal decisions are not separately identified, but are instead noted under the "Decision" field in the table of decisions.

${ }^{345}$ Geoff McLay and Christopher Murray and Jonathan Orpin New Zealand Law Style Guide (Thomson Reuters, Wellington, 2009).

${ }^{346}$ NZOC, above n 228, Submission 12 at 1.

${ }^{347}$ Ibid, Submission 6 at 1 .

${ }^{348} \mathrm{Ibid}$, Submission 4 at 3.

${ }^{349}$ Ibid, Submission 16.
} 
Between 1 June 2006 and March 2009 DNCL received 272 complaints. $^{350}$ There were 170 valid complaints, ${ }^{351}$ an average of 5 valid complaints per month over a 34 month period and an average of 56 per year. This is much higher than any of the estimates. The overall average number of complaints was 1 per 2079 domain names, almost exactly what Nominet predicted. ${ }^{352}$

Disputes therefore represent a fraction of total registered domain names. The domain name registration system works well and in the vast majority of cases there are no difficulties. But there have been more complaints received than were estimated and the number of complaints is evidence there was a need for the DRS.

This does not mean that all cases going to the DRS are ones that would otherwise have gone to court or which, conversely, might never have gone to court. The DRS statistics could simply reflect the fact that the dispute resolution system was established and implemented after the early significant case law. Precedents had been established and all that was needed was a cheap alternative to ensure their application. If so, this would mean that the DRS is dealing only with complaints that would otherwise have gone to litigation. This point can be better assessed by considering the nature of the disputes the DRS is dealing with compared to those which were predicted at the time it was established and the scope of the test of unfair registration.

This high number of invalid complaints is a concern. Over a third (102) of all complaints are invalid. It is difficult to ascertain what percentage of invalid complaints, if any, were subsequently resubmitted as valid complaints. Publication of the reasons for the various grounds of invalidity (not within jurisdiction of the DRS, inadequate information, failure to comply with DRS form or other requirements) would assist assessment of possible improvements. Several Experts comment on the quality of complaints and point, for example, to

\footnotetext{
${ }^{350}$ Summary total from each annual report: $84+73+116=272$. The DNCL annual report for 2009-2010 has not yet been published.

351 The statistics appear to have been rounded for reporting purposes as the percentage of valid and invalid complaints cited in the Annual Reports do not correlate to whole numbers.

${ }^{352}$ At 31 March 2009 there were 353,430 registered .nz domain names. Divided by the 170 valid complaints, this represents one dispute per 2079 registrations.
} 
the requirements for complaints that are highlighted on the DNC website where complaints forms are available. The 2007 policy review noted the issue of the quality of complaints, stating that "this issue is one of education.”353

(b) Nature of the disputes

Submissions on the DRS predicted that disputes would relate to trade marks, intellectual property disputes and cybersquatting. Information about the nature of disputes that go to mediation is confidential. But responses were filed in 42 per cent of all cases in 2007-2008 and 36 per cent in 2008-2009. This suggests that disputes were not simple cybersquatting but involved substantive rights in many cases.

This dissertation considers 65 Expert decisions published between 13 September 2006 and 31 January 2010. All but one involve .co.nz domain names, the other involving .org.nz. Ten complaints were dismissed, one ordering transfer was subsequently overturned on appeal, and one was cancelled. Name transfer was ordered in 53 cases (81.5 per cent).

The types of domain name disputes ${ }^{354}$ in the DRS cases fall into five broad groups: ${ }^{355}$

$\begin{array}{ll}\text { Cybersquatting } & 17 / 65(26 \%) \\ \text { Business or other prior relationship } & 14 / 65(21.5 \%) \\ \text { First come first served } & 10 / 65(15 \%) \\ \text { Business competition } & 14 / 65(21.5 \%) \\ \text { Blocking registration } & 10 / 65(15 \%)\end{array}$

Seven of the cybersquatting cases involved the same respondent and different complainants. In these cases well known registered trade marks were deliberately misspelled (or represented as phonetically similar to such marks or typographical errors of them) and registered as .nz domain names. In one of these

\footnotetext{
${ }^{353}$ Domain Name Commission Limited “.nz dispute Resolution Service - Policy Review” $<$ www.dnc.org.nz>.

${ }^{354}$ See also Chapter II Domain Name Disputes.

${ }^{355}$ Total percentage is 99 due to rounding down.
} 
cases, YPG IP Limited $v$ E-Promote, ${ }^{356}$ the Expert, Hon Robert Fisher QC, determined there was "undisputed evidence that Respondent has been repeatedly involved in similar cases and has been the subject of adverse decisions for the transfer of disputed Domain Names.”357 The Expert declared the Respondent to be in breach of the DRS policy provisions which relate to unfair registrations and evidence of a pattern of registrations relating to well known names or trade marks. The respondent, E-Promote, was involved in six other cases (Cases 235, 206, 203, 283, and 263) and was clearly cybersquatting.

A much larger group of cases (43\%) involved persons who were known to each other. This included people who had been in a contractual relationship (employer/employee, franchisor/franchisee) or who were former or prospective business partners with the domain name registration being one aspect of a wider dispute.

A small but significant number of cases appear to be genuine instances of first come first served. In these cases a person has for legitimate reasons, and with related rights, registered a domain name in which another person also has rights, but where the registrant is unaware of the rights of the other party. In these cases the complainant was less likely to succeed in obtaining transfer (transfer was declined in four cases) and was only granted in another where it was clear the domain name had been allowed to expire inadvertently.

Reasons for blocking registrations varied. In some cases the registration is made in an attempt to persuade the other party to transfer a domain name that the registrant actually wants, ${ }^{358}$ while in others it is simply to frustrate or annoy the would-be registrant. ${ }^{359}$ In some cases the blocking registration may be more like cybersquatting. For example, at least three cases involved an opportunistic registrant hoping to sell the domain name back to a person or company with legitimate rights who had not yet registered the domain name or registered other

\footnotetext{
${ }^{356}$ YPG IP Limited v E-Promote Case 434, 20 October 2009, Hon Robert Fisher QC.

${ }^{357}$ YPG IP Limited v E-Promote Case 434, 20 October 2009, Hon Robert Fisher QC, at Para 10.3.

${ }^{358}$ Carlton Haulage Ltd v John Burrill Case 340 Dunedin, 17 December 2008, Dr Clive Trotman.

359 The Animal Welfare Institute of New Zealand $v$ Animal Welfare in New Zealand Case 399 Auckland, 11 August 2009, Mr Clive Elliott.
} 
rights in New Zealand. ${ }^{360}$ These cases are included in the blocking category, rather than cybersquatting, because the registrant responded to the complaint and asserted rights or had some functional website which purported to be legitimate. However, the two categories can overlap.

Two major conclusions can be drawn. First, domain name disputes arise for a wider variety of reasons than was anticipated by submitters in 2005. Disputes have involved trade marks and intellectual property rights. There is also a broad diversity of disputes, more varied than earlier litigation and with different sorts of cases than under the UDRP. There have been cybersquatting cases, but these were mostly in 2006 and 2007 and are only a quarter of all cases. Cyberflight has not been a significant problem because domain names are locked as soon as a complaint is received.

Second, the volume of complaints has been almost double the highest estimate. InternetNZ decided to have a New Zealand based dispute resolution service and it is being used in all likelihood because it is a local service. More often than not, the parties know each other and are able to have the dispute dealt with quickly by an easily accessed New Zealand service.

(c) Categories of complainants and respondents

Disputes were expected to be by New Zealanders and relate to New Zealand registrants. In fact, a higher than expected proportion of cases relate to overseas complainants and respondents.

Complainants:

New Zealand

46

Overseas

19 (USA 5, United Kingdom 5, Australia 6, France

1, England and Ireland (as co-complainants) 1. Uruguay 1).

${ }^{360}$ Capital Conservator Group v Giordan Samuels Case 458 Dunedin 25 January 2010 Dr Clive Trotman; Insure \& Go Insurance Services Limited v 1 cover NZ Limited Case 453, 25 January 2010, Mr Andrew Brown QC; and Wicked Campers v Escape Rentals Case 353, Auckland, 17 February 2009, Hon Robert Fisher QC. 
Respondents:

New Zealand 41

Overseas

24 (USA 12, Australia 6, United Kingdom 3, Canada 1, Malaysia 1, Belarus 1)

One group of these cases relates to overseas registrants attempting to cybersquat on .co.nz registrations contrary to the rights of international companies with known and registered trade marks. Another relates to Australian and New Zealand companies and individuals who are in competition for domain names or in contractual or other business conflicts over their registration. A third group are competing but unknown to each other New Zealand companies and individuals (including the genuine cases of first come first served). The result is a greater diversity of persons using the DRS than was anticipated.

Given the number of overseas parties, further research on their experience of the DRS would be worthwhile. A number of these parties are companies which are likely to have experience of cybersquatting in other jurisdictions and are also likely to have experience of complaints in relation to gTLDs under the UDRP. Some may also have experience of the cost of litigation. Given that the UDRP and WIPO administration were an option for New Zealand, it would be interesting to know how those overseas parties with experience of both compared the processes. More research would also be useful with those New Zealand parties who may have experience of UDRP processes in relation to gTLDs and how the DRS process compares.

(d) Settlement rates

In 41 cases (24 per cent) the complaints were withdrawn. ${ }^{361}$ The reasons for withdrawal are not clear but include non-payment of the Expert fee. ${ }^{362}$ The Domain Name Commissioner has indicated that "all the withdrawn complaints are

\footnotetext{
${ }^{361}$ Calculated by adding $(22.2 \%$ of 54 in $2006-07=) 12+(26 \%$ of 48 in $07-08=) 12+(26 \%$ of 68 in 08-09 = ) $17=41$ out of 170 withdrawn.

${ }^{362}$ Domain Name Commission Annual Report 2007-2008 (InternetNZ, Wellington, 2008) at 11.
} 
essentially unresolved with the complainant choosing not to pay the Expert fee" ${ }^{363}$ This suggests the fee is a barrier.

As regards disputes settled, "settlement" means that the complaint has been finally determined or otherwise dealt with. The settlement rate is determined by subtracting the number of on-going (5) and withdrawn (41) cases $^{364}$ from the total across the period: $170-46=124$. Of the remaining 124 cases, 57 (46 per cent) settled at or before informal mediation, ${ }^{365} 47$ cases (28 per cent) were settled by Expert determination, ${ }^{366}$ and one case was settled on appeal. ${ }^{367}$ In summary:

$24 \%$ of cases withdrawn or on-going

$46 \%$ settled at or before mediation

28\% settled by Expert decision

1\% settled by Appeal Panel decision

Settlement is achieved in 3 out of 4 or approximately 75 per cent of cases.

The high rate of settlement suggests that the DRS is effective in getting a final determination. Experts dismiss very few cases and a high proportion result in a mediated outcome. The process produces actual outcomes with very few disputes left waiting for resolution. There is a significant issue with the withdrawn category: if these are complainants who can not or do not pay the Expert determination fee, and it is clear that the Expert determinations are overwhelmingly in favour of complainants, it suggests that cost is a barrier. This underscores the need to consider whether, where no response is filed to a complaint, some simpler process for name transfer could be developed in appropriate cases.

\footnotetext{
363 Debbie Monahan, Domain Name Commissioner, notes to the author on draft (23 March 2009).

${ }^{364}$ Calculated off the annual reports of which on the 08-09 year includes “ongoing”: period (7\% of 68 in $08-09=5+41=46$ )

$36521(06-07),+21 \%$ of $48=10(07-08)+39 \%$ of $68(08-09)=26=57$ total.

$366(06-07)+39 \%$ of $48=19(07-08)+27 \%$ of $68(08-09)=18=47$ total.

367 Totals add to 99 per cent (including the appeal) due to rounding.
} 
(e) Expert decisions and appeals

Experts ordered name transfer in 53 cases (81.5 per cent), dismissed ten complaints, and cancelled one domain name. There has been only one appeal from an order for transfer. On appeal the order for transfer cancelled,

This transfer rate is high, suggesting that where an Expert is appointed there is usually a substantive issue of unfair registration. The transfer rate also suggests that this part of the process is being used for substantive complaints, rather than frivolous or vexatious ones. This in turn suggests that the dispute resolution process is being used for the right sorts of cases, namely, those where there is a legitimate dispute. This finding is verified by an analysis of those cases in which transfer was refused. Four are in the category of genuine case of first come first served. Transfer was still ordered in 6 of these cases including one case where the domain name had inadvertently expired. But this category has the highest dismissed rate compared to all other cases.

Glover assesses just the Expert decisions and concludes there is a name transfer rate of 82 per cent in 2008. This compares to an 80 per cent transfer rate in cases that went to adjudication under the Nominet system in the United Kingdom. ${ }^{368}$

The one appeal was The Country Channel Ltd v The Country Channel Limited. ${ }^{369}$ The complaint was from a United Kingdom television company that was using the name “The Country Channel” for a channel offering programmes about rural life. The complainant claimed that a New Zealand television channel offering the same service was in breach of its rights and likely to cause confusion. The Expert found for the complainant and transferred the .nz domain name. The Panel overturned the Expert decision and ordered the name returned to the New Zealand registrant. The Panel held the likelihood of confusion was small and that the complainant did not have rights in the name in New Zealand justifying the name transfer.

\footnotetext{
${ }^{368}$ Glover, above $\mathrm{n} 32$, at 37.

369 The Country Channel Ltd v The Country Channel Limited (2009) DRS 334 Peterson QC.
} 
The dearth of appeals indicates parties are abiding by the generally good quality decisions of Experts. In a small number of cases, as with the withdrawn complaints, it might be that the $\$ 6,600$ plus GST fee for this stage is a barrier.

The lack of appeals may reflect the fact that the case law in New Zealand is well settled and the legal principles to be applied are clear. Glover notes "that there have been no domain name dispute cases listed in Linxplus as having been decided since the DRS came into effect.” ${ }^{370}$ In fact there have been some unreported cases relating to domain names, but these have been in contractual disputes where other legal issues were the primary causes of action ${ }^{371}$ or where domain name registration is adduced as evidence to support other legal claims. ${ }^{372}$ In addition, jurisprudence on domain name disputes has developed under the DRS and its scope is wider than statute and common law based causes of action. There have been no appeals to the Courts or appeals on a point of law during a complaint process.

\section{Conclusion}

InternetNZ took more than five years to develop the DRS, yet complaint numbers have exceeded all estimates. Very quickly the DRS became the first port of call for domain name disputes and High Court litigation has all but disappeared.

Just as the special nature of the operation of the DNS infused the DRS policy development process with principles of transparency and a consultative approach so, too, is the administration of the DRS. The DNCL draws on dispute resolution and subject matter experts and does not decide disputes itself. All Expert decisions are published along with the names and qualifications of mediators and experts.

\footnotetext{
${ }^{370}$ Ibid 37.

${ }^{371}$ Queenstown Management Services Ltd v St James Body Corporate 21507 \& Ors (HC Invercargill CIV-2007-425-000347 10 August 2007).

${ }^{372}$ IMAX Corporation v Village Roadshow Corporation Ltd HC, Auckland, CIV-2005-404-003248 29 March 2006.
} 
While InternetNZ took a hands off approach to the management of the domain name space and the content of dispute resolution, the DNCL took a very hands on approach to dispute management. This means that most complaints are resolved quickly (within 90 days of being received) and with a clear outcome. Administration of the DRS carries an inherent tension between the public good function of providing a complaints system and the private delivery of this by the organisation responsible for management of the .nz domain name space. The DNCL has managed these tensions in a principled way by delivering the service in an fair, open, transparent and efficient manner. Doing so is likely to have countered any risk of judicial or other intervention.

The DRS is appropriate for the nature of disputes falling within its scope. While domain name disputes represent a fraction of total registered domain names, there have been more complaints than estimated. The DRS is not flooded with complaints, but neither is it so tightly tailored that it captures only a subset of domain name disputes. Intellectual property rights holders are not unfairly advantaged or disadvantaged by the DRS nor are the interests of rights holders are advancing over the interests of users. Genuine cases of first come first served are generally upheld. The conclusions support Williams' comment that the DRS is attractive given the problems with litigation (particularly for overseas registrants), the difficulties in registering all possible domain name variations, and the deleterious effect of needing litigation in each case. ${ }^{373}$

While there is evidence of system clog with the UDRP (to the extent of 27,000 cases and 70 per cent being undefended), ${ }^{374}$ there is no evidence of this problem with the DRS. This may reflect that it was better designed for purpose and that cybersquatting happens more often in relation to gTLD rather than ccTLD domain names. But there is room for improvement in cases where no response is filed to a complaint, particularly if the filing fee for Expert determination is a barrier to seeking transfer in genuine cases. More research

\footnotetext{
373 The Laws of New Zealand Intellectual Property (on line ed) at [322].

374 Joo, above n 38.
} 
would also be useful with those New Zealand parties who may have experience of UDRP processes in relation to gTLDs and how the DRS process compares.

The DRS offers a low cost alternative to litigation for domain name disputes. Parties do not sacrifice quality and the service is cheaper and faster than litigation. Improvements could be made, however, particularly in relation to the publication of complaints data and Expert decisions. Some drafting improvements could be made to the provisions of the DRS and there are areas where further research would be desirable. The next Chapter returns to the primary research questions and considers the implications of the dissertation findings. 


\section{CHAPTER VI CONCLUSION}

\section{A Introduction}

The Internet has transformed life as we know it. The DNS is critical to the operation of the Internet, affecting why and how domain name disputes arise. New legal processes, such as the DRS have been created to deal with these disputes. As certainty about rights in domain names has become more important, questions have been asked about the efficacy of these new processes and the integrity of those responsible for them. This dissertation has taken a closer look at one aspect of Internet infrastructure in New Zealand. This Chapter returns to the primary research questions, summarises the answers, and concludes with what, if any, wider implications there might be.

\section{B The Primary Research Questions}

The two primary research questions were: (a) is the DRS operating effectively? and (b) is InternetNZ is acting responsibly in the exercise of its DRS functions? This dissertation developed criteria for assessing effectiveness in light of the special considerations that apply to domain name disputes and the fact that the DRS is a private adjudicative model of dispute resolution. Criteria were developed and applied to both the development of the DRS by InternetNZ and its subsequent operation.

\section{The DRS is Operating Effectively}

The DRS is a high quality, value for money alternative to litigation for domain name disputes. InternetNZ and DNCL take a hands off approach to the substance of disputes and a hands on approach to administration of the DRS. The result is an efficient process that is transparent and based on high standards. The DRS is appropriate for the nature of disputes falling within its scope, has process quality and rigour and is low cost and timely. Many more people have used the DRS than was anticipated and for a wider range of cases. 
InternetNZ has responsibility for the management of the .nz domain name space. That responsibility is carried out within a wider international system for operation of the DNS and policies must be coherent across that wider system. InternetNZ’s responsibility includes operating an asset that generates \$6 million revenue per annum. The DRS was set up, in part, to manage the risks for InternetNZ of managing the .nz domain name space. But InternetNZ developed the DRS in a pragmatic and principled way.

InternetNZ drew on the principles which underpin the DNS, namely developing policies by rough consensus, prioritising the rights of registrants, and emphasising transparency. These principles, drawn from the international system, guided InternetNZ into a policy development process that was open and included a working group, discussion papers, and submissions.

InternetNZ was also pragmatic, initially developing the DRS to stay ahead of international developments, rather than in response to them or because of difficulties in particular cases. InternetNZ looked at existing dispute systems and whether these should, or could, be adapted to New Zealand. Gradually the nature of disputes began to change. InternetNZ anticipated these changes well, developing a test of unfair registration which has ultimately enabled a much wider range of complaints to come before it than had previously gone to the Courts.

\section{Contribution to the Review of the DRS}

While the DRS operates effectively, there is room for some improvements. This dissertation has revealed several amendments that could usefully be made to the DRS. The most significant of these is to consider improvements where no response is filed to a complaint. Improvements could also be made to aspects of the DRS administration, for example, to publication of DRS information so that its effectiveness can continue to be monitored. Expert decisions should be published in line with the New Zealand Law Style Guide. More research could be done in some areas. Recommendations in relation to these matters are attached in 
an Appendix and will be submitted to the DRS review when it takes place in 2010.

\section{New Legal Processes}

The DRS is a new legal process. Chapter II noted that dispute resolution theorists rightly raise questions over the private provision of justice on matters of public importance and whether this interferes with access to justice and the rule of law.

This dissertation has shown that rather than moving away from legal principles, the development of a private dispute resolution system was strengthened by the public good nature of InternetNZ's role and the manner in which InternetNZ carried out that role. InternetNZ took its role seriously and was cautious, not moving unless there was a rough consensus on how best to proceed. The nature of the disputes led to a substantive test of unfair registration that went beyond existing law. Such a shift could only be implemented credibly if this was done fairly and effectively. The result, to paraphrase Sander and Goldberg, ${ }^{375}$ was that InternetNZ created a forum that fitted the fuss.

A well functioning DRS also lowers the risks of domain name fees being raised to cover costs, of liability being passed down the chain to registrars or registrants, and of stepping away from the principle of first-come first-served registration. An effective dispute resolution system is therefore one counterweight in the system of mutual recognition and cooperation on which the .$n z$ domain name space operates.

\section{Wider Implications}

InternetNZ placed a great deal of emphasis on consensus and an open process. In fact, the depth and breadth of participation was generally poor. The process stalled when a small group of people assigned to carry out preliminary work failed to agree on whether and, if so, how to proceed. The issue was later

\footnotetext{
${ }^{375}$ Sander and Goldberg, above n 127.
} 
picked by the Domain Name Commissioner who reinvigorated the process in light "shop front" issues with domain name disputes. While the outcome was an effective system, concerns linger about the participatory nature of these processes. This dissertation highlights the risks inherent in such processes.

InternetNZ is a membership organisation and, as such, its emphasis on rough consensus could change. A failure to resist one particular set of interests or an actual or perceived lack of fairness could tip the delicate balance and lead to capture by particular interests. Low levels of participation also creates a risk of the same individuals and organisations continuing to shape policy decisions and inevitably becoming invested in keeping the status quo. Conversely new members could see an opportunity to generate revenue by increasing domain name fees. There could be a disruption to the DNS causing the Internet to stop operating, bringing InternetNZ and its processes into sudden sharp relief, and leading to adverse public reaction or even intervention by government. There are two implications.

\section{$1 \quad$ Human Rights}

The first implication is that the administration of the Internet is not a technical matter far removed from human rights considerations. On the contrary, human rights lie at the very heart of these arrangements and there are new developments that will raise more human right issues. For example, the introduction of non-Latin scripts for domain names gives effect to the right to freedom of expression and the right to language and it also raises the question of whether English will remain the main language of the Internet. ${ }^{376}$ The rights of sexual, religious, cultural and other minorities and wider political interests will be tested by ICANN proposals to authorise a wider range of gTLDs (for example, will .tibet be permitted and how will that be decided?). ${ }^{377}$ Policies adopted by ccTLD or gTLD managers for dealing with law enforcement requests (for example to block domain names or search WHOIS information) have implications for the right to be free from unlawful search and seizure. My experience is that, despite

\footnotetext{
${ }^{376}$ ICANN “Internationalised Domain Names (2009) < www.icann.org>.

${ }^{377}$ ICANN “New gTLDs: Draft Application Handbook” (2010) <www.icann.org>.
} 
these implications, human rights advocates in New Zealand are still largely absent from such “technical” discussions.

Instead, legal debates in New Zealand have largely been about what is on the Internet rather than who runs it. But there are signs that this is changing. ${ }^{378}$ Concerns about the Internet and child pornography, intellectual property rights violations, and enforcement of Court suppression orders have been raising new legal issues. ${ }^{379}$ Increasingly these concerns are converging with concerns previously viewed as "technical", namely how the Internet operates and who decides. At the same time, public policy makers are increasingly looking to regulate content by using technology to regulate the use of technology.

For example, proposals to prevent access to child pornography resulted in a system whereby ISPs can volunteer to filter the content of material that their clients can access when they use their ISP accounts to go online. ${ }^{380}$ The proposals raised significant human rights issues. Such voluntary systems are viewed by the State as one way to prevent the distribution of child pornography. ${ }^{381}$ At the same time, action by the State to filter content is a troubling development, regardless of the objectionable nature of that content. ${ }^{382}$

The proposal also raises questions about the use of filtering mechanisms by the State when these have not been authorised by an Act of Parliament and therefore subjected to wider public scrutiny. ${ }^{383}$ At the same time, the proposal that the State pass laws to regulate Internet content raises concerns given, as Menkel Meadow notes, the Internet is an otherwise unregulated environment. ${ }^{384}$ Despite these clear human rights implications, the proposals received relatively little comment outside the Internet community.

\footnotetext{
${ }^{378}$ Joy Liddicoat and Dr Judy McGregor Internet Section of draft Chapter on the Right to Freedom of Expression (Human Rights Commission, Wellington, publication forthcoming in 2010).

379 See, for example, presentations by Professor Tony Smith, Steven Price and Robert Lithgow QC "R v The Internet” (2009) InternetNZ (Seminar Proceedings) <www.internetnz.net.nz>.

${ }^{380}$ Department of Internal Affairs Digital Child Exploitation Filtering System Code of Practice (2010).

${ }^{381}$ InternetNZ "InternetNZ: Child porn filter 'not the answer"” (28 January 2010, Press Release).

382 Tech Liberty New Zealand “Internet Filtering” (2010) <www.techliberty.org.nz>.

383 Ibid.

${ }^{384}$ Menkel Meadow, above n 177.
} 
There are also new conversations about whether access to the Internet should be a human right. ${ }^{385}$ The Victoria University of Wellington InternetNZ CyberLaw Fellow for 2009-2010 is focussing on this very topic. ${ }^{386}$ While beyond the scope of this dissertation, the second area of implication arising from it may be relevant to those new conversations.

\section{The State and Internet Administration}

The second implication relates to administration of the Internet. A key question is whether the role of InternetNZ and its responsibility for .nz domain name system should be formally, rather than informally, recognised by government. The benefits and risks for all involved need careful consideration including: whether the State should have a role in .nz domain name management; whether, if so, it would do a better job than InternetNZ; and whether formal recognition would protect or erode the current transparency, accountability and quality of InternetNZ processes (however narrow their participatory base).

In Oggi the Court observed that InternetNZ is serving a major public interest and acting in the public good. ${ }^{387}$ Baragwanath $\mathrm{J}$ went further: ${ }^{388}$

It appears that the international scientific community has engaged in a disinterested fashion in furnishing to the world community an invaluable facility which has, to an extraordinary extent, the effect of promoting a major principle of the International Covenant on Civil and Political Rights 1966 to which New Zealand and many other states are party. Article 19(2) provides:

(2) Everyone shall have the right to freedom of expression; this right shall include freedom to seek, receive and impart information and ideas of all kinds, regardless of frontiers, either orally, in writing or in print, in the form of art, or through any other media of his choice.

\footnotetext{
${ }^{385}$ Best, above n 41.

${ }^{386}$ Jonathon Penney, InternetNZ Senior Research Fellow in Cyberlaw, Victoria University of Wellington.

${ }^{387}$ Above n 96.

${ }^{388}$ Ibid, at 635.
} 
His Honour then stated that "Those values have received statutory expression in section 14 of the New Zealand Bill of Rights Act 1990”. A further question arises, namely, whether the New Zealand Bill of Rights Act 1990 also applies to InternetNZ itself? Section 3(b) provides that the Bill of Rights applies only to acts done "by any person or body in the performance of any public function, power or duty conferred or imposed on that person by or pursuant to law”. This highlights whether the international system of mutual recognition and cooperation on which the DNS operates could be described as a function, power or duty conferred or imposed on InternetNZ by or pursuant to law. More research is needed on this question and the implications need careful consideration.

In the meantime, the accountability of InternetNZ rests on its integrity in managing the .nz domain name space in a manner which is consistent with the public good nature of its functions. This dissertation has shown that InternetNZ is acting responsibly. My own view is that more support for the role of InternetNZ is needed both so that InternetNZ remains accountable and to avoid unnecessary intervention with the management of the .nz domain name space.

But a move to formal recognition by the State or State involvement in Internet administration does raise interesting questions. For example, if access to the Internet is to be a human right, what are the State's obligations to protect administration of the Internet and management of the .nz domain name system? In light of the convergence of regulation of content and technical matters, is the State to be trusted with the day to day management of the DNS? If international human rights standards do not apply to the technical operation of the Internet, then how is the State to be accountable for breaches of human rights in such administrative activities? Just as significantly, how is InternetNZ to be accountable?

Perhaps the answer lies, in the meantime, in the system of Internet administration remaining dependent on the collection of individuals and organisations and the system of mutual recognition and cooperation which have, so far, enabled the Internet to function without significant problems. Such a system provides a compelling framework within which contests for control have sufficient counterweights to ensure no single person or organisation has total 
autonomy. There should not be any changes to this system unless the implications are clearly thought through.

At the same time, this dissertation has revealed that the concept of the rights of registrants has a persuasive, if not constitutional, status among the collection of individuals and organisations responsible for the DRS and wider Internet administration. Yet the parameters of this concept are not clear. More research is needed on, for example, whether the State would consider the concept of the rights of registrants as binding or even persuasive. Parallels and links to the international human rights framework need to be explored.

The United Nations responded to concerns about the Internet by establishing the Internet Governance Forum. The Forum supports the United Nations Secretary-General in carrying out the mandate of the World Summit on the Information Society, which is to promote discussion about the Internet and monitors Internet administration by ICANN and related organisations. ${ }^{389}$ The Forum includes a Dynamic Coalition on the Internet Bill of Rights which: ${ }^{390}$

... aims at understanding how traditional human rights can be adapted and expanded in the new online environment, and how they could be formalized in one or more documents that could act as a reference and be adopted as a code of conduct on an opt-in basis.

The proposal for a Charter of Internet Rights or an Internet Bill of Rights should be explored. In the meantime, more people need to understand how the Internet functions and participate in processes that affect it, including the .nz domain name system. Risks of poor decision-making by InternetNZ, inappropriate intervention by government and breaches of human rights can be mitigated if more people know about and participate in Internet administration.

\footnotetext{
389 The Internet Governance Forum (2010) <www.intgovforum.org>.

${ }^{390}$ Ibid, at "Dynamic Coalition on the Internet Bill of Rights".
} 


\section{APPENDIX 1 DISPUTE RESOLUTION SERVICE POLICY}

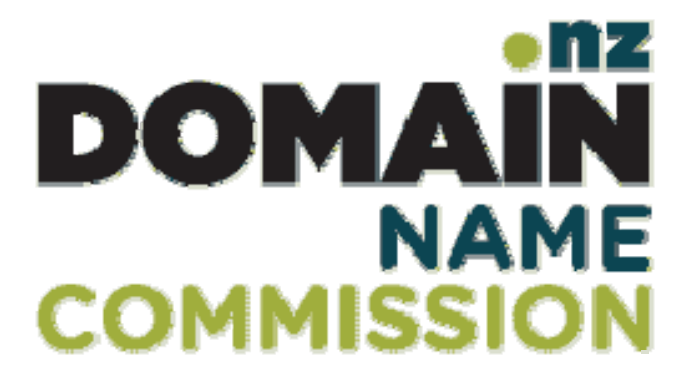

\begin{tabular}{|l||l|}
\hline Ref: & DRS \\
\hline Title: & Dispute Resolution Service Policy \\
\hline Date Issued: & I May 2008 \\
\hline Status: & Current \\
\hline Version: & 2.0 \\
\hline
\end{tabular}

This policy is issued by Domain Name Commission Limited (DNC or Domain Name Commission)

on behalf of InternetNZ, Internet New Zealand Incorporated.

\section{DISPUTE RESOLUTION SERVICE POLICY}

\section{Statement of Purpose}

1.1. This policy provides an alternative to the Courts in situations where two parties are in dispute over who the registrant of a .nz domain name should be. Part A defines the policy and Part B the procedure supporting the policy.

\section{Background}

2.1 InternetNZ has the ultimate responsibility within New Zealand for the .nz domain name space, and maintains a shared registry system (SRS) for the management of .nz domain name registrations. InternetNZ has appointed the Domain Name Commission ("DNC") to manage and administer the .nz domain name space on behalf of InternetNZ.

2.2 A SRS establishes a single register for registering domain names and associated technical and administrative information. .nz Registry Services (NZRS) operates the register.

2.3 The registration of domain names and modification of information associated with that name on the register can be effected only by authorised registrars. Registrars are responsible for the information they collect.

2.4 Neither registrars nor the DNC get involved in disputes regarding who the true registrant of a domain name should be, but will undertake actions as directed either by the Courts or by the Experts under this policy. 
2.5 This policy is one of the .nz policies that, as amended from time to time, all .nz registrants agree to be bound by when registering or renewing a .nz domain name.

2.6 Thanks go to Nominet UK for their assistance in establishing the .nz Dispute Resolution Service.

\section{Definitions}

Appeal Panel means a panel appointed by the DNC under paragraph B17.7;

Complainant means a third party who asserts to the DNC the elements set out in paragraph 4 of this Policy and according to the Procedure, or, if there are multiple complainants, the 'Lead Complainant' (see Procedure, paragraph B2.2);

Complaint means a complaint submitted to the DNC by a Complainant under paragraph B2;

Commencement of Dispute Resolution Service proceedings means the earliest date upon which the Complaint is deemed to have been received by the Respondent in accordance with paragraph B1.5;

Conclusion of Dispute Resolution Service proceedings means the date on which the Parties are notified of a Decision or the date on which the parties settle the dispute;

Days means, unless otherwise stated, any calendar day other than Saturday, Sunday or any public holiday in New Zealand;

Decision means the decision reached by an Expert and where applicable includes decisions of an appeal panel;

Dispute Resolution Service means the service provided by the DNC according to this Policy and the Procedure;

Domain Name means a domain name directly registered in any second level domain of the .nz system;

Domain Name Commission means Domain Name Commission Limited, a company wholly-owned by InternetNZ, responsible for the day to day oversight of the .nz domain name registration and management system;

Domain Name Hijacking means using the Policy in bad faith in an attempt to deprive a registered domain-name holder of a domain name;

DNC means the Domain Name Commission;

Expert means a person appointed to resolve a Domain Name Dispute under paragraphs B7 or B17 of the Procedure;

Informal Mediation means impartial mediation which is conducted under paragraph B6 to facilitate an acceptable resolution to the dispute;

ISP means an internet service provider;

InternetNZ means Internet New Zealand Incorporated, the organisation ultimately responsible for the .nz domain name space;

NZRS means New Zealand Domain Name Registry Limited, trading as .nz Registry Services, the body which operates and manages the Register; 
Party means a Complainant or Respondent and Parties has a corresponding meaning;

Policy means this Policy;

Procedure means the Procedure under this Policy for the conduct of proceedings under the Dispute Resolution Service;

Register means the authoritative database and record of .nz domain names managed and operated by NZRS;

Registrant means the entity entered in the Register as registrant in respect of the domain name;

Registrar means the entity entered in the Register as registrar in respect of the domain name;

Reply means a submission made to the DNC by a Complainant under paragraph B5;

Respondent means the entity in whose name or on whose behalf a Domain Name is registered and against whom the Complainant makes a Complaint;

Response means a submission made to the DNC by a Respondent under paragraph B4;

Rights includes, but is not limited to, rights enforceable under New Zealand law. However, a Complainant will be unable to rely on rights in a name or term which is wholly descriptive of the Complainant's business;

Unfair Registration means a Domain Name which either:

i) was registered or otherwise acquired in a manner which, at the time when the registration or acquisition took place, took unfair advantage of or was unfairly detrimental to the Complainant's Rights; OR

ii) has been, or is likely to be, used in a manner which took unfair advantage of or was unfairly detrimental to the Complainant's Rights;

\section{PART A - POLICY}

\section{Dispute Resolution Service}

4.1 This Policy and Procedure applies to Respondents when a Complainant asserts to the DNC according to the Procedure, that:

4.1.1 The Complainant has Rights in respect of a name or mark which is identical or similar to the Domain Name; and

4.1.2 The Domain Name, in the hands of the Respondent, is an Unfair Registration.

4.2 The Complainant is required to prove to the Expert that both elements are present on the balance of probabilities.

4.3 The DNC recommends that both Parties use the guidance and help information, which can be found on the DNC website. 


\section{Evidence of Unfair Registration}

5.1. A non-exhaustive list of factors which may be evidence that the Domain Name is an Unfair Registration is set out in paragraphs 5.1.1 - 5.1.5:

5.1.1. Circumstances indicating that the Respondent has registered or otherwise acquired the Domain Name primarily:

(a) for the purposes of selling, renting or otherwise transferring the Domain Name to the Complainant or to a competitor of the Complainant, for valuable consideration in excess of the Respondent's documented out-of-pocket costs directly associated with acquiring or using the Domain Name;

(b) as a blocking registration against a name or mark in which the Complainant has Rights; or

(c) for the purpose of unfairly disrupting the business of the Complainant; or

5.1.2. Circumstances demonstrating that the Respondent is using the Domain Name in a way which is likely to confuse, mislead or deceive people or businesses into believing that the Domain Name is registered to, operated or authorised by, or otherwise connected with the Complainant;

5.1.3. The Complainant can demonstrate that the Respondent is engaged in a pattern of registrations where the Respondent is the registrant of domain names (under .nz or otherwise) which correspond to well known names or trade marks in which the Respondent has no apparent rights, and the Domain Name is part of that pattern;

5.1.4. The Complainant can demonstrate that the Respondent has knowingly given false contact details to a Registrar and/or to the DNC; or

5.1.5. The Domain Name was registered arising out of a relationship between the Complainant and the Respondent, and the circumstances indicate that it was intended by both the Complainant and the Respondent that the Complainant would be entered in the Register as the Registrant of the Domain Name;

5.2. Failure on the Respondent's part to use the Domain Name for the purposes of e-mail or a web-site is not in itself evidence that the Domain Name is an Unfair Registration.

5.3. There shall be a presumption of Unfair Registration if the Complainant proves that the Respondent has been found to have made an Unfair Registration in three (3) or more Dispute Resolution Service cases in the two (2) years before the Complaint was filed. This presumption can be rebutted (see paragraph 6.3).

5.4. In making their decision, the Expert shall not take into account any evidence of acts or omissions amounting to unfair registration or use which occurred more than three (3) years before the date of the Complaint.

\section{How the Respondent may demonstrate in its Response that the Domain Name is not an Unfair Registration}

6.1. A non-exhaustive list of factors which may be evidence that the Domain Name is not an Unfair Registration is set out in paragraphs 6.1.1 - 6.1.4:

6.1.1. Before being aware of the Complainant's cause for complaint (not necessarily the Complaint itself), the Respondent has: 
(a) used or made demonstrable preparations to use the Domain Name or a Domain Name which is similar to the Domain Name in connection with a genuine offering of goods or services;

(b) been commonly known by the name or legitimately connected with a mark which is identical or similar to the Domain Name;

(c) made legitimate non-commercial or fair use of the Domain Name; or

6.1.2. The Domain Name is generic or descriptive and the Respondent is making fair use of it in a way which is consistent with its generic or descriptive character;

6.1.3. In relation to paragraph 5.1.5; that the Registrant's holding of the Domain Name is consistent with an express term of a written agreement entered into by the Parties; or

6.1.4. In relation to paragraphs 5.1 .3 and/or 5.3; that the Domain Name is not part of a wider pattern or series of registrations because the Domain Name is of a significantly different type or character to the other domain names registered by the Respondent.

6.2. Fair use may include sites operated solely in tribute to or in criticism of a person or business.

6.3. If paragraph 5.3 applies, to succeed the Respondent must rebut the presumption by proving in the Response that the registration of the Domain Name is not an Unfair Registration.

\section{Informal Mediation}

7.1. After the DNC has received the Parties' submissions under the Procedure (Part B), it will initiate and conduct a period of Informal Mediation under paragraph B6 of the Procedure.

\section{Without Prejudice}

8.1. Documents and information which are 'without prejudice' (or are marked as being 'without prejudice') may be used in submissions and may be considered by the Expert except that the Expert will not consider such materials if:

8.1.1. they are generated within Informal Mediation; or

8.1.2. the Expert believes that it is in the interests of justice that the document or information be excluded from consideration.

\section{Appointment of Expert}

9.1. If an acceptable resolution cannot be achieved by Informal Mediation the DNC will notify the Parties that it will appoint an Expert when the Complainant has paid the applicable fees set out in paragraph B20.1 and within the time specified in paragraph B7.1. The Expert will come to a written Decision.

\section{Notification and Publication}

10.1. A Decision will be communicated to the Parties according to paragraph B16 and all Decisions will be published in full on the DNC website. 
10.2. Fees are payable by the Complainant or otherwise according to paragraph B20 only if an acceptable resolution has not been achieved by Informal Mediation and once the DNC has notified the Parties that an Expert is to be appointed.

10.3. Decisions may contain personal information, including the contact details of the Parties, and the Parties consent to personal information being displayed in this way.

\section{Exclusion of Liability}

11.1 None of InternetNZ, the DNC, NZRS, any Registrar, Expert or Mediator, nor any of those entities' councillors, officers, employees or servants (as applicable) shall be liable to a party for anything done or omitted, whether negligently or otherwise, in connection with any proceedings under the Dispute Resolution Service unless the act or omission is shown to have been in bad faith.

\section{Appeal, Repeat Complaints and Availability of Court Proceedings}

12.1. Either Party will have the right under paragraph B17 to appeal a Decision. The Appeal Panel will consider appeals on the basis of a full review of the matter and may review procedural matters.

12.2. The DNC may refer questions of interpretation of the Policy and Procedure to the Appeal Panel. Any decision rendered as a result of this referral will not affect any Decision in any other previous proceedings under the Dispute Resolution Service.

12.3. The DNC will publish Decisions of the Appeal Panel. Appeal Decisions will not be binding precedents, but will be of persuasive value to Experts in future decisions.

12.4. The operation of the Dispute Resolution Service will not prevent either the Complainant or the Respondent from submitting the dispute to a New Zealand court or decision-making body of competent jurisdiction or to an arbitral tribunal of competent jurisdiction.

12.5. If a Complainant has obtained a Decision in previous Dispute Resolution Service proceedings it will not be reconsidered by an Expert (but there may be rights of appeal, see paragraph 12.1 and paragraph B17). If the Expert finds that the Complaint is a resubmission of an earlier Complaint which has been resolved he or she shall reject the Complaint without a consideration of its merits.

12.6. In determining whether a Complaint is a resubmission of an earlier Complaint, or contains a material difference that justifies the Complaint being heard the Expert shall consider the following questions:

12.6.1. Are the Complainant, the Respondent and the Domain Name at issue the same as in the earlier case?

12.6.2. Does the substance of the Complaint relate to acts that occurred prior to or subsequent to the close of submissions in the earlier case?

12.6.3. If the substance of the Complaint relates to acts that occurred prior to the close of submissions in the earlier case, are there any exceptional grounds for the rehearing or reconsideration, bearing in mind the need to protect the integrity and smooth operation of the Policy and Procedure?

12.6.4. Does the substance of the Complaint relate to acts that occurred subsequent to the close of submissions in the earlier Decision? (Acts on which the re-filed Complaint is 
based should not be, in substance, the same as the acts on which the previous Complaint was based).

12.7. A non-exhaustive list of examples which may be exceptional enough to justify a rehearing under paragraph 12.6.3 include:

12.7.1. serious misconduct on the part of the Expert, a party, witness or lawyer;

12.7.2. false evidence having been offered to the Expert;

12.7.3. the discovery of credible and material evidence which could not have been reasonably foreseen or known for the Complainant to have included it in the evidence in support of the earlier Complaint;

12.7.4. a breach of natural justice.

\section{Implementation of Expert Decisions}

13.1. The Expert's powers, as part of a Decision, include powers to direct that a domain name should be cancelled, transferred, suspended or otherwise amended. The Expert may not, however, make any orders directing a party to pay costs of the Dispute Resolution Service proceedings.

13.2. If the Expert makes a Decision that a Domain Name registration should be cancelled, suspended, transferred or otherwise amended, the DNC will implement that Decision by causing any necessary changes to the Register to take place according to the process set out in paragraph B16. The details set out in the Complaint form will be used unless the Complainant specifies other details in good time.

\section{Other action}

14.1. The DNC will not cause any Domain Name registration to be cancelled transferred, activated, deactivated or otherwise changed except as set out in paragraphs 13 and B3.4 and in accordance with the .nz policies, which are available on the DNC website.

\section{Transfers During a Dispute}

15.1. A Domain Name registration may not be transferred:

15.1.1. if the electronic form of a Complaint has been received by the DNC Dispute Resolution Service staff and the matter is pending the receipt of a valid paper copy to confirm the Complaint (to a maximum of five (5) Days); or

15.1.2. whilst Dispute Resolution Service proceedings are ongoing in relation to the Domain Name or for a period of ten (10) Days after the conclusion of Dispute Resolution Service proceedings, unless to the Complainant as a result of a settlement reached between the Parties whether or not pursuant to Informal Mediation; or

15.1.3. whilst a court proceeding, other dispute resolution hearing or arbitration in respect of the Domain Name registration is ongoing in a New Zealand court or decision-making body of competent jurisdiction or arbitral tribunal of competent jurisdiction.

15.2. The DNC may reverse any transfer of a Domain Name registration which does not comply with paragraph 15.1 . 
15.3. A Respondent may not without the Complainant's consent (which the Complainant will not unreasonably withhold) transfer the Domain Name to another Registrar whilst proceedings under the Dispute Resolution Service are ongoing in relation to the Domain Name or for a period of ten (10) Days after the conclusion of Dispute Resolution Service proceedings.

\section{Modifications to the Policy and Procedure of the Dispute Resolution Service}

16.1. The Internet is an emerging and evolving medium and the regulatory and administrative framework under which it operates is constantly developing. For these reasons the DNC reserves the right to make reasonable modifications to the Policy and Procedure at any time. Except where the DNC is acting in pursuance of a statutory requirement or a court order, substantive changes will be implemented following a process of open public consultation. Each such change will be published in advance (where practicable, 30 calendar days in advance) on the DNC web site: http://www.dnc.org.nz/policies and will become binding and effective upon the date specified therein.

16.2. In any Dispute Resolution Service proceedings, the Parties will be bound by the Policy and Procedure which are current at the commencement of Dispute Resolution Service proceedings, until the conclusion of the Dispute Resolution Service proceedings.

\section{General Information}

17.1. If anyone has any questions regarding this document they should email policies@dnc.org.nz

\section{PART B - PROCEDURE}

\section{B1. Communication}

B1.1. The DNC will send a Complaint (see paragraph B2) to the Respondent by:

B1.1.1. sending the Complaint by post, fax or e-mail to the Respondent at the contact details shown as the registrant or other contacts in the Register for the Domain Name in dispute;

The DNC may also, at its discretion use any or all of the following means:

B1.1.2. sending the Complaint in electronic form (including attachments to the extent available in that form) by e-mail to:

a) postmaster@<the Domain Name in dispute>;

b) if the Domain Name resolves to an active web page (other than a generic page which the DNC concludes is maintained by an ISP for parking Domain Names), to any e-mail address shown or e-mail links on that web page so far as this is practicable; or

B1.1.3. sending the Complaint to any addresses provided to the DNC by the Complainant under paragraph B2.3.3 so far as this is practicable.

B1.2. Except as set out in paragraph B1.1 above, all written communication to a Party or a Party's representative under the Policy or this Procedure shall be made by fax, post or email. 
B1.3. Communication shall be made in English. E-mail communications should be sent in plain text so far as this is practicable.

B1.4. During the course of proceedings under the Dispute Resolution Service, if either Party wishes to change its contact details it must notify the DNC of all changes.

B1.5. Except as otherwise provided in this Procedure or as otherwise decided by the DNC or if appointed, the Expert, all communications provided for under this Procedure shall be deemed to have been received:

B1.5.1. if sent by facsimile, on the date transmitted; or

B1.5.2. if sent by post, on the second Day after posting;

B1.5.3. if sent via the Internet, on the date that the communication was transmitted;

B1.5.4. and, unless otherwise provided in this Procedure, the time periods provided for under the Policy and this Procedure shall be calculated accordingly.

\section{B1.6. Any communication (except for communications relating to Informal Mediation)} between:

B1.6.1. the DNC and any Party shall be copied by the DNC to the other Party and if appointed, the Expert, subject to paragraph B12; and

B1.6.2. a Party to another Party shall be copied by the sender to the DNC and the DNC will copy such correspondence to the Expert, if appointed.

\section{B2. The Complaint}

B2.1. Any person or entity may submit a Complaint to the DNC in accordance with the Policy and this Procedure. In exceptional circumstances, the ability to accept complaints may have to be suspended. If so, a message will be posted to that effect on the DNC website which will indicate when the suspension is likely to be lifted.

B2.2. More than one person or entity may jointly make a Complaint. Where this occurs the joint Complainants must:

B2.2.1. all sign the hard copy of the Complaint (or have it signed on their behalf);

B2.2.2. specify one of the Complainants, or a single representative, who will be the 'Lead Complainant' who will receive correspondence on behalf of all the Complainants and is entitled to act on behalf of them all (e.g. in Informal Mediation); and

B2.2.3. specify which Complainant the Complainants wish to become the sole registrant of each Domain Name(s) which are the subject of the Complaint if the Complainants are successful (this does not bind the Expert).

B2.3. The Complainant must send the Complaint to the DNC in hard copy and (except to the extent not available for attachments) in electronic form. The Complaint shall:

B2.3.1. not exceed 2000 words (not including the text set out in paragraph B2.3.9 and annexes);

B2.3.2. specify whether the Complainant wishes to be contacted direct or through an authorised representative, and set out the e-mail address, telephone number, fax number and postal address which should be used; 
B2.3.3. set out any of the Respondent's contact details which are known to the Complainant;

B2.3.4. specify the Domain Name(s) which is the subject of the dispute and the name or mark which is identical or similar to the Domain Name and in which the Complainant asserts it has Rights;

B2.3.5. describe in accordance with the Policy the grounds on which the Complaint is made including in particular: what Rights the Complainant asserts in the name or mark; why the Domain Name should be considered to be an Unfair Registration in the hands of the Respondent; and any applicable aspects of paragraph 5 of the Policy above, as well as any other grounds which support the Complainant's assertion;

B2.3.6. specify whether the Complainant is seeking to have the Domain Name transferred, suspended, cancelled or otherwise amended;

B2.3.7. tell the DNC whether any legal proceedings have been commenced or terminated in connection with the Domain Name which is the subject of the Complaint;

B2.3.8. state that the Complainant will submit to the exclusive jurisdiction of the New Zealand courts with respect to any legal proceedings seeking to reverse the effect of a Decision requiring the suspension, cancellation, transfer or other amendment to a Domain Name registration, and that the Complainant agrees that any such legal proceedings will be governed by New Zealand law;

B2.3.9. conclude with the following statement followed by the signature of the Complainant or its authorised representative:

"I, the Complainant agree that my claims and remedies concerning the registration of the Domain Name, the dispute, or the dispute's resolution shall be solely against the Respondent and that none of InternetNZ, the DNC, NZRS, any Registrar, Expert or Mediator, nor any of those entities' councillors, officers, employees or servants (as applicable) shall be liable for anything done or omitted in connection with any proceedings under the Dispute Resolution Service unless the act or omission is shown to have been in bad faith.";

"The information contained in this complaint is to the best of my knowledge true and complete. This complaint is not being presented in bad faith, including not being for a dominant purpose other than resolving the issue of who the proper registrant of a Domain Name is, and the matters stated in this complaint comply with the Policy and Procedure and applicable law.";

"I agree to the terms of the Dispute Resolution Services Policy and Procedure, and agree to be bound by any resulting Decision, subject to any rights of review or appeal."

and

"I acknowledge that if the Expert orders a transfer of the domain name(s) to me or at my request, I will need to select an Authorised .nz Registrar to provide me with the necessary .nz registry and other services in respect of domain name(s). I will advise the DNC of my decision on request."

B2.3.10. attach four (4) copies of any evidence on which the Complainant relies including correspondence and any trade mark registration and/or evidence of use of or reputation in a name or mark, together with an index of the material attached.

B2.4. The Complaint may relate to more than one Domain Name, provided that those Domain Names are registered in the name of the Respondent. 


\section{B3. Notification of Complaint}

B3.1. The DNC will check that the Complaint sufficiently complies with the Policy and, if satisfied, this Procedure and, if so, will forward it to the Respondent together with an explanatory coversheet within three (3) Days of the receipt of the hard copy of the Complaint.

B3.2. If the DNC considers that the Complaint does not sufficiently comply with the Policy and this Procedure, the Complainant will be promptly notified of the deficiencies identified. The Complainant shall have three (3) Days from receipt of notification within which to correct the deficiencies and return the Complaint, failing which the DNC will deem the Complaint to be withdrawn. This will not prevent the Complainant submitting a different Complaint.

B3.3. The DNC will promptly notify the Parties of the date of Commencement of Dispute Resolution Service proceedings.

B3.4. On receipt of the complaint the DNC will cause the domain name to be locked until the conclusion of the proceedings, at which time the domain name will be unlocked.

\section{B4. The Response}

B4.1. Within fifteen (15) Days of the date of commencement of Dispute Resolution Service proceedings, the Respondent shall submit a Response, if they choose to do so.

B4.2. The Respondent must send the Response to the DNC signed, and in hard copy and (except to the extent not available for attachments) in electronic form at the addresses set out in the explanatory coversheet. The Response shall:

B4.2.1. not exceed 2000 words (not including the text set out in paragraph B4.2.5 and annexes);

B4.2.2. include any grounds that the Respondent wishes to rely upon to rebut the Complainant's assertions under paragraph B2.3.5 including any relevant factors set out in paragraph 6 as well as any other factors which rebut the Complainant's assertions

B4.2.3. specify whether the Respondent wishes to be contacted direct or through an authorised representative, and set out the e-mail address, telephone number, fax number and postal address which should be used;

B4.2.4. tell the DNC whether any legal proceedings have been commenced or terminated in connection with the Domain Name(s) which is the subject of the Complaint;

B4.2.5. conclude with the following statement followed by the signature of the Respondent or its authorised representative:-

"The information contained in this response is to the best of the Respondent's knowledge true and complete and the matters stated in this response comply with the Policy and Procedure and applicable law."; and

B4.2.6. attach four (4) copies of any evidence on which the Respondent relies including correspondence and any trade mark registration and/or evidence of use of or reputation in a name or mark together with an index of the material attached.

B4.3. Within three (3) Days following the receipt of the signed copy of the Response, the DNC will forward the Response to the Complainant. 
B4.4. If the Respondent does not submit a Response, the Parties will be notified that an Expert will be appointed on receipt from the Complainant of the applicable fees according to paragraph B20 and in the absence of exceptional circumstances.

\section{B5. Reply by the Complainant}

B5.1. Within five (5) Days of receiving the Response from the DNC, the Complainant may submit a Reply to the Respondent's Response, which shall not exceed 2000 words (not including annexes). The Reply should be confined to answering any new points raised in the Response and not previously dealt with in the Complaint. The expert will not be obliged to consider any other material included in the Reply.

B5.2. If a Reply is submitted it must be submitted in signed, hard copy (including four (4) copies of all annexes) and as far as possible in electronic form. If the Complainant does not submit a Reply within five (5) Days the DNC will proceed to Informal Mediation.

\section{B6. Informal Mediation}

B6.1. No Informal Mediation will occur if the Respondent does not file a Response. Within three (3) Days of the receipt of the Complainant's Reply (or the expiry of the deadline to do so), the DNC will arrange for Informal Mediation to be conducted. Informal Mediation will be conducted in a manner which the DNC, at its sole discretion, considers appropriate. The DNC will appoint a Mediator on a rotational basis from its list of Mediators.

B6.2. A Mediator may only be a person named in the list of Mediators which the DNC will maintain and publish along with the Mediators' qualifications. No Mediators' appointment will be challenged on the grounds that they are insufficiently qualified. Once the DNC has appointed the Mediator, the Parties will be notified of the name of the Mediator appointed.

B6.3. Negotiations conducted between the Parties during Informal Mediation (including any information obtained from or in connection to negotiations) shall be confidential as between the Parties, the mediator and the DNC. Any such information will not be shown to the Expert. Neither the DNC nor the Mediator nor any Party may reveal details of such negotiations to any third parties unless a court or decision-making body of competent jurisdiction orders disclosure, or the DNC, the Mediator or either Party are otherwise required to do so by applicable laws or regulations. Neither Party shall use any information gained during mediation for any ulterior or collateral purpose or include it in any submission likely to be seen by any court or decision-making body of competent jurisdiction or arbitral tribunal of competent jurisdiction in this dispute or any later dispute or litigation.

B6.4. Notwithstanding paragraph B6.3, the Parties may refer to the fact of Informal Mediation in subsequent proceedings before any New Zealand court or decision-making body of competent jurisdiction or arbitral tribunal of competent jurisdiction in this dispute or any later dispute or litigation.

B6.5. If the Parties reach a settlement during Informal Mediation then the existence, nature and terms of the settlement shall be confidential as between the Parties, the mediator and the DNC, unless the Parties specifically agree otherwise, a court or decision-making body of competent jurisdiction orders otherwise, or applicable laws or regulations require it.

B6.6. No binding verbal agreements can be reached as part of the Informal Mediation: any settlement reached by the Parties must be in writing to be enforceable.

B6.7. The DNC will notify the Registrar of a settlement reached in accordance with B6.5 where that settlement requires the Registrar to take action to give effect to that settlement. 
B6.8. Any action to be taken by the Registrar will be completed by it as soon as possible, and no later than three days, after receiving notice from the DNC.

B6.9. Where the settlement requires a change of registrant, the new registrant is deemed to have accepted the Registrar's standard terms and conditions.

B6.10. If the Parties do not achieve an acceptable resolution through Informal Mediation within ten (10) Days, the DNC will send notice to the Parties that it will appoint an Expert when the Complainant has paid the applicable fees set out under paragraph B20.1 within the time limit specified in paragraph B7.1. The Expert will be told whether or not Informal Mediation occurred, but will not be told what happened during Informal Mediation or why it failed to resolve the dispute.

B6.11. No Party may ask the DNC (including its officers, employees, contractors, agents and any Expert or Mediator) to reveal information or materials gained as a result of any Informal Mediation under the Dispute Resolution Service unless such disclosure has been ordered by a court or decision-making body of competent jurisdiction. Neither Party shall call the Expert, Mediator or the DNC (including its officers, employees, contractors, or agents) as a witness (either in person or to produce documents or other materials) in any proceedings which arise from, or are in connection with, the matters discussed in the mediation.

\section{B7. Appointment of the Expert and Timing of Decision}

B7.1. If the DNC does not receive the Complainant's request to refer the matter to an Expert together with the applicable fees within ten (10) Days of the Complainant's receipt of the notice referred to in paragraph B6.10, the Complaint will be deemed to have been withdrawn. This will not prevent the Complainant submitting a different Complaint.

B7.2. Within five (5) Days of the receipt of the applicable fees from the Complainant the DNC will appoint an Expert on a rotational basis from its list of Experts.

B7.3. An Expert may only be a person named in the list of Experts which the DNC will maintain and publish along with the Experts' qualifications. No Expert's appointment will be challenged on the grounds that they are insufficiently qualified. Once the Expert has been appointed, the Parties will be notified of the name of the Expert appointed and the date by which, except in exceptional circumstances, the Expert will forward his or her Decision to the DNC.

\section{B8. Impartiality and Independence}

B8.1. The Mediator and/or Expert shall be impartial and independent and both before accepting the appointment and during the proceedings will disclose to the DNC any circumstances giving rise to justifiable doubt as to their impartiality or independence. The DNC will have the discretion to appoint a substitute Mediator or Expert if necessary in which case the timetable will be adjusted accordingly.

\section{B9. Communication Between Parties and the Expert}

B9.1. A Party and the Expert must not communicate directly. All communication between a Party and the Expert must be made through the DNC.

\section{B10. Transmission of the File to the Expert}

B10.1. The DNC will forward the file except for documents relating to Informal Mediation to the Expert as soon as the Expert is appointed. 


\section{B11. General Powers of the DNC and the Expert}

B11.1. The DNC, or the Expert if appointed, may in exceptional cases extend any period of time in proceedings under the Dispute Resolution Service.

B11.2. The Expert shall determine the admissibility, relevance, materiality and weight of the evidence.

B11.3. The DNC shall decide a request by a Party to consolidate multiple Domain Name disputes in accordance with the Policy and this Procedure.

\section{B12. Further Statement}

B12.1. In addition to the Complaint, the Response and if applicable the Reply, any appeal notice and appeal notice response, the Expert may request further statements or documents from the Parties. The Expert will not be obliged to consider any statements or documents from the Parties which he or she has not received according to the Policy or this Procedure or which he or she has not requested. The Expert may request that a further statement be limited to a defined topic, and the Expert will not be obliged to consider any material beyond that requested.

B12.2. Any communication with the DNC intended to be passed to the Expert which is not part of the standard process (e.g. other than a Complaint, Response, Reply, submissions requested by the Expert, appeal notice or appeal notice response) is a 'non-standard submission'. Any non-standard submission must contain as a separate, first paragraph, a brief explanation of why there is an exceptional need for the non-standard submission. The DNC will pass this explanation to the Expert and the Respondent, and the remainder will only be passed to the Expert and the Respondent at the Expert's sole discretion. If there is no explanation, the DNC may not pass on the document or information.

\section{B13. In Person Hearings}

B13.1. No in person hearings (including hearings by conference call, video conference and web conference) will be held unless the Expert determines in his or her sole discretion and in exceptional cases, that such a hearing is necessary to enable him or her to come to a Decision.

\section{B14. Default}

B14.1. If the DNC finds that a submission by a Party exceeds the word limit, the submission will be returned to that Party who will within three (3) Days return a submission which complies with the word limits. If the DNC does not receive the submission back within the deadline from:

B14.1.1. the Complainant, the Complaint will be deemed to have been withdrawn, which will not stop the Complainant from submitting a different Complaint; or

B14.1.2. the Respondent, the Parties will be notified that the Expert will be appointed when the Complainant has paid the applicable fees set out in paragraph B20 and in the absence of exceptional circumstances. Once appointed the Expert will decide the dispute based upon the Complaint and evidence attached to it.

B14.2. If, once the Expert has been appointed, and in the absence of exceptional circumstances, a Party does not comply with any time period laid down in the Policy or this Procedure, the Expert will proceed to a Decision on the Complaint. If the Expert has 
not been appointed the DNC shall take any action which it deems appropriate in its sole discretion, unless prescribed by this Procedure.

B14.3. If, in the absence of exceptional circumstances, a Party does not comply with any provision in the Policy or this Procedure or any request by the DNC or the Expert, the Expert will draw such inferences from the Party's non compliance as he or she considers appropriate.

\section{B15. Expert Decision}

B15.1. The Expert will decide a Complaint on the basis of the Parties' submissions, the Policy and the Procedure.

B15.2. Unless exceptional circumstances apply, an Expert shall forward his or her Decision to the DNC within ten (10) Days of his or her appointment pursuant to paragraph B7.

B15.3. The Decision shall be in writing and signed by the Expert, provide the reasons on which it is based, indicate the date on which it was made, the place the Decision was made and identify the name of the Expert.

B15.4. If the Expert concludes that the dispute is not within the scope of paragraph 4, he or she shall state that this is the case. If, after considering the submissions, the Expert finds that the Complaint was brought in bad faith, for example in an attempt at Domain Name Hijacking, the Expert shall state this finding in the Decision. If the Complainant is found on three separate occasions within a 2-year period to have brought a Complaint in bad faith, the DNC will not accept any further Complaints from that Complainant for a period of 2 years from the date of the third such Decision.

\section{B16. Communication of Decision to Parties and Implementation of Decision}

B16.1. Within three (3) Days of the receipt of a Decision from the Expert, the DNC will communicate the full text of the Decision to each Party and the date for the implementation of the Decision in accordance with the Policy.

B16.2. The DNC will publish the full Decision and the date that any action which the Decision requires will be taken, on the DNC website.

B16.3. If the Expert makes a Decision that a Domain Name registration should be cancelled, suspended, transferred or otherwise amended, the DNC will implement that Decision by causing the necessary changes to be made to the Register after ten (10) Days of the date that the parties were notified, unless, during the ten (10) Days following the date that the parties were notified the DNC receives from either Party:

B16.3.1. an appeal or statement of intention to appeal complying with paragraph B17, in which case the DNC will take no further action in respect of the Domain Name until the appeal is concluded; or

B16.3.2. official documentation showing that the Party has issued and served legal proceedings before a New Zealand Court or decision-making body of competent jurisdiction, or an arbitral tribunal of competent jurisdiction against the other Party in respect of the domain name. In this case, the DNC will take no further action in respect of the Domain Name unless it receives:

a). evidence which satisfies it that the Parties have reached a settlement; or

b). evidence which satisfies it that such proceedings have been disposed of 
B16.3.3. In the event of the DNC being satisfied that a judgment, decision or award has been made directing or requiring that a Domain Name be cancelled, suspended, transferred or otherwise amended, the DNC will implement that Decision by causing any necessary changes to the Register to take place and the dispute resolution service proceeding will be terminated.

\section{B17. Appeal}

B17.1. Either Party shall have the right to appeal a Decision by submitting either:

B17.1.1. a statement of the intention to appeal (see paragraph B17.2), plus the nonrefundable deposit (see paragraph B20.4), which must be followed within fifteen (15) Days by an appeal notice (see paragraph B17.3) and the balance of the fee (see paragraph B20.4); or

B17.1.2. an appeal notice (see paragraph B17.3) and the whole fee (see paragraph B20.4).

B17.2. A statement of intention to appeal should only contain sufficient information to make it clear that an appeal is requested. The statement of intention to appeal should not contain the actual grounds or reasons for appeal, and the panel of Experts will not be obliged to consider any such grounds or reasons.

B17.3. An appeal notice should not exceed 1000 words, should set out detailed grounds and reasons for the appeal, but shall contain no new evidence or annexes.

B17.4. Within three (3) Days of the receipt of the:

B17.4.1. statement of the intention to appeal and deposit; or

B17.4.2. appeal notice and the full fee,

the statement of intention to appeal or appeal notice (as the case may be) will be forwarded to the other Party.

B17.5. Within ten (10) Days of receiving the appeal notice from the DNC, the other Party may submit an appeal notice response (paragraph B17.6).

B17.6. An appeal notice response must not exceed 1000 words, should set out detailed grounds and reasons why the appeal should be rejected but should contain no new evidence or annexes.

B17.7. Following the filing of an appeal notice response (or the expiry of the deadline to do so) an appeal panel of three Experts will be appointed. The test of impartiality shall apply to each appeal Expert. Subject to that qualification the appeal panel shall consist of:

B17.7.1. the Chair of the group of Experts, or at his or her discretion, an Expert of his or her choice; and

B17.7.2. the next available two Independent Experts appointed by rotation from the list.

B17.8. The appeal panel should not normally take into consideration any new evidence presented in an appeal notice or appeal notice response unless they believe that it is in the interests of justice to do so.

B17.9. So far as is appropriate in the circumstances paragraphs B15 and B16 apply equally to appeal Decisions, except that: 
B17.9.1. appeal Decisions should be returned by the appeal panel to the DNC within thirty (30) Days of the appointment of the last panellist, but this deadline may be extended by up to ten (10) Days by agreement with the DNC; and

B17.9.2. appeal Decisions cannot be subject to any appeal within the Dispute Resolution Service.

\section{B18. Settlement or Other Grounds for Termination}

B18.1. If, before a Decision is made the Parties agree and notify the DNC of a settlement, whether or not pursuant to Informal Mediation, proceedings under the Dispute Resolution Service will terminate.

B18.2. If, before a Decision is made, it becomes unnecessary or impossible to continue proceedings under the Dispute Resolution Service for any reason, the DNC will terminate proceedings under the Dispute Resolution Service unless a Party raises justifiable grounds for objection within a period of time which the DNC will determine and notify the Parties of.

\section{B19. Effect of Court Proceedings}

B19.1. If the DNC is satisfied that legal proceedings relating to a Domain Name which is the subject of a Complaint are issued before a New Zealand court or decision-making body of competent jurisdiction or an arbitral tribunal of competent jurisdiction, before or during the course of proceedings under the Dispute Resolution Service and are brought to its attention, it will suspend the Dispute Resolution Service proceedings, pending the outcome of the legal proceedings.

B19.2. A Party must promptly notify the DNC if it initiates or becomes aware of legal proceedings in a court or decision-making body of competent jurisdiction or arbitral tribunal of competent jurisdiction relating to a Domain Name which is the subject of a Complaint during the course of proceedings under the Dispute Resolution Service.

B19.3. Either party may request, before or during the Dispute Resolution Service, an interim measure of protection from a Court.

\section{B20. Fees}

B20.1. The applicable fees in respect of the referral of proceedings under the Dispute Resolution Service to an Expert are $\$ 1,800$ plus GST for disputes involving 1-5 Domain Names and only one Complainant. For disputes involving 6 or more Domain Names, and/or more than one Complainant, the DNC will set a fee in consultation with the Complainant. Fees are calculated on a cost-recovery basis, and are passed on in their entirety to the Expert(s). The DNC does not charge for its mediation or administration services in respect of the Dispute Resolution Service.

B20.2. Fees are payable by the Complainant only if an acceptable resolution has not been achieved after Informal Mediation and the DNC notifies the Parties that an Expert is to be appointed.

B20.3. In exceptional circumstances, for example if an in-person hearing is held, the DNC will request that the Parties pay additional fees to be agreed between it, the Parties and the Expert.

B20.4. The applicable fees for the submission of an appeal are $\$ 6,600+$ GST. If the option is used to pay a deposit and the balance, the deposit is \$700 + GST and non- 
refundable, and the balance is $\$ 5,900+$ GST. If the deposit is paid, and the balance of the fee and/or appeal notice are not filed in time, that appeal is deemed withdrawn and the case will be closed.

\section{B21. Exclusion of Liability}

B21.1. None of InternetNZ, the DNC, NZRS, any Registrar, Expert or Mediator, nor any of those entities' councillors, officers, employees or servants (as applicable) shall be liable to a party for anything done or omitted, whether negligently or otherwise, in connection with any proceedings under the Dispute Resolution Service unless the act or omission is shown to have been in bad faith.

\section{B22. Modifications to the Policy and Procedure of the Dispute Resolution Service}

B22.1. The Internet is an emerging and evolving medium and the regulatory and administrative framework under which the DNC operates is constantly developing. For these reasons the DNC reserves the right to make reasonable modifications to the Policy and Procedure at any time. Except where the DNC is acting in pursuance of a statutory requirement or a court order, substantive changes will be implemented following a process of open public consultation. Each such change will be published in advance (where practicable, 30 calendar days in advance) on the DNC web site: http://www.dnc.org.nz/policies and will become binding and effective upon the date specified therein.

B22.2. The Parties will be bound by the Policy and Procedure which are current at the commencement of the Dispute Resolution Service proceedings until the conclusion of the Dispute Resolution Service proceedings. 
APPENDIX 2 SUBMISSIONS ON 2004 CONSULTATION PAPER

\begin{tabular}{|c|l|}
\hline Number & \\
\hline 1 & Domainz Limited \\
\hline 2 & Emirates Team New Zealand \\
\hline 3 & Andrew Brown QC \\
\hline 4 & Baldwins \\
\hline 5 & Bell Gully \\
\hline 6 & New Zealand Law Society, Electronic Commerce Committee \\
\hline 7 & New Zealand Institute of Patent Attorneys \\
\hline 8 & BengeWeb Services \\
\hline 9 & WebAdress \\
\hline 10 & AA Guides \\
\hline 11 & Garth Piesse \\
\hline 12 & Nominet UK \\
\hline 13 & Free Parking \\
\hline 14 & The International Trademark Association \\
\hline 15 & Brendan McNeill \\
\hline 16 & Maxnet \\
\hline 17 & Peter Belt \\
\hline 18 & Sir Ian Barker QC \\
\hline & \\
\hline
\end{tabular}




\section{APPENDIX 3 RECOMMENDATIONS TO THE REVIEW OF THE DISPUTE RESOLUTION SERVICE POLICY}

The DRS is to be reviewed in 2010. This dissertation makes the following recommendations on matters to be taken into account in that review:

(a) Where no response is filed to a complaint consideration should be given to automatic transfer of the name after the period for a response has expired. Alternatively the DNC should have the discretion to transfer the domain name after proof of "final notice" to the respondent by the complainant

(b) A purposive provision could usefully be added to the DRS to make clear the duty of the DNCL to deal with complaints promptly and manage cases in a timely manner.

(c) The DRS data should be published in a consistent style, with the raw data on the number of actual cases, not only percentages.

(d) The summary data published on the DNC website should have a consistent style so that years can be compared.

(e) A small but significant proportion of cases are withdrawn. The reasons for withdrawal should be monitored and may warrant further research.

(f) Expert decisions should be published according to The New Zealand Law Style Guide.

(g) The role of the DNC in mediations should be clarified.

(h) The reasons for invalidity (such as not within jurisdiction of the DRS, inadequate information, failure to comply with DRS form or other requirements) should be published.

(i) The DRS should be amended to clarify, for the avoidance of doubt, that the Arbitration Act does not apply.

(j) More research would be useful to examine New Zealand registrants with experience of UDRP processes in relation to gTLDs and how the DRS process compares. 
APPENDIX 4 TABLE OF INTERNETNZ POLICIES, AGREEMENTS AND FORMS

\section{Policies}

\begin{tabular}{|l|l|l|l|}
\hline Reference & Title & Version & Date issued \\
\hline PDP & $\begin{array}{l}\text { Policy Development } \\
\text { Process }\end{array}$ & V2.1 & $1 / 4 / 08$ \\
\hline OLD & Outline Document & V1.8 & $22 / 12 / 08$ \\
\hline 2LD & Second Level Domains & V2.3 & $30 / 7 / 09$ \\
\hline AOR & $\begin{array}{l}\text { Authorisation of } \\
\text { Registrars Process }\end{array}$ & V2.0 & $28 / 7 / 08$ \\
\hline CON & Connection Process & V1.3 & $10 / 6 / 08$ \\
\hline COR & Change of Registrant & V1.2 & $1 / 4 / 08$ \\
\hline DCP & $\begin{array}{l}\text { Dispute and Complaints } \\
\text { Process }\end{array}$ & V2.0 & $22 / 12 / 08$ \\
\hline DRS & $\begin{array}{l}\text { Dispute Resolution } \\
\text { Service }\end{array}$ & V2.0 & $1 / 5 / 08$ \\
\hline IDN-Sun & $\begin{array}{l}\text { IDN Sunrise Registration } \\
\text { Policy }\end{array}$ & V0.4 & $6 / 4 / 10$ \\
\hline IIP & $\begin{array}{l}\text { Investigations and } \\
\text { Inquiries Process }\end{array}$ & V2.0 & $22 / 12 / 08$ \\
\hline PRI & Privacy Policy & V2.0 & $14 / 5 / 09$ \\
\hline POD & $\begin{array}{l}\text { Process on De- } \\
\text { Authorisation of a } \\
\text { Registrar }\end{array}$ & V2.1 & $1 / 4 / 08$ \\
\hline RAR & Roles and Responsibilities & V2.2 & $1 / 4 / 08$ \\
\hline RMC & $\begin{array}{l}\text { Registering, Managing } \\
\text { and Cancelling Domain } \\
\text { Names }\end{array}$ & V2.0 & $3 / 6 / 08$ \\
\hline TAR & $\begin{array}{l}\text { Transfer to Another } \\
\text { Registrar }\end{array}$ & V2.1 & $1 / 4 / 08$ \\
\hline WSP & WHOIS Server Policy & V2.1 & $1 / 4 / 08$ \\
\hline ZTP & Zone Transfer Policy & V2.1 & $1 / 4 / 08$ \\
\hline
\end{tabular}

\section{Agreements}

\begin{tabular}{|l|l|l|}
\hline Title & Version & Date issued \\
\hline $\begin{array}{l}\text { Registrar Authorisation } \\
\text { Agreement }\end{array}$ & $\mathrm{V} 4.0$ & $1 / 4 / 08$ \\
\hline $\begin{array}{l}\text { Registrar Connection } \\
\text { Agreement }\end{array}$ & $\mathrm{V} 3.0$ & $1 / 4 / 08$ \\
\hline $\begin{array}{l}\text { Registrant Agreement } \\
\text { Core Terms and } \\
\text { Conditions }\end{array}$ & $\mathrm{V} 1.1$ & $1 / 4 / 08$ \\
\hline
\end{tabular}


Forms

\begin{tabular}{|c|c|c|c|}
\hline Reference & Title & Version & Date issued \\
\hline AOR1 & $\begin{array}{l}\text { Application for } \\
\text { Authorisation as a } \\
\text { Registrar }\end{array}$ & V1.2 & $1 / 4 / 08$ \\
\hline CON1 & $\begin{array}{l}\text { Application for } \\
\text { Connection to the } \\
\text { SRS }\end{array}$ & V1.2 & $1 / 4 / 08$ \\
\hline COR1 & $\begin{array}{l}\text { Change of } \\
\text { Registrant }\end{array}$ & V1.2 & $1 / 4 / 08$ \\
\hline DCP1 & Complaints form & V1.2 & $1 / 4 / 08$ \\
\hline NUD1 & $\begin{array}{l}\text { Application for } \\
\text { Unmoderated } \\
\text { Second Level } \\
\text { Domain }\end{array}$ & V2.1 & $1 / 4 / 08$ \\
\hline NMD1 & $\begin{array}{l}\text { Application for } \\
\text { Moderated Second } \\
\text { Level Domain }\end{array}$ & V2.1 & $1 / 4 / 08$ \\
\hline NMD2 & $\begin{array}{l}\text { Moderation } \\
\text { Application }\end{array}$ & V2.1 & $1 / 4 / 08$ \\
\hline ZTP1 & $\begin{array}{l}\text { Application for } \\
\text { Release of Zone } \\
\text { File }\end{array}$ & V1.2 & $1 / 4 / 08$ \\
\hline
\end{tabular}




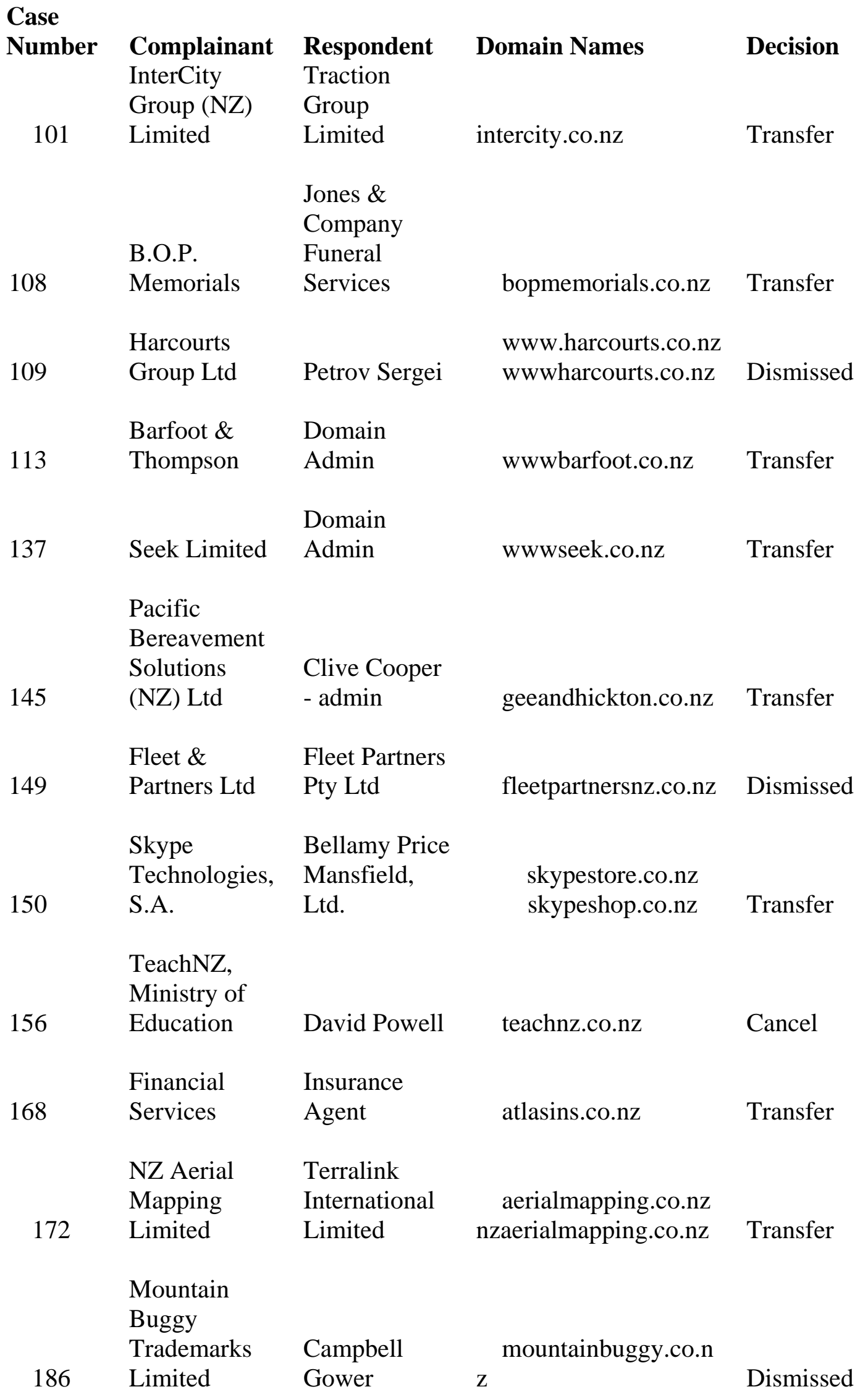


Case

Number

Respondent

Domain Names

Decision

Kiwispy

188

limited

Everlast

kiwispy.co.nz

Transfer

Monarch

Natural

DLE

monarchnaturalhealt

198

Health

Investments

h.co.nz

Transfer

TradeFree

202

Ltd.

Adnet

tradefree.co.nz

Dismissed

Thai Airways

International

Public

Company

203

Limited

E-Promote

thaiairways.co.nz

Transfer

KBB Music

Bonfire

204

Ltd

Development

kbb.co.nz

Transfer

TELECOM IP

206

LIMITED

E-Promote

wwwferrit.co.nz

Transfer

tellecom.co.nz

yelllowpages.co.nz

YPG IP

208

Limited

E-Promote

witepages.co.nz

whitpages.co.nz

Transfer

223

Pet Mania

Petmania

petmania.co.nz

Transfer

McIntyre

Dick \&

228

Partners

Alpro New

basecampwanaka.co.

Zealand Ltd

$\mathrm{nz}$

Transfer

Active Trave

Frontier

229

Ltd

Travel

activetravel.co.nz

Transfer

Melbourne IT

235

CBS

E-Promote

umbro.co.nz

Dismissed

Retail

Distribution

Limited

Sarah Perkins

adman.co.nz

Transfer

Daddios

Lincoln

Developments

Archer

(Struck Off)

daddios.co.nz

Transfer 
Case

Number

Complainant Respondent Domain Names

Decision

Cine Craft

244

Limited

Vixen

private.co.nz

Transfer

Apollo

Marketing

250

Apollo

and

apollomarketing.co.n

Advertising

Transfer

Inland

Revenue

Portfolio

252

Department

Brains, LLC

inlandrevenue.co.nz

Transfer

UMBRO

International

Ltd

E-promote

umbro.co.nz

Transfer

Harvey

Norman

Woosh

Retailing Pty

Domains

256

Limited

Limited

harveynormans.co.nz Transfer

COMPAGNI Triple Eight

E GERVAIS Holdings

DANONE Limited

danone.co.nz

Transfer

Magic Pulse

Limited

(trading as

260

Kitomba)

Gregg Nelson

kitomba.co.nz

Transfer

Kimberly-

Clark

Worldwide,

Inc.

E-Promote

huggies.co.nz

Transfer

Facebook,

Inc.

Sanjay Dalal

facebook.co.nz

facebook.net.nz

Transfer

Telstra

telstaclear.co.nz

Corporation

283

Limited

E-Promote

telsraclear.co.nz

telstarclear.co.nz

Transfer

Fiji Water James

Company Robinson and

290 LLC

Mel Daly

fijiwater.co.nz

Transfer 
Case

\begin{tabular}{|c|c|c|c|c|}
\hline Number & Complainant & Respondent & Domain Names & Decision \\
\hline & Auckland & Dave & aucklandairport.co.n & \\
\hline 291 & Airport & Burghardt & $\mathrm{z}$ & Dismissed \\
\hline & Sato New & Ansutek & & \\
\hline & Zealand & Commercial & & \\
\hline 302 & Limited & Ltd & sato.co.nz & Transfer \\
\hline 11 & $\begin{array}{l}\text { Transformer } \\
\text { Winding } \\
\text { Sevices Ltd }\end{array}$ & $\begin{array}{l}\text { Marcus } \\
\text { Maraldo }\end{array}$ & $\begin{array}{l}\text { transformerwindings } \\
\text { ervices.co.nz }\end{array}$ & Dismissed \\
\hline & Budget Rent & & & \\
\hline 313 & $\begin{array}{l}\text { A Car System, } \\
\text { Inc. }\end{array}$ & Ian Willis & $\begin{array}{l}\text { budgetrentalcars.co.n } \\
\text { z }\end{array}$ & Transfer \\
\hline
\end{tabular}

$\begin{array}{llll}\text { A1 Radiator } & & & \\ \text { \& Air } & & & \\ \text { Conditioning } & \text { Heat } & \text { a1radiator.co.nz } & \\ \text { Specialists } & \text { Exchanger } & \text { a1rad.co.nz } & \\ \text { Limited } & \text { Services } & \text { a1rads.co.nz } & \text { Transfer }\end{array}$

Hot Water Heat Pumps Ltd

Richard

Hayes

hotwaterheatpumps.c o.nz

Dismissed

The Country

The Country Channel Ltd

Channel

thecountrychannel.co .$n z$

Appeal: no Limited action

1. A1

Radiators \& Airconditioni ng Specialists

Carlton

Haulage

Limited

John Burrill

carltonhaulage.co.nz

Transfer

CRW Group

Pacific Brands 
Case

Number

Complainant

Respondent

Domain Names

Decision

Sabco

HARCO

344

Australia Pty

(Harkness \&

Ltd

Young Ltd)

sabco.co.nz

Transfer

Trade Me thought box

Limited

ltd

trademetender.co.nz

Transfer

Wicked Escape

wickedcampers.co.n

353

Campers

Rentals

Z

Transfer

Metrotest.Co

m Ltd

David Rohani

metrotest.co.nz

Transfer

Law Staff

Law Staff

International

Australia Pty.

Limited

Limited

lawstaffinternational.

The Animal

Welfare

animal

Institute of

welfare in

399

New Zealand

new zealand

awinz.org.nz

Transfer

Profile Boats

(2008)

jan

402

Limited

mccutcheon

profileboats.co.nz

Transfer

Frucor

Beverages

Clark R F

409

Ltd.

Mills

V.co.nz

Transfer

Macnaught

Pty Limited

Neville Stuart

macnaught.co.nz

Transfer

First Direct

Eva

420

Limited

Romanowska

ecocabs.co.nz

Dismissed

G.J. Gardner

423

Homes

SpecName

gjgardener.co.nz

Transfer

Stainless

Bending

425

Limited

Paul Granich

stainlessbending.co.n

Toshiba

(Australia)

Leigh

Pty Ltd

Brotherston

mytoshiba.co.nz

Transfer 
Case

\begin{tabular}{|c|c|c|c|c|}
\hline Number & Complainant & Respondent & Domain Names & Decision \\
\hline 434 & $\begin{array}{l}\text { YPG IP } \\
\text { Limited }\end{array}$ & E-Promote & $\begin{array}{l}\text { yellowpagers.co.nz } \\
\text { yelloepages.co.nz } \\
\text { whitepagers.co.nz } \\
\text { yellopages.co.nz }\end{array}$ & Transfer \\
\hline 438 & $\begin{array}{l}\text { First Mobile } \\
\text { New Zealand } \\
\text { Limited }\end{array}$ & $\begin{array}{l}\text { The TEC } \\
\text { Group } \\
\text { Limited }\end{array}$ & $\begin{array}{l}\text { 1stmobile.co.nz } \\
\text { 1stmobile.net.nz }\end{array}$ & Transfer \\
\hline 441 & Senator Boats & $\begin{array}{l}\text { Firmans } \\
\text { Marine Centre }\end{array}$ & senatorhoats conz & Transfer \\
\hline 443 & $\begin{array}{l}\text { Insure and Go } \\
\text { Insurance } \\
\text { Services } \\
\text { Limited } \\
\text { Capital } \\
\text { Conservator }\end{array}$ & $\begin{array}{l}1 \text { cover NZ } \\
\text { Limited }\end{array}$ & Insureandgo.co.nz & Transfer \\
\hline 458 & Group & Samuels &.$n z$ & Transfer \\
\hline
\end{tabular}


BIBLIOGRAPHY

\section{Legislation}

New Zealand

Arbitration Act 1996

Copyright Act 1994

Fair Trading Act 1986

Judicature Act 1908

New Zealand Bill of Rights Act 1990

Trade Marks Act 2002

\section{United States of America}

The AntiCybersquatting Consumer Protection Act 106 Pub. L. 113 U.S.C. § 1125.

The Truth in Domain Names Act (2003) 18 US § 2252B (Supp 2003).

\section{Parliamentary Bills}

The Copyright (Infringing File Sharing) Bill 2010.

\section{Domain Name System Policies and Guidelines}

New Zealand

The Domain Name Commission Limited “Disputes and Complaints Policy” (2008) $<$ www.dnc.org.nz> .

Domain Name Commission Limited “Dispute Resolution Service Policy” (2008) Domain Name Commission <www.dnc.org.nz >

The Domain Name Commission Limited “Second Level Domains Policy” (2009) Domain Name Commission <www.dnc.org.nz>.

International

International Organisation for Standardization “ISO 3166-1” (2010)

$<$ Www.iso.org $>$.

Internet Assigned Numbers Authority “Root Zone Database (2010)

$<$ www.iana.org $>$. 
Internet Corporation for Assigned of Names and Numbers Principles For The

Delegation And Administration Of Country Code Top Level Domains

(Government Advisory Committee, 2000).

Internet Corporation for Assigned of Names and Numbers Universal Dispute Resolution Policy (ICANN, United States of America, 1999).

Internet Corporation for Assigned of Names and Numbers Rules for Universal Dispute Resolution Policy (ICANN, United States of America, 1999).

Internet Corporation for Assigned of Names and Numbers Information Concerning Approval Process for Dispute Resolution Service Providers (ICANN, United States of America, 2003).

Internet Corporation for Assigned of Names and Numbers "Internationalised Domain Names (2009) <www.icann.org>.

Internet Corporation for Assigned of Names and Numbers “New gTLDs: Draft Application Handbook” (2010) <www.icann.org>.Nominet Dispute Resolution Service Procedure (NominetUK, Oxford, 2008).

Postel, Jon “Domain Name System Structure and Delegation” Request For Comment 1591 (United States of America, 1994)

\section{Table of cases}

New Zealand

Dominion Breweries Ltd v The Domain Name Company Limited (2000) 1 NZECC 70-009 (HC).

IMAX Corporation v Village Roadshow Corporation Ltd HC, Auckland, CIV2005-404-003248, 29 March 2006.

Forestry Corporation of New Zealand v Attorney-General [2003] 3 NZLR 328.

Oggi Advertising Limited v McKenzie [1999] 1 NZLR 631.

New Zealand Post Ltd v Leng [1999] 3 NZLR 667 (CA).

Qantas Airways Limited v Domain Name Company Limited (2000) 1 NZECC 70005 (HC).

Queenstown Management Services Ltd v St James Body Corporate 21507 \& Ors HC, Invercargill CIV-2007-425-000347, 10 August 2007.

Wells v Haden [2008] DCR 859.

Case Note 18511 [2001] NZPrivCmr 9. 


\section{United Kingdom}

British Telecommunications plc v One in a Million Ltd [1998] 4 All ER 476 (CA).

Carus-Wilson v Greene (1886) 18 QB 7.

Phones4u Ltd and Anor v Heykali and Ors [2006] EWCA Civ 244.

Pankajkumar Patel v Allos Therapeutics Inc [13 June 2008] 2008 WL 2442985, Sonia Proudman QC.

United States of America

Kremen v Cohen 2001 F. 2d 1502 (9th Cir 1991).

Panavision International v Toepenn 141 F 3d 1316 (9th Cir 1998).

\section{Secondary Materials}

\section{Texts}

Australian Law Reform Commission Alternative or Assisted Dispute Resolution (Adversarial Background Paper 2, Sydney, 1996).

Australian National Alternative Dispute Resolution Advisory Council "What is ADR” (2007) <www.nadrac.gov.au>.

Bellia, Patricia L, Berman, Paul Schiff, and Post, David G. Cyberlaw Problems of Policy and Jurisprudence in the Information Age (3rd ed, Thomson/West, St. Paul, 2007).

Best, Michael L. “Can the Internet Be A Human Right?” in Steven Hick and others (eds) Human Rights and the Internet (Palgrave MacMillian, New York, 2000).

Cabinet Paper “Infrastructure Stocktake Report” (17 May 2004 Ministry of Economic Development, Wellington).

Commercial Law in New Zealand (loose leaf, LexisNexis NZ Limited, Wellington, last updated December 2008).

Department of Internal Affairs Digital Child Exploitation Filtering System Code of Practice (2010).

Domain Name Commission Annual Report 2006-2007 (InternetNZ, Wellington, 2007).

Domain Name Commission Annual Report 2007-2008 (InternetNZ, Wellington, 2008). 
Domain Name Commission Annual Report 2008-2009: Advocating for the Next Generation (InternetNZ, Wellington, 2008).

Frankel, Susy and McLay, Geoff Intellectual Property in New Zealand (Lexis Nexis Butterworths, Wellington, 2002).

Harvey, David internet.law.nz (2nd ed LexisNexis NZ Limited, Wellington, 2005). Hedley, Steve The law of electronic commerce and the Internet in the United Kingdom and Ireland (Cavendish Publishing, London, 2006).

Internet Corporation for Assigned of Names and Numbers Annual Report 2008 (ICANN 33rd International Meeting, Cairo, 2008).

Katsh, Ethan and Rifkin, Janet Online Dispute Resolution, Resolving Disputes in Cyberspace (Jossey-Bass, A Wiley Company, San Francisco, 2001).

Law Commission "Delivering Justice for All: A Vision for New Zealand Courts and Tribunals” (2004) Report 85, Wellington, New Zealand.

McLay, Geoff and Murray, Christopher and Orpin, Jonathan New Zealand Law Style Guide (Thomson Reuters, Wellington, 2009).

Menkel-Meadow, Carrie and others, Dispute Resolution Beyond the Adversarial Model, (Aspen Publishers, New York, 2005).

Moffitt, Michael L., and Schneider, Andrea Kupfer Dispute Resolution: examples and explanations (Aspen Publishers, New York, 2008).

Mueller, Milton L. Ruling the Root: internet governance and the taming of cyberspace (Massachusetts Institute of Technology, Harvard, 2002).

Newman, Keith Connecting the Clouds: The Internet in New Zealand (The Internet Society of New Zealand and Activity Press, Wellington, 2008) also available at $<$ www.nethistory.co.nz $>$.

Post, David G. “Against “Against Cyberanarchy” ” in Patricia Bellia (ed) Cyberlaw Problems of Policy and Jurisprudence in the Information Age (3rd ed, Thomson/West, St Paul, 2007).

Rau, Alan Scott, Sherman, Edward F. and Peppet, Scott R Processes of Dispute Resolution 21 (4th ed, Foundation Press, Thomsen Reuters, 2006).

Reed, Chris and Angel, John Computer Law: the Law and Regulation of Information Technology (6th ed, Oxford University Press, London, 2007).

Riskin, Leonard L. and Westbrook, James E. Dispute Resolution and Lawyers (2nd ed, West Publishing Co. St Paul, 1997). 
Rowland, Diane and McDonald, Elizabeth Information Technology Law (3rd ed, Cavendish Publishing, London, 2005).

Saville-Smith, K and Fraser, R. Alternative Dispute Resolution: General Civil Cases (prepared for the Ministry of Justice, Wellington, 2004).

Scott, Michael D Scott on Information Technology Law (3rd ed, Aspen Publishers Wolters Kluwer Law and Business, United States of America and the Netherlands, 2007 (includes 2008 supplement)).

Smith, Philippa and others World Internet Project New Zealand: The Internet in New Zealand 2009 (World Internet Project New Zealand, Institute of Culture, Discourse and Communication, Auckland University of Technology, Auckland, 2010).

Sourdin, Tania Alternative Dispute Resolution (2nd ed Thomson Law Book Co, Sydney, 2005).

Sourdin, Tania Dispute Resolution (3rd ed Law Book Company, Australia, 2008). Spiller, Peter (ed) Dispute Resolution in New Zealand (2nd ed, Oxford University Press, Melbourne, 2007).

Todd, Elle, (ed) Gringas: The Laws of the Internet (3rd ed, Tottle Publishing, Haywards Heath, 2008).

Tyler M and Bretherton D Research into On-Line Alternative Dispute Resolution, Exploration Report (prepared for the Department of Justice by the University of Melbourne, Victoria, 2003).

Ware, Stephen J., Alternative Dispute Resolution (2nd ed, Thomsen West, St Paul, 2007).

World Intellectual Property Organisation “Domain Name Dispute Resolution” $<$ www.wipo.int $>$.

\section{Journal articles}

Alschuler, Albert W. "Mediation with a mugger: the shortage of adjudicative services and the need for a two tier trial system in civil cases” (1986) 99 Harv. L. Rev. 1808.

Bayer, Judit "Liability of Internet Service Providers for Third Party Content" (2007) VUWLR Working Paper Series 1.

Boulle, L “Options for Cyber-med” (1999) 10 ADR Bulletin 128. 
Christopher M. Bruner "States, Markets, And Gatekeepers: Public-Private

Regulatory Regimes In An Era Of Economic Globalization Copyright” 30 MIJIL 125.

Capelletti, Mauro “Alternative Dispute Resolution Processes” (1993) 56 Modern Law Review 282.

Cerf, Vint "Histories of the Internet: A brief history of the Internet and related works” (2010) Internet Society <www.isoc.org>.

Cheung, Anna and Weber, Rolf H., "Internet Governance and the Responsibility of Internet Service Providers” (2008) WILJ Summer 403.

Clark, Christopher G "The Truth in Domain Names Act of 2003 and a Preventative Measure to Combat Typosquatting” (2004) 89 Cornell Law Review 1476.

Davies, Todd “Symposium: I think I can, I think ICANN: Regulating the Internet ... or Not: A Behavioural Perspective on Technology Revolution and Domain Name Regulation” (2008) Pacific McGeorge Global Business and Development Law Journal 327.

Developments in the Law “The Paths of Civil Litigation” 113 Harv. L. Rev. 1752.

Howe, Walt “A Brief History of the Internet” (2009) < www.walthowe.com>.

Edwards, Harry T. “Alternative Dispute Resolution: Panacea or Anathema?” 99 Harv. L. Rev. 668.

Ellinghausen Jr, Don “Justice Trumps Peace: the Enduring Relevance of Owen Fiss’s Against Settlement” (2007) (Michigan, <www.pegasus.rutgers.edu>).

Fennell, Lee Anne “Adjusting Alienability” 122 Harv. L. Rev. 1403.

Fiss, Owen “Against Settlement” (1984) 93 Yale L.J. 107.

Freeman, Jody “Extending Public Law Norms Through Privatisation” 116 Harv. L. Rev. 1285.

Froomkin, A. Michael "Habermas@discourse.net: towards a critical theory of cyberspace (2003) 116 Harv. L. Rev. 749.

Gillies, Lorna E., “Addressing The "Cyberspace Fallacy”: Targeting The Jurisdiction Of An Electronic Consumer Contract” (2008) 16 INTLJIT 242.

Glover, Kevin “Domain name dispute resolution” (2009) February NZLJ 35.

Grainer, Jacob “Not abusive, just unfair? Dispute resolution in “.nz” domain namespace and the New Zealand Dispute Resolution Service Policy” (2006) NZIPJ 4(8) 186. 
Gunasekara, Gehan and Dillon, Erin, "Data Protection Litigation in New Zealand: Processes and Outcomes” (2008) 39 VUWLR 457.

Kee, Jac Sm, “Take Back The Tech” (2010) Association for Progressive Communications $<$ www.apc.org $>$.

Leiner, Barry M. and others "Histories of the Internet: A brief history of the Internet” (2010) Internet Society <www.isoc.org>.

Lipton, Jacqueline, D. "Bad Faith in Cyberspace: Grounding Domain Name Theory in Trademark, Property and Restitution” (October 7, 2009) Harvard Journal of Law and Technology, Forthcoming; Case Studies Legal Research Paper No. 09-28.

Nominet "Summary of Changes to the Dispute Resolution Service Policy and Procedure Changes” (NominetUK, Oxford, 2008) <www.nominet.org.uk>).

Powell C, “Alternative Dispute Resolution” (1998) NZLJ 91.

Quirk, Patrick “Curriculum Themes: Teaching Global Cyberlaw” 16 INTJLIT 297.

Ryan, Stephen M., Plzak, Raymond A., and Curran, John "Legal and Policy Aspects of Internet Number Resources” 24 SCCHITLJ 335.

Sander, E.A. "Varieties of Dispute Processing” (1976) 70 FRD 111.

Sander, Frank E.A. and Goldberg, Stephen B. "Fitting the forum to the fuss: a user friendly guide to selecting and ADR procedure” (1994) 10 Neg.J 49.

Schleimer, Joseph D., "Protecting Copyright at the "Backbone” Level of the Internet” 15 UCLAELR 139.

Sturzaker "Dispute Resolution in the New Millennium - International Arbitration” (1999) 2(6) ADR Bulletin 60.

Tech Liberty New Zealand “Internet Filtering” (2010) <www.techliberty.org.nz>.

The Internet Governance Forum "Dynamic Coalition on the Internet Bill of Rights”. 2010) <www.intgovforum.org>.

Tidwell, A, “Handling Disputes in Cyberspace” (1996) 7 Australian Dispute Resolution Journal 245.

Zondag, Berry “Let’s not get mediation into our Courts at all” (2009) 120 NZ Lawyer 12.

\section{Unpublished Papers}

Domain Name Commissioner, note from Domain Name Commissioner to author regarding draft dissertation (Wellington, 23 March 2010). 
Joo, Eun “ICANN'S new gTLD procedure - Trademark-related concerns” World Intellectual Property Organisation, (paper presented to ICANN Conference Sydney, June 2009).

Professor Tony Smith, “The Law of Contempt” (2009) InternetNZ (Seminar Proceedings) <www.internet.net.nz $>$.

Price, Steven, “R v The Internet” (2009) InternetNZ (Panel on Contempt Issues, Seminar Proceedings) <www.internet.net.nz $>$.

Lithgow QC, Robert “R v The Internet” (2009) InternetNZ (Panel on Contempt, Seminar Proceedings) < www.internet.net.nz >

Liddicoat, Joy “The Copyright (New Technologies) Amendment Act 2008 Internet Service Provider Liability” (LLM Research Paper, Victoria University of Wellington, 2008).

Liddicoat, Joy “Domain Name Dispute Resolution in New Zealand” (LLM

Research Paper, Victoria University of Wellington, 2009).

Liddicoat Joy and Dr Judy McGregor, Draft Chapter on the Right to Freedom of Expression, The Internet (Human Rights Commission, Wellington, publication forthcoming in 2010).

Sarras, Naela “ccTLD Best Practices and Considerations” (paper presented on behalf of the Internet Assigned Numbers Authority presentation to ccTLD workshop, Dubai, 2006).

Taylor, David “ICANN Paris - UDRP Workshop” (presentation to ICANN Meeting, 2008).

\section{Online Encyclopedias}

The Laws of New Zealand (LexisNexis, Wellington, last updated 2009).

Electronic Business and Technology Law (LexisNexis NZ Limited, Wellington, last updated October 2008).

Wikipedia (2010) <www.wikipedia.org>.

\section{InternetNZ Papers, Records of Meetings and Press Releases}

In this research a number of references are sourced to the Uniform Resource Locator <www.old.internetnz.net.nz $>$. This refers to the Uniform Resource Locator on which the cited documents are currently hosted. In 2010 InternetNZ 
created a new website <www.internetnz.net.nz $>$ which does not host all of the documents cited in this research. The InternetNZ website was previously $<$ www.internetnz.org.nz $>$. All materials cited in this research were publicly available at the previous Uniform Resource Locator and remain available at $<$ www.old.internetnz.net.nz $>$. To assist with verifying the research trail, reference is made to the Uniform Resource Locator at which all of the referenced material can be located.

Domain Name Commission Limited “Common Terms” ((InternetNZ, Wellington, 2003) <www.dnc.org.nz>.

Domain Name Commission Limited “Dispute Resolution” (InternetNZ, Wellington, $2010<$ www.dnc.org.nz>.

Domain Name Commission Limited “Minutes of meeting” (InternetNZ, Wellington, 29 February 2009).

Domain Name Commission Limited “.nz dispute Resolution Service - Policy Review” (InternetNZ, Wellington, 2007).

Domain Name Dispute Resolution Task Force Domain Name Dispute Resolution in the .nz Space: A Discussion Paper (InternetNZ, Wellington, 2001).

Domain Name Dispute Resolution Working Group Domain Name Disputes Resolution - Trigger Questions (InternetNZ, Wellington, 2001).

Domain Name Dispute Resolution Working Group Implementation of a dispute resolution process for .nz domain names (InternetNZ, Wellington, 2005).

InternetNZ (2001) Council Motion, 01/19.

InternetNZ “Domain name dispute process to be implemented” (18 May 2005) Press Release.

InternetNZ “InternetNZ: Child porn filter 'not the answer”” (18 January 2010)

Press Release.

Letter from Internet Corporation for Assigned of Names and Numbers to InternetNZ regarding .nz domain name space (27 October 2007).

.nz Oversight Committee Consultation on establishing a dispute resolution process for the .nz domain name space (InternetNZ, Wellington, 2004). .nz Oversight Committee, Summary of Submissions (round one) - Establishing a Dispute Resolution Process for the .nz domain name space (InternetNZ, Wellington, 2005). 
.nz Oversight Committee “Minutes of Meeting” (Wellington 14 March 2003)

$<$ www.dnc.org $>$.

.nz Oversight Committee "Minutes of Meeting” (Wellington 3 May 2003)

$<$ www.dnc.org.nz>.

.nz Oversight Committee “Minutes of Meeting” (Wellington 29 August 2003)

$<$ www.dnc.org.nz $>$.

.nz Oversight Committee “Minutes of Meeting” (Wellington 18 October 2003)

$<$ www.dnc.org.nz $>$.

.nz Oversight Committee “.NZ Newsletter” (June 2002, Wellington

$<$ www.dnc.org.nz $>$ ).

.nz Oversight Committee "Submissions” (2005) (InternetNZ, Wellington, $<$ www.dnc.org.nz>). 